Dominique Cardon

Jean-Philippe Heurtin

Olivier Martin

Anne-Sylvie Pharabod

Sabine Rozier

\title{
Les formats de la générosité : trois explorations du Téléthon
}

In: Réseaux, 1999, volume 17 n95. pp. 15-105.

Citer ce document / Cite this document :

Cardon Dominique, Heurtin Jean-Philippe, Martin Olivier, Pharabod Anne-Sylvie, Rozier Sabine. Les formats de la générosité : trois explorations du Téléthon. In: Réseaux, 1999, volume 17 n95. pp. 15-105.

http://www.persee.fr/web/revues/home/prescript/article/reso_0751-7971_1999_num_17_95_2156 


\section{Abstract}

Every year the Telethon, organized since 1987 by the French myopathie patients' association (AFM) and the TV channel France 2, brings together researchers, patients, singers and the general public in an immense movement of collective solidarity. This movement is materialized in a flow of donations which amounted to 460 million francs for the year 1998 alone. The money thus collected is used to finance research on neuromuscular diseases, to support patients and their families and to cover costs. The success of this French version of the Telethon, inspired by the US Muscular Distrophy Association, is constantly growing. Apart from two instances where the Telethon was adversely affected by controversy between the organizers and the state, the amount in donations promised during the programme increases every year. Originally a purely televisual event, the Telethon is today deeply rooted in local life in France. Throughout the country, more and more events are organized annually on the ground by the active AFM network, in partnership with diverse local associations. These actions are currently the source of over half of the funds collected.

\section{Résumé}

Organisé depuis 1987 par une association de malades, I'Association française de lutte contre la myopathie (AFM) et une chaîne de télévision, France 2, le Téléthon réunit chaque année pendant trente heures des chercheurs, des malades, des chanteurs et le grand public dans un immense mouvement de solidarité collective qui se concrétise par un ensemble de dons qui s'élevait, lors de l'édition de 1998, à plus de 460 millions de francs. L'argent collecté lors de cette opération est destiné à financer les recherches sur les maladies neuromusculaires, à soutenir les malades et leur famille et à assurer les frais de collecte. La version française du Téléthon, inspirée d'un format créé par la Muscular Distrophy Association américaine, rencontre depuis plus de dix ans un succès toujours grandissant. A l'exception de deux éditions contrariées par des polémiques entre les organisateurs et l'Etat, la progression du chiffre de don enregistré au compteur de l'émission est en augmentation constante. A l'origine, événement simplement télévisuel, le Téléthon s'est aujourd'hui assez profondément enraciné dans la vie locale des communes françaises avec la croissance continue des manifestations de terrains organisés sur tout le territoire par le réseau militant de l'AFM en partenariat avec les différents tissus associatifs locaux; actions qui sont aujourd'hui à l'origine de plus d'un quart de la collecte.

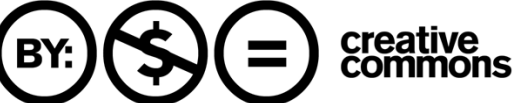




\title{
LES FORMATS DE LA GENEROSITE
}

Trois explorations du Téléthon

\author{
Dominique CARDON, Jean-Philippe HEURTIN, \\ Olivier MARTIN, Anne-Sylvie PHARABOD, \\ Sabine ROZIER
}




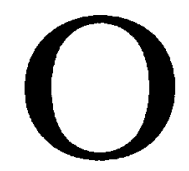

rganisé depuis 1987 par une association de malades, l'Association française de lutte contre les myopathies (AFM), et une chaîne de télévision, France 2, le Téléthon réunit chaque année pendant plus de trente heures des chercheurs, des malades, des chanteurs et le grand public dans un immense mouvement de solidarité collective qui rassembla plus de 460 millions de francs de dons lors de l'édition 1998. Cet argent est destiné à financer les recherches sur les maladies neuromusculaires et à soutenir les malades et leurs familles. Ce programme télévisé, doublé d'une mobilisation collective à l'échelle nationale, rencontre depuis plus de 10 ans un succès toujours grandissant, dont témoigne la progression quasi ininterrompue du chiffre des promesses de don enregistré au compteur de l'émission. Le Téléthon est sans doute l'une des formes contemporaines les plus abouties des techniques de sollicitation publique. Dès son origine, il a fait l'objet d'un fort investissement de la part des professionnels du marketing humanitaire dont il est aujourd'hui l'une des plus éclatantes réussites. Il constitue, dans la sphère télévisuelle, un modèle de management de la sollicitation jalousé par beaucoup d'autres associations. Parmi les différentes formes d'énonciation télévisuelle, le Téléthon présente en effet la spécificité de rendre totalement transparente son ambition performative : sensibiliser de téléspectateur afin de réunir des fonds auprès des téléspectateurs pour soutenir la recherche sur les maladies neuromusculaires. On comprend, dans ces conditions, que l'identification de la dimension instrumentale du programme est sans doute la chose la mieux partagée par les différents commentateurs, professionnels ou profanes, de l'émission. Elle constitue l'un des principaux thèmes d'interprétation des chroniqueurs de télévision, des essayistes, des spécialistes de marketing direct, des sociologues mais aussi, comme nous le montrerons, des téléspectateurs et des donateurs.

C'est une particularité bien étrange pour une émission de télévision que de susciter une adhésion de principe, tout en laissant profondément insatisfaits ceux qui la font, ceux pour qui elle est faite et ceux qui la regardent. Parce que, d'abord, son existence rappelle chaque année que les maladies génétiques n'ont pas disparu. Mais surtout parce que ce genre de dispositif ne peut 
trouver de justification proprement télévisuelle. Les compromis qui président à la confection de l'émission sont si nombreux que bien souvent, ceux-là mêmes qui ont accepté de les passer ne les défendent qu'à demi-mot. Voilà des animateurs gênés d'avoir à rappeler incessamment aux téléspectateurs de «faire leur don », un réalisateur que les «déroulants de sensibilisation» indisposent, des chanteurs qui ne peuvent se défaire du soupçon de participer à l'émission à des fins promotionnelles, des scientifiques prenant des risques avec leur éthique professionnelle, des malades dont la vie se résume à la mise en scène de vignettes émouvantes. Bien que le Téléthon constitue l'un des plus importants dispositifs de production de solidarité collective, bien qu'il suscite des engagements passionnés et des fidélités indéfectibles, tant chez ceux qui le produisent et l'animent que chez ceux qui le regardent et s'y engagent, peu revendiquent pourtant le dispositif pour lui-même. Nombre de téléspectateurs estiment, en effet, que l'émission n'exerce aucun effet sur eux, tout en affirmant qu'elle joue un rôle mobilisateur pour les autres. Ils ne cessent de la critiquer tout en louant pourtant son utilité. Cet écart entre le Téléthon comme dispositif télévisuel et le Téléthon comme cause constitue, sous une forme exacerbée, une déclinaison des tensions que suscite, dans toutes les formes d'action humanitaire et de solidarisation à distance ${ }^{1}$, l'arbitrage entre fins et moyens. Il invite à interroger le succès paradoxal de cette mobilisation dont l'instrument ne cesse d'être décrié alors qu'il suscite un indéniable mouvement de solidarité collective. C'est ce paradoxe que nous tenterons d'élucider en mobilisant les ressources descriptives de la sociologie des médias.

\section{Entre le texte et le téléspectateur : transactions tendues, souples et réflexives}

La question des effets des médias est inséparable des outils dont se dotent les sciences sociales pour décrire les articulations plausibles entre le monde de la télévision et celui des téléspectateurs. On peut soutenir, à gros traits, qu'elles proposent trois formes de transaction entre le programme et le public : tendue, souple et réflexive. Par transactions tendues, on désigne tout d'abord les modèles de description qui établissent des relations de causes à effets entre certains éléments du programme et les comportements ou les représentations des récepteurs (étude d'audience, études sur la violence ou les effets psychosociaux de la télévision), ainsi que les approches sémiologiques, qui

1. BOLTANSKI, 1993. 
prétendent lire dans le texte du programme les caractéristiques idéales de la figure du récepteur. Par transactions souples, on entend les travaux propres à l'ethnographie de la réception qui, à partir de l'analyse des commentaires qu'émettent les récepteurs dans des circonstances différentes (devant le programme, après l'avoir regardé, ou bien interrogés dans des cours d'action ordinaire sans relation avec le programme), étudient, en recourant à différentes variables explicatives (l'appartenance sociale, le sexe, la position familiale, l'identité culturelle ou nationale), les écarts existants entre l'intention de communication des concepteurs du programme et son interprétation par ceux auxquels il est destiné. Par transactions réflexives, on désigne les approches herméneutiques des médias qui cherchent à restituer les codes culturels communs aux programmes et aux publics en s'attachant à la manière dont se constituent des communautés d'interprétation.

Ces différentes approches entretiennent de nombreuses polémiques sur leur frontières respectives. Un premier débat oppose les approches internalistes et externalistes. Les premières enferment les principaux paramètres de la production et de la réception à l'intérieur du couple programme/récepteur. Les secondes mobilisent des variables extérieures à l'appareillage télévisuel pour expliquer les différents modes d'engagement du public, et postulent l'existence d'une relation beaucoup plus «souple » entre le programme et les téléspectateurs. La confrontation entre approche internaliste et externaliste a souvent été au centre du débat entre sémiologues et sociologues de la télévision. Elle recouvre aussi, de façon très grossière, deux conceptions opposées de la force des instruments de communication : la première prête souvent des effets forts aux programmes quand la seconde diffracte les effets en une myriade de médiations qui échappent à l'emprise exercée par l'outil télévisuel. Inaugurées à partir d'un modèle d'analyse visant à diagnostiquer les écarts entre la «lecture » des récepteurs et la « lecture » attendue par les concepteurs du «texte » télévisuel ${ }^{2}$, les études de réception ont progressivement fait apparaître un spectre si large d'herméneutiques spectatoriales qu'elles se sont émancipées des intentions des programmateurs. Certaines études ont si fortement approfondi le caractère situé et contextuel des pratiques de réception qu'elles ont aussi dû renoncer à l'ambition de produire des repères stables permettant de définir une condition commune du spectateur ${ }^{3}$. Aussi est-ce sur le terrain de la deuxième articulation, entre approche «souple » et «réflexive» de la

2. HALL, 1994.

3. ANG, 1996, p. 66-81. 
relation au programme, que se développent aujourd'hui, de manière disparate, des perspectives cherchant à s'affranchir de l'affrontement entre le texte et le lecteur, ainsi que du constat de l'indécidabilité de la réception. En dotant le téléspectateur de la compétence de membre d'un public, certains de ces travaux s'attachent à montrer le rôle de la télévision dans la constitution de "communautés imaginées ", à explorer des horizons d'attentes relatifs à certains thèmes de société ${ }^{5}$ ou à établir un lien entre l'organisation des pratiques de réception et une approche herméneutique inspirée des travaux de l'école de Constance'.

\section{Des images, des appels et des conversations}

Dans ce travail, nous chercherons à représenter successivement ces trois espaces de transaction entre programme et téléspectateur, puisque la particularité du Téléthon rend possible le croisement de ces démarches. Nous étudierons le Téléthon en trois temps prenant chacun appui sur un corpus différent de données collectées pendant l'enquête : (1) la bande vidéo de l'émission, (2) la courbe des appels téléphoniques des promesses de don et (3) les conversations tenues par les récepteurs devant le programme. Bien que de formats très différents, ces trois séries d'images, d'appels et de discussions s'ordonnent sur un même axe temporel. Il est dès lors possible de fixer sur chacune d'elle un certain nombre de repères descriptifs et d'établir des articulations entre ces trois chronologies d'événements parallèles. Cependant, poser des repères et établir entre eux des articulations, c'est aussi inscrire les relations entre programme et téléspectateurs dans l'un ou l'autre des paradigmes travaillés par la sociologie des médias. Cette recherche vise justement à conduire vers plusieurs pistes interprétatives les manières d'articuler ces trois séries d'événements. Nous entreprendrons même de dramatiser l'opposition de deux interprétations apparemment contradictoires en mettant successivement en scène le paradigme des effets forts et celui de l'indécidabilité de la réception. En interprétant la scénographie télévisuelle du Téléthon depuis la courbe téléphonique des donateurs, on constatera l'exceptionnelle capacité du programme à guider et à coordonner les conduites des donateurs. En revanche, l'approche ethnographique de la réception nous permettra

\footnotetext{
4. DAYAN, KATZ, 1996 ; ANDERSON, 1996.

5. CHALVON-DEMERSAY, 1994.

6. ALLARD, 1994 ; QUERE, 1996.
} 
d'introduire dans le rapport à l'émission des médiations qui semblent annuler le pouvoir du programme. La manière dont le programme « est parlé » pendant sa réception apparaîtra ainsi en décalage avec les réalités observées par les commutateurs téléphoniques. Cette contradiction qui constitue l'intrigue principale de notre enquête nous conduira à utiliser les instruments de la sociologie des médias pour interroger la place qu'occupe aujourd'hui le don, et les significations qui lui sont attribuées dans l'espace public. Comment est-il possible de rendre compte en même temps d'une coordination par le programme et de l'espace critique que mobilisent les téléspectateurs pour en circonscrire les prétentions ? Comment, par ailleurs, se déploient des engagements enthousiastes et fidèles qui oublient le dispositif qui les a constitués? Nous chercherons, dans ce texte, à répondre à ces deux questions? .

\section{REDONDANCE ET RASSEMBLEMENT}

Procédons d'abord à une lecture de la scénographie du programme afin de repérer le type d'instrument qu'il utilise pour capter l'attention du téléspectateur et favoriser la mobilisation. D'un point de vue strictement télévisuel, le Téléthon est une émission parfaitement redondante. Duplex, reportages, animations en plateau avec les malades, sollicitations, duplex, reportages, animations... trente heures durant. Les séquences reproduisent avec régularité une structure immuable, les messages concernant la maladie ou l'avancée de la recherche sont répétés sous la même forme, les appels

7. Les données présentées dans cet article ont été collectées lors d'une recherche menée sur le Téléthon du 6 et 7 décembre 1996. Celle-ci s'est déployée dans plusieurs directions afin d'épouser la forme réticulaire de l'émission. Nous avons d'abord entrepris, pendant les trois mois qui précèdent l'émission, une ethnographie du montage du dispositif en suivant les principaux organisateurs du programme de l'AFM et France 2. Pendant l'émission, nous avons observé la scène, les coulisses et l'organisation des manifestations locales de la Force T. Par ailleurs trois dispositifs de recueil de données différents ont été mis en place pendant l'émission : un enregistrement du trafic téléphonique au 3637 ; une enquête menée par des étudiants dans des groupes de réception regardant le Téléthon; des interviews téléphoniques des donateurs rappelés juste après avoir fait une promesse de don. Cette enquête a été soutenue par l'AFM. Nous tenons tout particulièrement à remercier Pierre Birambeau, Bruno Desbuleux, Michel Doucet, Anne Kuperberg, Martine Frishmann et Antoine Tchernia du soutien qu'ils nous ont apporté ainsi que l'ensemble des équipes du Téléthon. L'enquête de réception n'aurait pu voir le jour sans le concours de Pierre Chambat, Sabine Chalvon-Demersay, Catherine Delcroix, François Jost, Josiane Jouët, Pascale Laborier, Brigitte Le Grignou, Cyril Lemieux et Sandrine Lévêque qui ont encadré le travail des étudiants. Patrice Flichy, enfin, nous a apporté son soutien tout au long de cette recherche. 
aux dons sont réitérés toutes les quatre ou cinq minutes, les déroulants de sollicitation semblent incrustés au bas de l'écran... Depuis la première édition de l'émission, le Téléthon a certes connu bien des modifications, mais sa structure d'ensemble reste invariablement constituée par la répétition du même type d'événement pris en charge dans des formats télévisuels identiques. Le programme parvient cependant à produire une apparence de désorganisation, d'improvisation et d'empressement: les enchaînements sont saccadés, les intervenants doivent faire court, les séquences s'enchevêtrent et se superposent sur des murs d'écrans, les images de mobilisation semblent si nombreuses que le réalisateur doit constamment effectuer des collages rapides de saynètes juxtaposées, les trois animateurs ne cessent de se couper la parole, de courir d'un bout à l'autre de la scène et de passer avec célérité du plateau au duplex, du malade au chercheur, de la vedette au compteur. En occupant de façon débordante une forme redondante, le Téléthon s'efforce ainsi de représenter le combat urgent et enthousiaste contre la maladie et de figurer le rassemblement de toutes les énergies qui ont accepté de se mettre à son service.

Ceux qui font le Téléthon portent parfois un regard sévère sur le format télévisuel de l'émission - trop rapide, trop segmenté, trop répétitif -, mais reconnaissent qu'il est commandé par la nature de l'événement: une émission qui crée de la solidarité en lançant une multitude de défis de trente heures (ceux-ci sont appelés «Force $T$ » dans le vocabulaire du Téléthon). Le choix d'une scénographie télévisuelle séquencée apparaît comme le résultat d'un arbitrage entre deux temporalités distinctes, le temps long de la mobilisation et le temps court du téléspectateur. Le Téléthon semble conçu pour un téléspectateur inconstant qui n'est pas dans la même temporalité que les acteurs engagés dans la mobilisation. Quelle que soit l'unité temporelle qu'il choisit de prélever dans le programme, il peut accéder à l'ensemble de l'univers du Téléthon déployé dans ces différents espaces et animés par ses différents acteurs. Il voit des enfants malades, des animateurs, des vedettes, des chercheurs, la fête populaire, le compteur et l'appel à donner. Le découpage extrêmement serré de ses différents composants en petites unités temporelles de deux à cinq minutes fait du Téléthon une sorte de poupée russe; chaque moment du programme enferme l'ensemble de son contenu. 


\section{Une poupée russe}

Les émissions qui composent le Téléthon ne se distribuent pas en genres différents réservant, par exemple, une tranche horaire à la «vie des malades" (témoignage), suivie d'une partie consacrée aux avancées scientifiques (émission de débats) et conclue par un programme d'animations et de festivités (variétés), comme dans le Sidaction 1998, qui séparait l'émission consacrée aux malades et le programme de variétés. Le Téléthon ne s'organise pas non plus autour d'une population spécifique, comme la corporation des artistes de variétés françaises qui se rassemble, sans animateurs, autour d'elle-même pour gagner la sympathie du public à la cause des Restaurants du cœur. A l'inverse, les producteurs de l'émission se sont donnés pour ambition, du vendredi $18 \mathrm{~h}$ au milieu de la nuit du dimanche, d'entrecroiser incessamment les genres, les lieux et les acteurs. En effet, les seize émissions qui se déroulent sur les trente heures du programme ne proposent que des variations thématiques mineures afin de s'adapter aux plages horaires de la grille d'une chaîne généraliste (les émissions du matin proposent un réveil tonique, entre petit-déjeuner et gymnastique, celles du midi organisent des défis culinaires, celles de l'après-midi des défis sportifs, etc.).

Ces différences thématiques entre les émissions du Téléthon importent moins que la similarité de leur organisation interne. Chacune des 16 émissions du programme est constituée de courtes séquences de quelques minutes construites de manière identique à partir de trois sources d'images qui donnent accès aux différents espaces du Téléthon ${ }^{8}:$ les scènes sur le plateau central $(57 \%)$, les scènes ayant lieu en duplex $(35 \%)$ et les reportages $(8 \%)$.

8. Nous avons procédé à un codage minute par minute des deux émissions de soirée du Téléthon 1996 (vendredi de 20 h 50 à 01 h 44 et samedi de 20 h 50 à 03 h $22 ; N=792$ minutes). Les minutes y sont caractérisées dans leur globalité : si plus de la moitié est consacrée à un duplex, la minute est codée comme duplex. Ce codage précise les pourcentages de temps accordés aux divers éléments du Téléthon. Nous avons aussi repéré la présence ou l'absence à l'intérieur de la minute d'un certain nombre d'événements ponctuels tels que solliciter, citer la participation financière de personne physique ou morale, montrer en gros plan le compteur. les malades, etc. 


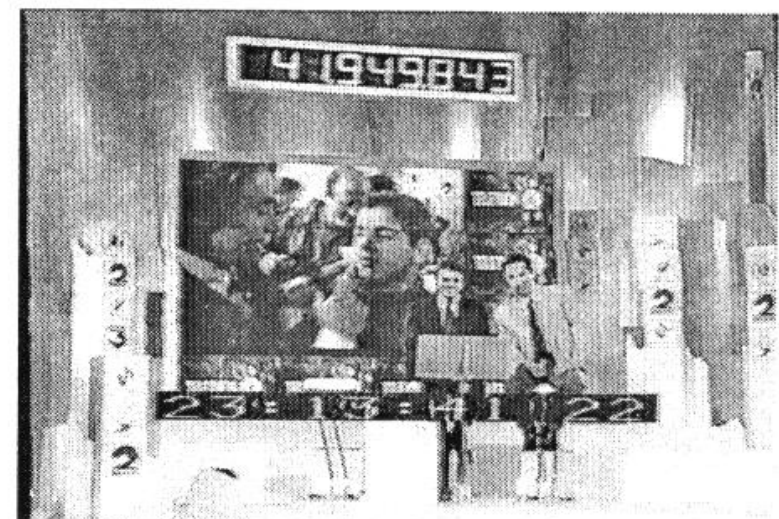

Photo 1. Le compteur sur le plateau central

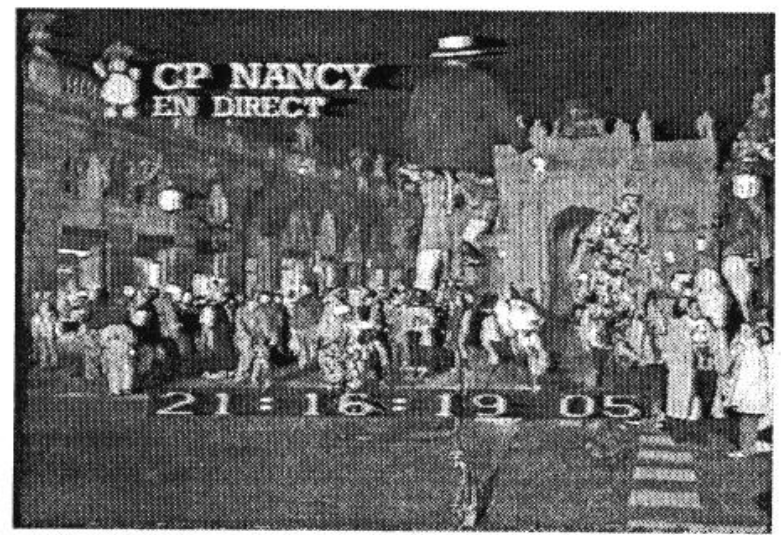

Photo 3. Un duplex à Nancy

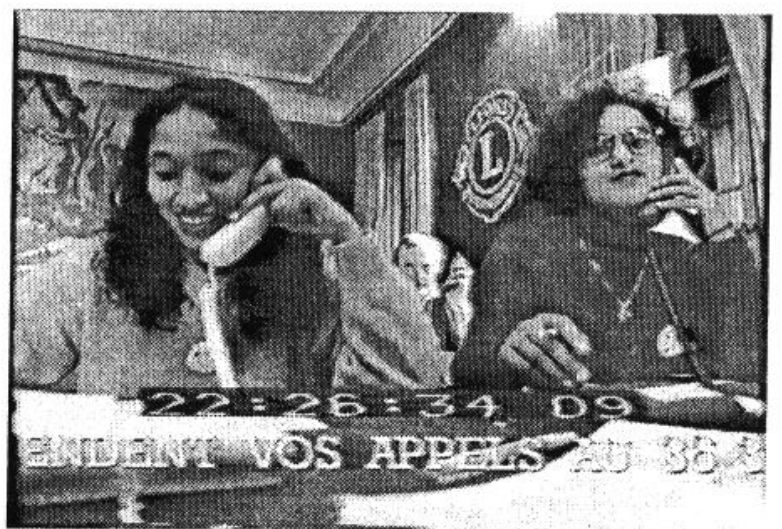

Photo 5. Un centre de promesses téléphoniques

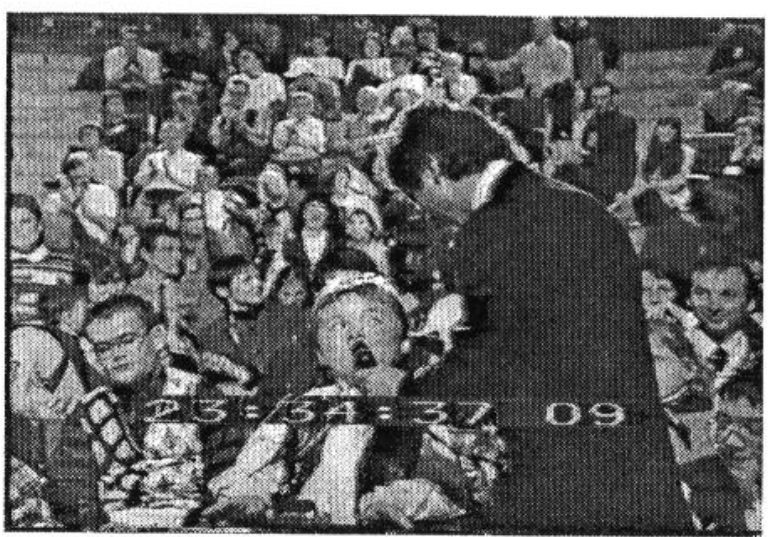

Photo 2. Claude Sérillon interviewe un malade

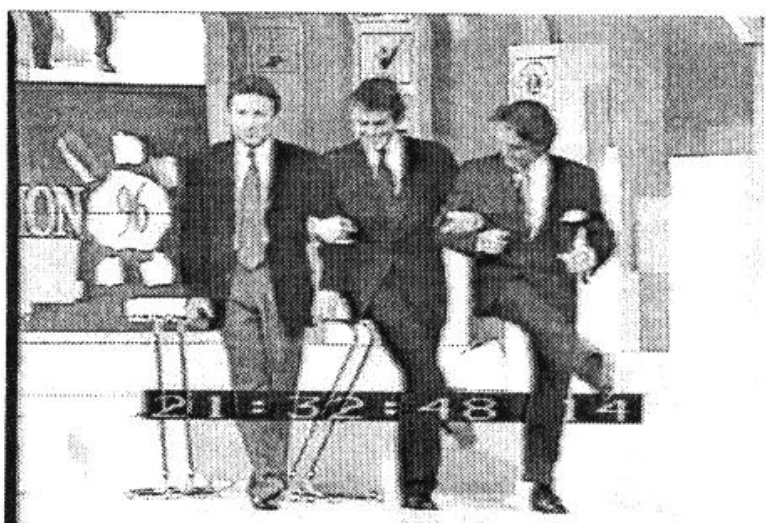

Photo 4. Les trois animateurs

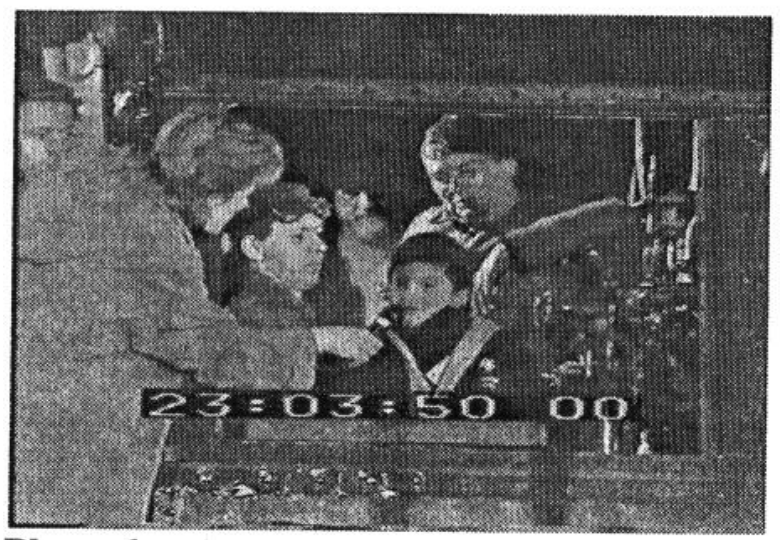

Photo 6. «Alexandre voudrait courir » 


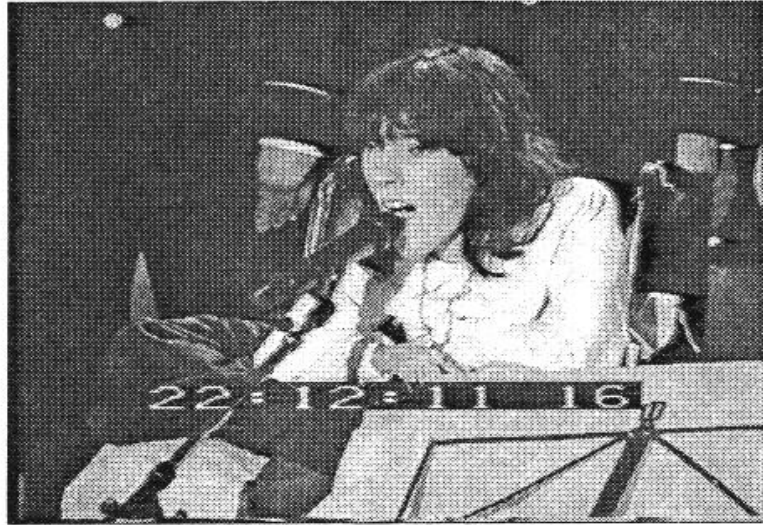

Photo 7. La chanson de Marie-Jo

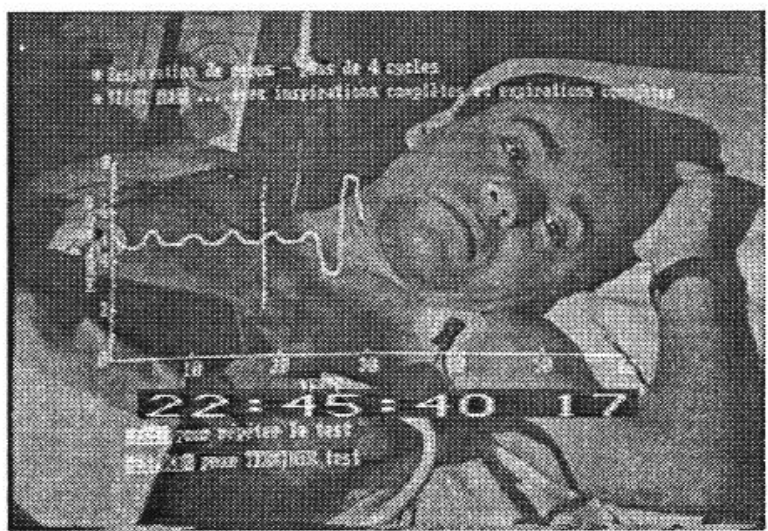

Photo 9. Reportage « malade » à l'Institut de Myologie

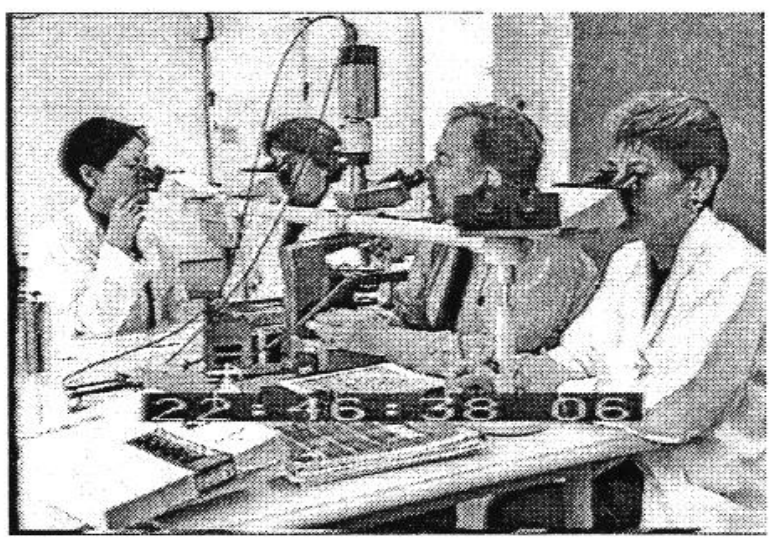

Photo 11. Reportage à l'Institut de Myologie

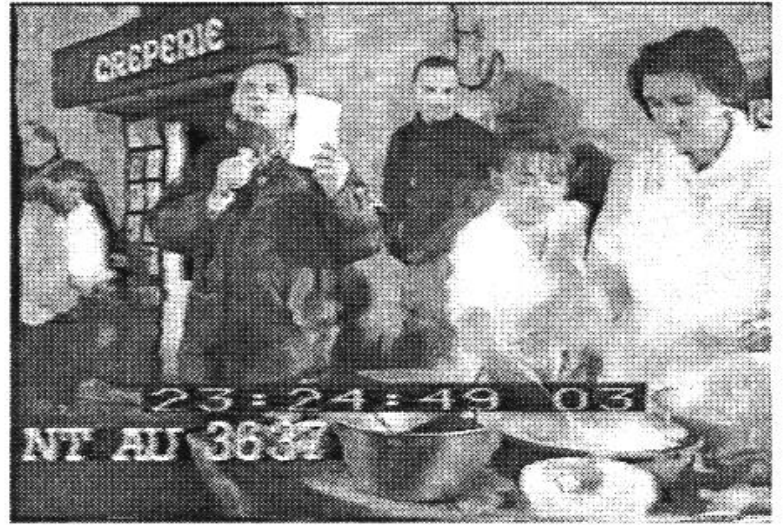

Photo 8. Des crêpes à Quimper

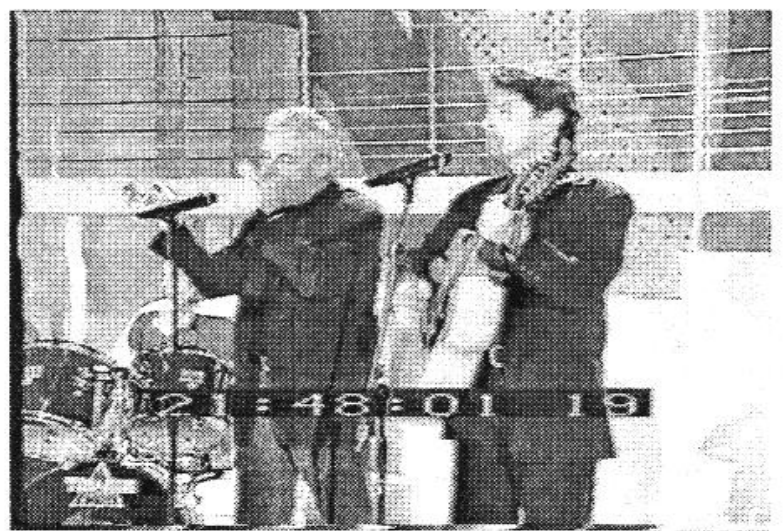

Photo 10. Francis Cabrel

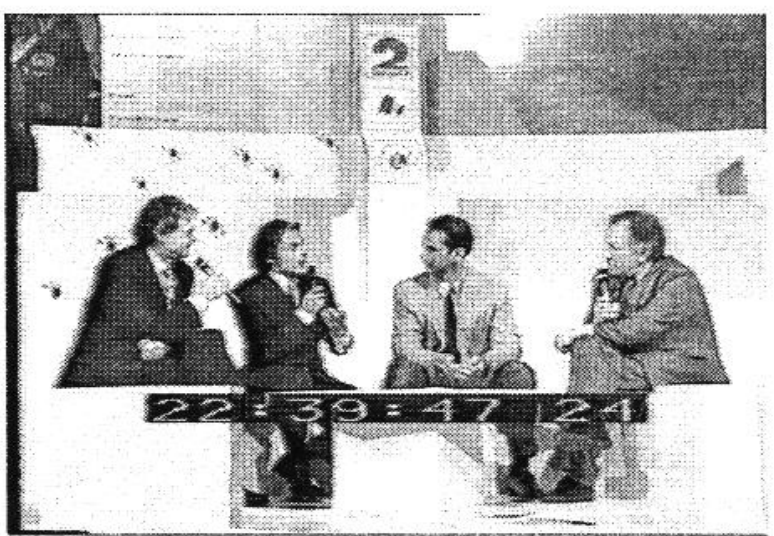

Photo 12. Plateau scientifique avec le Pr. Fardeau 
Traditionnellement installé en Ile de France, le plateau central de l'émission constitue le centre névralgique de l'opération. Devant un public de spectateurs et d'enfants en fauteuil, les trois animateurs principaux de l'émission (Gérard Holtz, Michel Drucker et Claude Sérillon) ainsi que son parrain (Thierry Lhermitte) s'activent sur une grande scène coiffée par le compteur indiquant la progression des promesses de don tout au long des trente heures. Un orchestre est installé sur le côté de la scène, à l'opposé d'un mur d'images servant à la retransmission des duplex (cf. photo 1).

Les duplex permettent de retransmettre des images depuis les différentes scènes périphériques du Téléthon. Certaines sont fixes, d'autre itinérantes. Les premières sont traditionnellement installées sur la place centrale des villes retenues par l'AFM et France 2 où se déroulent, à proximité d'un centre de promesses télévisé, de nombreuses animations. Les secondes scènes périphériques sont itinérantes et constituent les fils rouges de l'émission. Un studio mobile suit une équipe qui parcourt l'espace national pendant trente heures en utilisant des outils de locomotion variés (train, vélo, péniche, traîneau) et en multipliant les escales pour aller à la rencontre des malades et du public (cf. photo 6). D'autres dispositifs ajoutent encore d'autres lieux à la mobilisation. Partenaire de l'opération, Radio France organise un duplex son, permettant de contacter ses 39 radios locales; l'Armée installe ses quartiers dans le parc de Versailles d'où sont envoyées des images spectaculaires - parade, fanfare, feux d'artifice. Enfin, la couverture du territoire national est assurée par la retransmission d'images réalisées par des vidéastes amateurs (le "Caméthon ») dans des lieux où les caméras de France 2 sont absentes. De toutes les séquences du Téléthon, seuls les reportages, enregistrés plusieurs semaines à l'avance, viennent rompre le rythme empressé de la mobilisation en direct. Ils portent sur l'univers de la maladie : le malade, sa famille, les médecins, les chercheurs, les aides techniques, un centre médical (cf. photo 9), etc.

La fragmentation du Téléthon en une multitude de séquences est commandée par l'exigence d'ubiquité qui pèse sur les producteurs de l'émission. Ils doivent en effet transmettre des événements se produisant au même moment mais en des endroits différents. Comment y parviennent-ils ? En pliant le programme aux contraintes de la mobilisation : en opérant des coupes longitudinales dans l'écheveau des mobilisations. La production de l'émission constitue ainsi une véritable prouesse. Le réalisateur doit visiter les différents lieux du Téléthon dans une tranche horaire très étroite. Le programme parvient à faire le tour des onze différents duplex (centres de 
promesses et fils rouges) en une heure trente. Le conducteur de l'émission est une partition réglant minutieusement l'ordre des séquences, harmonisant la réservation des faisceaux hertziens avec le déroulement des mobilisations de terrain, équilibrant le passage entre les différents partenaires, synchronisant les emplois du temps et les déplacements d'un nombre impressionnant de personnes.

\section{Différents mondes en interaction}

Le programme ne se contente pas de visiter incessamment les multiples lieux de la mobilisation. Il s'oblige aussi, à chaque fois qu'il se rend quelque part, à réunir les représentants des différentes catégories d'acteurs du Téléthon. Que l'on soit sur le plateau central, que l'on aille prendre le pouls d'un fil rouge ou que l'on se rende dans un centre situé en région, c'est à chaque fois la même «ronde » que l'on voit partout se former, composée des trois animateurs, de la vedette parrainant l'émission, d'enfants malades et de membres du public, auxquels viennent régulièrement se joindre des chanteurs, des porte-parole de la cause, des quidams, des parents, des chercheurs et des médecins (cf. tableau 1). Les différentes catégories d'acteurs ne sont pas enfermées dans un temps et un lieu bien précis auxquels elles seraient assignées. Elles sont toutes, tôt ou tard, amenées à se croiser et à se rencontrer : dans les scènes locales bien sûr mais aussi sur le plateau central, qui, loin d'être réservé aux seuls vedettes et animateurs professionnels, s'ouvre à ceux (bénévoles, anonymes, etc.) auxquels il est d'ordinaire interdit. La scène centrale apparaît ainsi comme un calque des scènes périphériques, même si les attributs de ceux qui s'y produisent (en termes de notoriété, de légitimité) est plus grande qu'en région et le traitement qui leur est réservé meilleur (temps de parole plus long, etc.).

Tableau 1. Taux de présence des différents acteurs en duplex et en plateau

\begin{tabular}{|l|c|c|}
\hline Taux de présence (en \%) & Plateau & Duplex \\
\hline Animateurs & 25 & 31 \\
\hline Chanteurs & 20 & 12 \\
\hline Porte-parole & 20 & 3,5 \\
\hline Force T & 11 & 45 \\
\hline Malades & 15 & 3 \\
\hline Chercheurs et médecins & 9 & 5,5 \\
\hline Total & 100 & 100 \\
\hline
\end{tabular}


Le Téléthon se caractérise également par la volonté d'ouvrir les différents acteurs les uns aux autres et de mêler leurs univers. Cette volonté apparaît nettement dans la construction des reportages qui s'appliquent à déployer les différentes identités des personnes filmées - en révélant l'éventail de leurs compétences (un malade révèle sous l'œil de la caméra ses dons de bricoleur), en les montrant sous un jour inédit (un médecin avoue ses doutes et ses espoirs) ou les filmant aux côtés de personnes étrangères au monde médical (quand un animateur célèbre rend par exemple visite à une jeune malade atteinte d'amyotrophie spinale) - et contribuent à extraire ces individus de l'univers de la maladie. L'interpénétration des différents mondes auxquels appartiennent les acteurs du Téléthon apparaît plus nettement encore dans les séquences en direct. Les acteurs n'interprètent pas le rôle convenu que l'on pourrait attendre d'eux (un malade joue du saxophone, le parrain de l'émission révèle sa connaissance approfondie de l'informatique, une chanteuse envoie un message d'anniversaire à son fils) et n'hésitent pas, afin de se joindre aux autres participants de l'émission, à se plier à un exercice incongru ou inhabituel (une vedette interroge ainsi un chercheur, un animateur s'engage dans une épreuve sportive). Les distinctions d'état, de statut et de réputation tendent à être gommées : des enfants malades participent aux animations de rue ; des boulangers viennent saluer les animateurs en leur offrant un pithiviers géant; une chanteuse discute avec le conducteur d'une vieille locomotive; l'organisateur d'un circuit Strasbourg-Paris en rollers est accueilli par l'un des animateurs de l'émission sur la scène du Téléthon. Les attitudes attendues des participants en viennent même parfois à être renversées, comme lorsque le parrain arbore une mine grave, et qu'un sourire illumine le visage d'un enfant en fauteuil. De toutes les rencontres que suscite le Téléthon, ce sont celles qui permettent la confrontation des acteurs «vivant quotidiennement avec la maladie - soit parce qu'ils en sont les victimes, soit parce qu'ils travaillent à la combattre - qui sont privilégiées : le programme abonde ainsi en dialogues improvisés entre de jeunes malades et des chercheurs, et révèle la complicité qui les unit ("Arnold, et tous les autres chercheurs, on a vraiment le même combat, c'est contre la maladie, sauf que nous on le vit au quotidien et toi tu le vis dans ton laboratoire, et je crois que c'est pour ça $q u$ 'on est vraiment très proches en fait» dit ainsi une jeune fille à l'un des chercheurs). En encourageant les acteurs de la scène télévisuelle à endosser des rôles différents, le Téléthon contribue ainsi à recomposer leur identité publique en s'efforçant, comme on le verra plus loin, de révéler leur « humanité ». 
Chacun semble insuffler aux autres (son voisin, son interlocuteur, le téléspectateur) un peu de la «force » qui est en lui : un chanteur fait rire un enfant engoncé dans son fauteuil ; un cycliste professionnel ayant pris part à un fil rouge encourage des journalistes fatigués ; un chercheur lit, ému, la lettre de remerciement que lui a adressé le père d'un malade ("ça m'aide à vivre, c'est ça qui me motive »); le parrain fait le récit émerveillé de sa visite à l'Institut de myologie (en évoquant «la symbiose que les chercheurs ont les uns avec les autres, c'est quelque chose d'inouï »). L'espoir, sous le signe duquel est placé le Téléthon, n'est pas enfermé dans des mots ou des déclarations d'intention : il circule d'une personne à l'autre, d'un groupe à l'autre, et semble à chaque fois fortifier davantage ceux qu'il a traversés. Cette circulation est favorisée par un travail permanent de liaison entre les séquences qui se chevauchent plus qu'elles ne se succèdent. De plus, le programme paraît affecté d'un hoquet incessant tant les ruptures de rythmes et de tons $\mathrm{y}$ sont fréquentes: les scènes joyeuses côtoient les récits empreints de gravité, les démonstrations festives succèdent aux témoignages des souffrances endurées, les gestes sportifs contrastent avec l'immobilité des malades. Ces discontinuités sont constamment cultivées dans le Téléthon : les acteurs du programme tirent en effet parti des contraintes qui pèsent sur sa confection pour transformer les multiples petites ruptures qu'il suscite en autant de marques de sa capacité d'adaptation à des situations diverses, et dès lors de sa force cohésive.

\section{L'articulation de la temporalité de la mobilisation et de celle du téléspectateur}

Le Téléthon ne développe qu'une seule intrigue, celle du rassemblement. Il contribue en effet à tramer, au fur et à mesure de son déroulement, un écheveau de mobilisations parallèles et multiformes, que le programme s'efforce d'intégrer progressivement tout au long des trente heures. En ce sens, le Téléthon constitue sans doute bien moins un genre télévisuel qu'une technologie de mobilisation, plus proche du répertoire de l'action collective que des techniques de production télévisuelle. Dès le vendredi soir sont présentées une à une les principales manifestations que va suivre le programme. Les participants - animateurs, vedettes ou participants anonymes d'un fil rouge - sont, site après site, visités par l'émission. Ce n'est que le samedi soir que les groupes mobilisés à travers le territoire commencent à converger vers les scènes, centrale ou locales, afin de remettre le chèque correspondant au montant des dons récoltés au cours de 
leur action. La structure ternaire de l'émission (plateau-duplex-reportage) demeure, mais le Téléthon semble alors s'emballer et échapper à ses organisateurs et ses participants : les séquences télévisuelles se succèdent à un rythme de plus en plus rapide ; le réalisateur ne parvient plus à maîtriser le fil du conducteur de l'émission; les standards téléphoniques saturent ; le chiffre du compteur connaît de brusques variations. Le programme visite avec encore plus de célérité les multiples mobilisations qui couvrent le territoire national : à chaque fois qu'il en fait le tour, une photographie instantanée de l'ampleur prise par les différentes manifestations parvient au téléspectateur, de telle sorte que ce dernier peut apprécier l'effort accompli par les participants (les visages sont creusés, les corps sont fatigués...) et mesurer l'écart entre le niveau atteint par la mobilisation et son niveau précédent (le flot des participants a grossi, la montagne de briques de lait aussi, la construction du pont de bois est achevée...).

\section{Le présent de la sollicitation}

Le rythme de la mobilisation s'imprime d'abord sur l'ordre de succession des différentes séquences. Elles empruntent une trajectoire balisée faite d'allers et retours entre le niveau national et le niveau local, le centre et ses périphéries, l'univers des malades et celui des bien portants. Ainsi, après chaque déplacement vers les centres de promesses, le programme revient toujours vers le plateau central. Cette pulsation mime le mouvement de la sollicitation : après le reportage, la sollicitation est émise depuis le plateau central par les animateurs; elle se propage au sein du public mobilisé et revient vers la scène centrale pour que ses effets soient enregistrés au compteur de l'émission'. Ce mouvement ne se referme pourtant jamais sur les seuls mobilisés. Le programme offre en permanence des points d'entrée aux téléspectateurs qui sont invités, toutes les cinq minutes environ, à faire une promesse de don au téléphone (3637), avec leur minitel ou sur Internet. Les sollicitations ponctuent donc sans cesse le programme. Elles ont une place réservée dans le conducteur de l'émission et un solliciteur désigné, l'animateur du plateau central ou le parrain. Cependant elles débordent aussi très largement le cadre prévu par le conducteur, puisque de nombreux autres acteurs (animateurs, chanteurs, représentants des entreprises partenaires, malades, animateurs de manifestation, élus ou simples quidams) lancent également à tout moment des appels au don.

9. CARDON, HEURTIN, PHARABOD, ROZIER, 1998. 
Sur les deux soirées du vendredi et du samedi, plus de trois heures d'antenne (soit $24,5 \%$ de la durée considérée) sont ainsi absorbées par des appels au don. La plupart ponctuent la clôture d'une séquence et l'ouverture de la suivante. Ils rythment également le déroulement interne des séquences (lors d'un changement d'interlocuteur ou d'un déplacement sur la scène du plateau). Ces sollicitations sont brèves et ne comportent pas de justification : elles indiquent le chiffre du compteur ( 38 occurrences) ou prennent la forme d'un très court énoncé : "Faites le 3637! »(106 occurrences). Le 3637 est un fétiche constamment agité par les acteurs du Téléthon. Il est chanté, mimé, voire exprimé dans le langage des sourds. On le moque (Thierry Lhermitte: "Pourquoi tout le monde répète 3637 tout le temps, j'ai pas

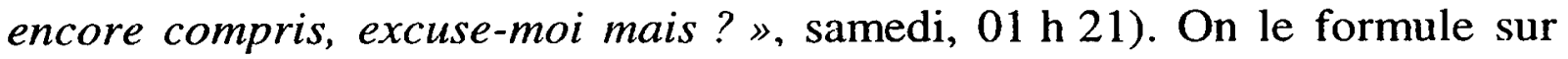
tous les tons (Michel Boujenah: "Non, je suis pas malade. Je vais reprendre ma respiration. C'est dingue! Alors, pour reprendre ma respiration, je voudrais que vous téléphoniez au $3637 . .$. pour nous envoyer

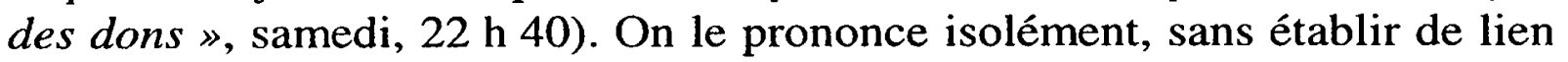
avec ce qui précède ou ce qui suit ( $3637 \ldots$ Serge [Lama], on a reçu un poème d'un garçon », samedi, $00 \mathrm{~h} 09$ ). La répétition régulière du numéro imprime ainsi une sorte d'urgence à l'émission qui rappelle l'impérieuse nécessité des dons pour le financement des recherches ("Vite 3637, vite le 3615 code Téléthon. Nous allons maintenant, Michel je crois, on va rejoindre le vélo, nos amis du vélo », vendredi, 23 h 36).

Ces répétitions rituelles du numéro du Téléthon sont cependant marginales au regard des séquences au cours desquelles la sollicitation s'articule à la formulation de l'énoncé d'une ou de plusieurs justifications (40 minutes) : le plus souvent, au terme d'une animation, d'une chanson ou d'un reportage, les animateurs et le parrain se réunissent sous le compteur, rappellent les raisons pour lesquelles le Téléthon a été créé, disent l'attente des malades et soulignent l'engagement des chercheurs. Ils se tournent ensuite vers le compteur pour faire applaudir sa progression. Ces sollicitations portent l'empreinte des recommandations produites par les professionnels du marketing humanitaire: elles ont une rhétorique propre, des points de passage obligés et des propriétés communes.

Les justifications qui soutiennent les sollicitations sont toutes construites de façon similaire. Elles présentent d'abord un résumé des précédentes séquences de l'émission, puis s'enroulent sur le programme pour sommer les principaux événements du Téléthon et les transformer en raisons de donner. Claude Sérillon, qui excelle dans l'exercice, enchâsse d'abord dans 
ses appels tous les ingrédients qui composent le programme; il évoque tour à tour les malades ("Vous avez vu l'exemple de Damien, qui lui est obligé

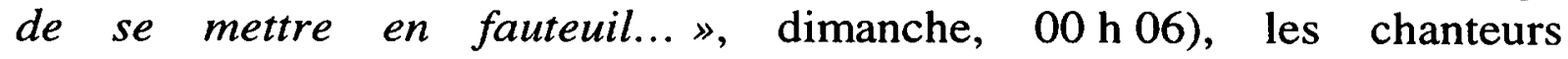
("Téléphonez dès maintenant pour faire grimper ce compteur, lui donner autant de vitamines que John Wood à Amiens", samedi, 02 h 18), les personnes mobilisées ( $i l$ y a des milliers de Français qui courent", vendredi, 23 h 09), les chercheurs ( Vous avez entendu Arnold Munich, vous avez entendu Michel Fardeau, beaucoup de chercheurs", samedi, 23 h 43), les sportifs ("Aimé Jacquet, Raï, Paul Le Guen aussi, ils sont venus donner les maillots de l'équipe de France. [...] Ils les ont distribués à

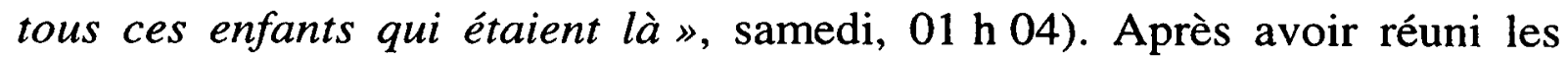
acteurs de la mobilisation en une ou deux phrases d'appel, l'animateur peut alors avancer des arguments soutenant la cause du Téléthon. Il évoque ainsi la bonne utilisation des fonds par l'AFM, certifiée par la Cour des comptes, l'amélioration concrète de la vie quotidienne des malades (grâce aux appareillages techniques) ou encore leur citoyenneté : "C'est aussi ça le Téléthon, c'est une manière de modifier le regard, de nous encourager à intégrer plus encore tous ces citoyens, qu'ils soient valides ou moins valides. Et c'est aussi toute l'action de l'AFM depuis 1987, à travers le Téléthon, à travers l'argent que vous avez bien voulu donner " (samedi,

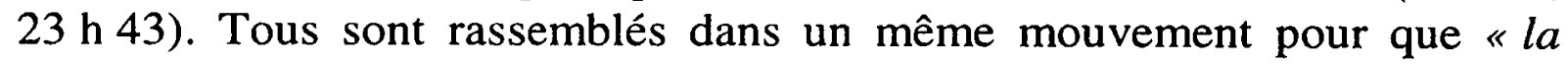
somme soit un encouragement, un signe très fort de solidarité nationale et de générosité »(dimanche, $00 \mathrm{~h} \mathrm{06).}$

La prise en charge du téléspectateur à l'intérieur des messages de sollicitation évolue avec les actes de parole qui lui sont destinés. Il est d'abord remercié par le solliciteur ("c'est grâce à vous que de l'argent a pu être collecté, que l'espoir commence à naître, que des chercheurs ont obtenu des moyens... », "à travers l'argent que vous avez bien voulu

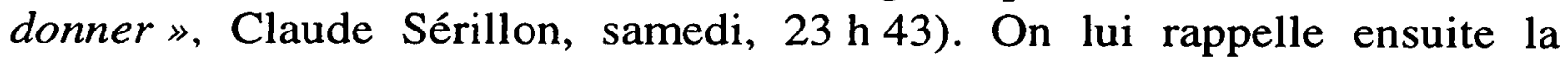
"promesse » contractée depuis le premier Téléthon en 1987, entre donateurs, malades et chercheurs pour vaincre la maladie. Ce n'est qu'ensuite que le message adressé au téléspectateur prend une tournure plus impérative : "Donnez ainsi les moyens d'accomplir l'étape ultime, l'étape vers la guérison: les thérapies géniques. Pour l'instant, ça ne marche pas, il faut le dire franchement. Ce sont des essais. Alors, on va essayer. Il y a au bout un formidable espoir, et vous avez entendu ces enfants qui rêvent de courir, d'être comme les autres. Eh bien, c'est pour eux que vous devez donner ce soir, en faisant le 3637 » (idem). Le caractère impérieux, presque brutal, de cet ordre ( Donnez!») ne se justifie que parce qu'il trouve dans 
la démonstration produite par l'émission ses conditions de félicité. C'est "cet édifice que nous construisons petit à petit contre l'ensemble des maladies génétiques » (dimanche, $00 \mathrm{~h} 06$ ), cette "chaîne de l'espoir 》 (samedi, $00 \mathrm{~h} 08$ ).

Les solliciteurs ne cessent d'interpeller les téléspectateurs, dont la temporalité propre ne s'articule pas, ou mal, à celle du Téléthon. Aussi accueille-t-on les nouveaux venus, "ceux qui nous rejoignent maintenant, parce qu'il y a des Français qui ont des semaines plus longues que les autres, qui n'ont pas encore eu le temps de téléphoner» (Michel Drucker, samedi, 20 h 51), ceux "qui comme moi se couchent tôt. [...] On a le droit de se coucher à onze heures, même un jour de Téléthon. Mais avant de vous coucher... " (Thierry Lhermitte, samedi, 22 h 50), ceux qui sortent le samedi soir ( Dans votre voiture, vous avez peut-être un portable. Vous allez danser. Vous rentrez, vous avez dîné tard. Avant de vous coucher, avant d'éteindre la lumière, hop! 3637 sur votre téléphone! », Michel Drucker, dimanche, 00 h 50). L'appel au 3637 est présenté comme un moyen simple et économe de "prendre le train » de la mobilisation et d'échanger ainsi la contribution financière des uns contre l'énergie des autres: "ceux qui prennent l'émission en cours et qui voient ça » doivent savoir qu' "il y a des millions de gens qui se sont dépensés pendant 24 heures, qui n'ont pas arrêté de faire des trucs ». Alors explique, non sans insistance, le parrain : "pour des gens qui rentrent, c'est très vite fait. C'est quelques instants de votre vie, quelques secondes. Vous faites 3637 pour votre don, ou 3615 Téléthon et c'est fait, et vous changez quelque chose, et vous dormez bien après. Voilà " (samedi, 01 h 37). C'est aussi en insistant sur la brièveté de cette fenêtre ouverte entre téléspectateurs et mobilisés que les impératifs d'urgence et d'immédiateté sont soulignés par les solliciteurs. Comme l'indique avec une force particulière Thierry Lhermitte "c'est maintenant qu'il faut donner ", "dans deux heures, il sera trop tard, les gens seront couchés ", "demain c'est un autre jour, il y aura d'autres choses, et ce sera l'année prochaine. Et c'est aujourd'hui qu'on en a besoin, c'est aujourd'hui que c'est important. Alors faites-le maintenant 》 (dimanche, $00 \mathrm{~h} \mathrm{50).} \mathrm{Le}$ présent de l'action est le seul territoire sur lequel peuvent se rencontrer le temps, court et limité, des solidarisés, le temps, long et borné, de la vie des malades et le temps, laborieux et patient, des efforts des chercheurs.

Les sollicitations permettent ainsi au téléspectateur d'entrer dans le temps de la mobilisation. La double mise en scène de l'enthousiasme festif et de l'invocation de l'urgence constitue une manière particulière de définir le 
présent de l'action à laquelle est invité le téléspectateur. En bouleversant l'espace du Téléthon, les hiérarchies et les rôles sociaux ordinaires, en plaçant la mobilisation sous le signe d'un combat incertain et audacieux contre la maladie, en montrant constamment des signes d'empressement, en rappelant que toutes ces actions se déroulent sous le signe de la promesse faite aux malades de participer à leur guérison, etc., le Téléthon dote le présent d'une densité dont est dépourvue la vie quotidienne ordinaire.

\section{LA FORCE DU DISPOSITIF A L'EPREUVE DU RESEAU TELEPHONIQUE}

Une des particularités du Téléthon est de posséder un dispositif qui mesure en temps réel ses propres effets sur les téléspectateurs et de faire de cette mesure un élément de sa scénographie. Le compteur des promesses de don, qui ne quitte jamais l'antenne plus de quelques minutes, est présenté de façon spéculaire au téléspectateur comme le témoin animé de la force des énergies rassemblées par le programme. Aussi, sur la scène centrale de l'émission, les animateurs associent-ils généralement la sollicitation à la lecture des chiffres du compteur en mimant parfois une relation de cause à effet entre l'appel au don et l'évolution du montant des promesses.

Gérard Holtz : Ouais ! Eh! Debout! Eh! Chantez aussi !

L'orchestre reprend la musique. Claude Sérillon et Gérard Holtz continuent de chanter puis s'arrêtent.

G. H. : Et vous savez pourquoi on fait ça? Regardez le compteur!

Claude Sérillon : Le compteur!

G. H. : Le compteur...

C. S. : Il va monter, il va monter, il va monter! Il passe à 360 millions !

G. H. : 360 millions! (dimanche, 01 h 22).

Une telle mise en scène n'est rendue possible qu'au terme d'un laborieux travail de saisie, de calcul, de coordination et de transport des chiffres produits par les différents réseaux de collecte (téléphone, internet, actions de la Force $T$, participation des entreprises, des fédérations sportives et de diverses institutions). Bien que le chiffre du compteur soit en réalité produit en coulisses à partir de données différées issues de la collecte, il est toutefois présenté tout au long de l'émission comme un capteur sensible aux moindres réactions du public, enregistrant dans l'instant le don de chacun pour l'ajouter à ceux de tous les autres. "Si ce compteur bouge, indique 
Claude Sérillon, s'il y a un mouvement des chiffres, c'est aussi le symbole de votre mouvement, de votre mobilisation » (vendredi, $19 \mathrm{~h} \mathrm{50).}$

Si le public est habituellement présenté comme l'auteur des variations du compteur, le programme n'oublie jamais de rappeler son rôle originel dans le déclenchement du comportement des donateurs. Il n'est pas rare que les animateurs et les vedettes du Téléthon se promettent mutuellement de "faire grimper le compteur», "de lui donner la pêche » en commandant, depuis le programme, les réactions du public que le compteur viendra ensuite mesurer. Une animatrice s'exclame : " on compte encore sur votre générosité bien sûr pour faire gonfler, faire exploser littéralement ce compteur » (samedi, 23 h 48). Sur un mode décalé et légèrement ironique, le parrain de l'émission entreprend à plusieurs reprises de faire "sauter » le chiffre du compteur avec une baguette magique que lui a offerte une malade. Tout en manifestant une certaine distance à l'égard de ses propres outils de sollicitation, le programme prétend contenir en lui-même les ressorts de son efficacité. Des professionnels du marketing humanitaire, bien que n'étant pas directement associés à la production de l'émission, sont sollicités pour doter le programme d'instruments destinés à agir sur le téléspectateur. Ils contribuent à la préparation des messages, proposent quelques règles de conduite aux animateurs et dessinent des scénarios pour animer ensemble le programme et le compteur. Ils invitent, ce faisant, à lire la courbe des dons comme un calque précis et sensible des stratagèmes glissés dans la texture du programme.

\section{La relation entre la courbe des dons et le programme}

La sociologie des médias est peu disposée à accréditer l'hypothèse d'une relation immédiate et automatique entre une instruction télévisuelle et une action en retour du téléspectateur. Sans doute minorerait-elle ces «effets forts » de la télévision (en montrant, par exemple, le rôle d'autres types de déterminations du comportement du donateur), déconstruirait-elle les recettes télévisuelles les plus triviales (la multiplication des défilants, par exemple, dont l'effet sur la courbe des dons paraît très incertaine) et mettrait-elle à jour le faisceau de croyances qui permet de créditer d'un savoir-faire particulier les professionnels du marketing. Sans renier cette défiance qui s'inspire du souci de ne pas contribuer à accroître la rationalisation des gestes de générosité, il nous semble cependant utile d'engager le débat sur le terrain même des effets « tendus » des médias pour 
prendre la mesure de l'efficacité des dispositifs d'interpellation du téléspectateur mis en place dans le Téléthon. Mais l'explication de ces effets restera incomplète (tout en étant suffisante pour ceux dont le travail est d'améliorer la qualité de la collecte) tant qu'elle ne prendra pas en compte les modes de réception des messages, l'horizon d'arrière-plan qui en constitue les conditions de félicité et les raisons que les donateurs confèrent à leur geste.

Le programme prétend plier le téléspectateur à ses volontés. Pour le vérifier, nous avons recueilli le trafic téléphonique indexé à la seconde du 3637 , numéro unique pour tous les donateurs français. Cette base de données est extrêmement fiable pour apprécier les réactions téléphoniques des donateurs $^{10}$. Durant les 30 heures du Téléthon, plusieurs centaines de milliers d'appels sont passés en direction du 3637. Les informations collectées ne portent pas sur la totalité de ces appels, mais seulement sur un échantillon représentant un tiers de cet ensemble ${ }^{11}$.

Pour les commodités de l'exposé et pour préserver la confidentialité des données du trafic téléphonique du 3637 , on considérera, de façon conventionnelle, qu'un million d'appels ont été enregistrés au total : tous les chiffres dont il sera question sont relatifs et doivent donc être rapportés à cette base de comparaison.

10. Les téléspectateurs peuvent aussi faire une promesse de don par minitel au 3615 code Téléthon. Nous avons conduit une recherche spécifique sur ces données. Si les résultats ne sont pas présentés ici, c'est en raison de la très grande similitude des résultats obtenus à partir des données du minitel et de ceux obtenus à partir des données téléphoniques. Examinée à l'échelle de l'émission ou des séquences, la structure de la courbe des connexions minitel est très proche de la structure de la courbe des appels téléphoniques; elle montre simplement une inflexion lorsque la sollicitation ne concerne que le 3615 sans mention du 3637 (ce qui est très rare dans le Téléthon).

11. Nous remercions Eliane Fournial et Jacky Bourasseau pour l'aide qu'ils nous ont apportée dans le décryptage des données de France Télécom. Cet échantillon est constitué par tout ou partie des appels transitant par les centraux téléphoniques des régions d'Agen, de Bordeaux, de Corse, de Chaumont, de Créteil, de Lyon, de Nice, de Paris, de Perpignan, de Rennes, de Strasbourg et de Tours. Cet échantillon peut être considéré comme représentatif dans la mesure où le territoire national est assez bien couvert et où l'allure générale de la courbe des trafics téléphoniques durant l'émission est identique d'une région à l'autre. 

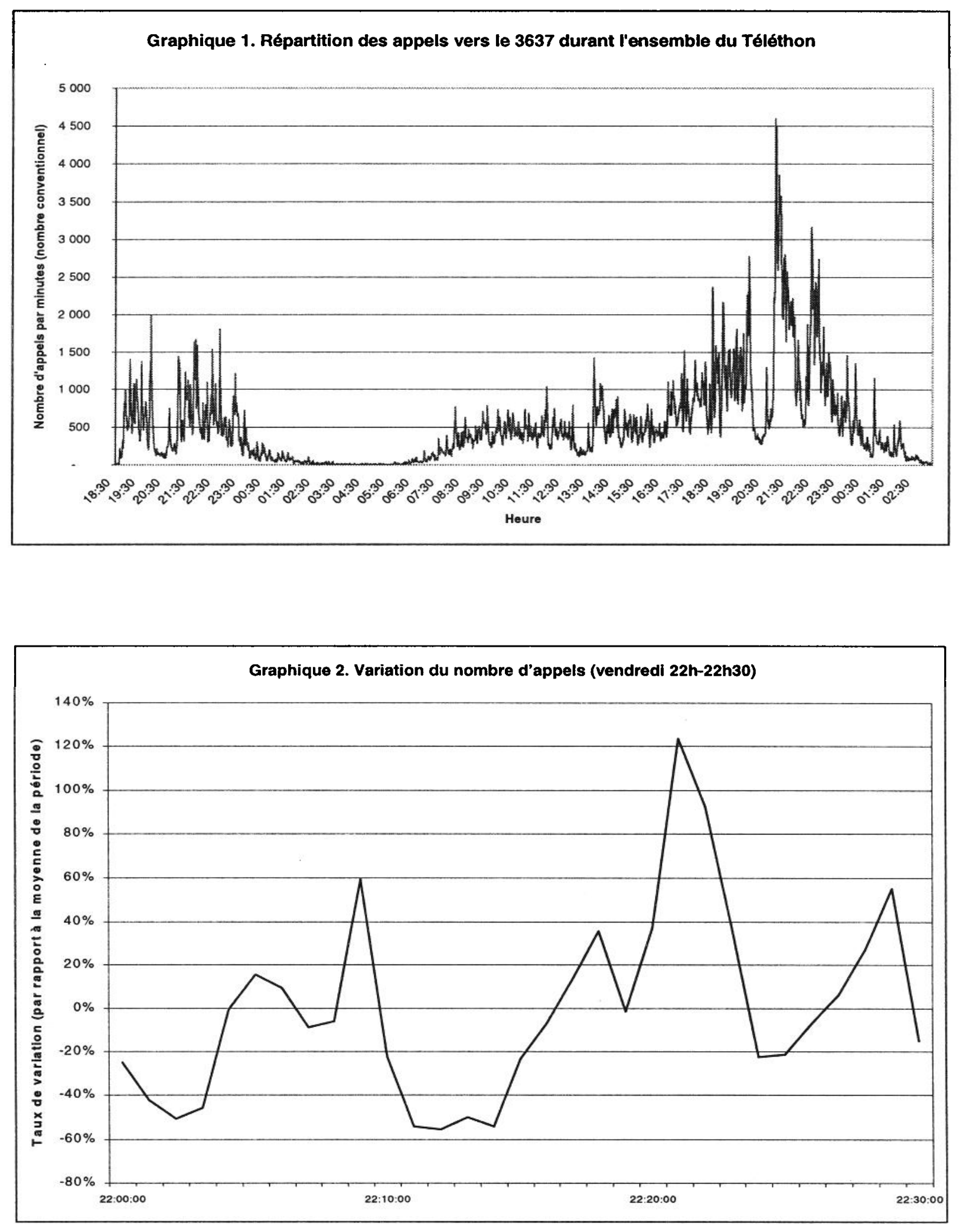
Comme l'illustre le graphique 1, ces appels se répartissent très inégalement durant les 1920 minutes d'ouverture des standards téléphoniques: si le nombre moyen d'appels par minute se situe aux alentours de 520, un quart des minutes voit moins de 130 appels transiter et un autre quart des minutes enregistre plus de 680 appels. Une minute sur dix voit transiter plus de 1135 appels et plusieurs minutes regroupent plus de 2850 appels (par minute); le record étant détenu par une minute durant laquelle plus de 4532 appels sont passés. La variabilité des appels est donc très grande.

Si la variabilité est très grande, la réactivité, c'est-à-dire la rapidité des changements dans les trafics téléphoniques, est elle aussi très importante (cf. graphique 2). Pour environ une minute sur cinq, la variation du nombre d'appels par rapport à la minute précédente est supérieure à $25 \%$ (soit à la baisse, soit à la hausse). Et pour près d'une minute sur dix, cette variation est supérieure à $40 \%$.

Cette variabilité peut encore être constatée à une échelle inférieure à la

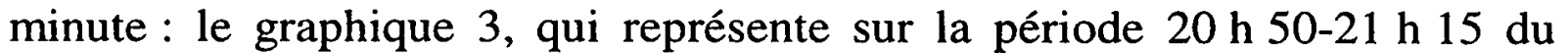
samedi soir les évolutions des flux téléphoniques, permet à nouveau de constater une forte variabilité. Elle est ici accentuée par des phénomènes aléatoires de distribution des appels dans le temps qui, à l'échelle de la minute, disparaissent en étant « lissés ».

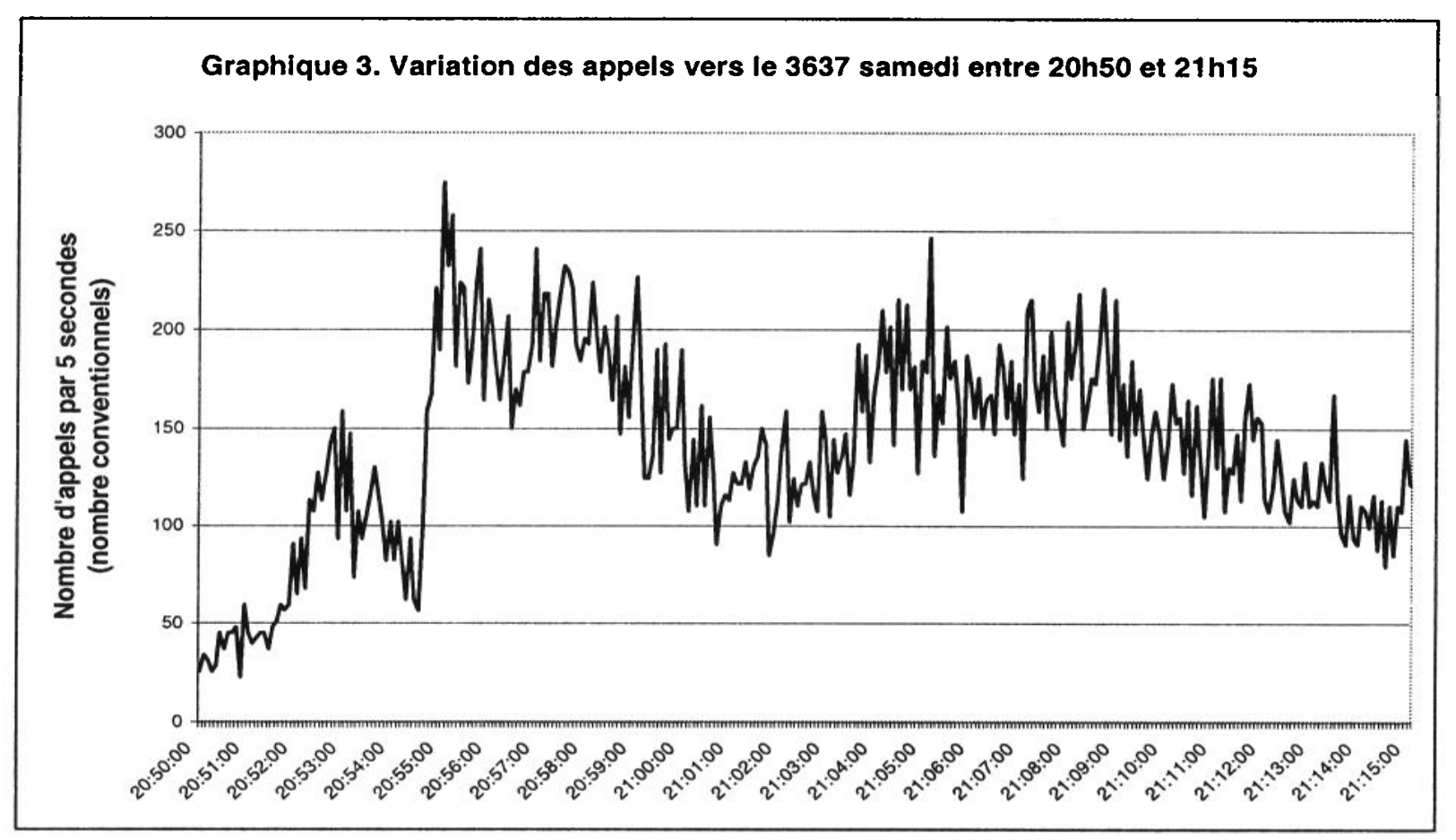


En somme, saisies à l'échelle de la minute, les évolutions du nombre d'appels téléphoniques sont à la fois rapides et d'une grande amplitude. Ces variations ne peuvent pas être mises sur le compte de simples fluctuations, d'aléas individuels indépendants dont l'accumulation produirait, à l'échelle collective, de fortes et rapides variations. Il est nécessaire de chercher ailleurs la cause de ces variations.

\section{A la recherche des liens entre le trafic téléphonique et l'émission}

La première explication plausible de ces fluctuations est la variation d'audience de l'émission (saisie ici comme la part des possesseurs de télévision ayant choisi de regarder le Téléthon). Elle permettrait de rendre compte de la forte variabilité du trafic par les usages sociaux de la télévision sans avoir recours à des éléments d'explication issus du programme luimême. Les variations constatées dans les appels peuvent-elles s'expliquer à partir des variations d'audience ? Les évolutions des taux d'audience de l'émission Téléthon peuvent-elles rendre compte des évolutions du nombre d'appels téléphoniques ? Répondre à ces questions suppose de préciser l'échelle à laquelle sont évaluées les éventuelles liaisons. A l'échelle la plus large, pour l'ensemble de l'émission ou pour une plage horaire de plusieurs heures, la liaison entre l'audience ${ }^{12}$ et le trafic téléphonique est évidente (cf. graphique 4). Le rythme social d'une journée ou d'une soirée conditionne à la fois l'audience et l'usage du téléphone. Les appels sont rares en pleine nuit, tout comme sont rares les personnes devant leur poste de télévision à ce même moment ; inversement, les appels sont très nombreux en début de soirée puisque le nombre de personnes devant le téléviseur est structurellement très élevé. Au fond, la temporalité des appels suit celle de l'audience car l'une comme l'autre sont socialement déterminées. Le graphique suivant illustre cette liaison «naturelle » entre l'audience et le trafic téléphonique à l'échelle de la journée ou de l'émission.

12. L'audience est ici mesurée par le taux de pénétration, c'est-à-dire la part (exprimée en pourcentage) des personnes devant leur téléviseur par rapport à l'ensemble des personnes possédant un poste de télévision. 


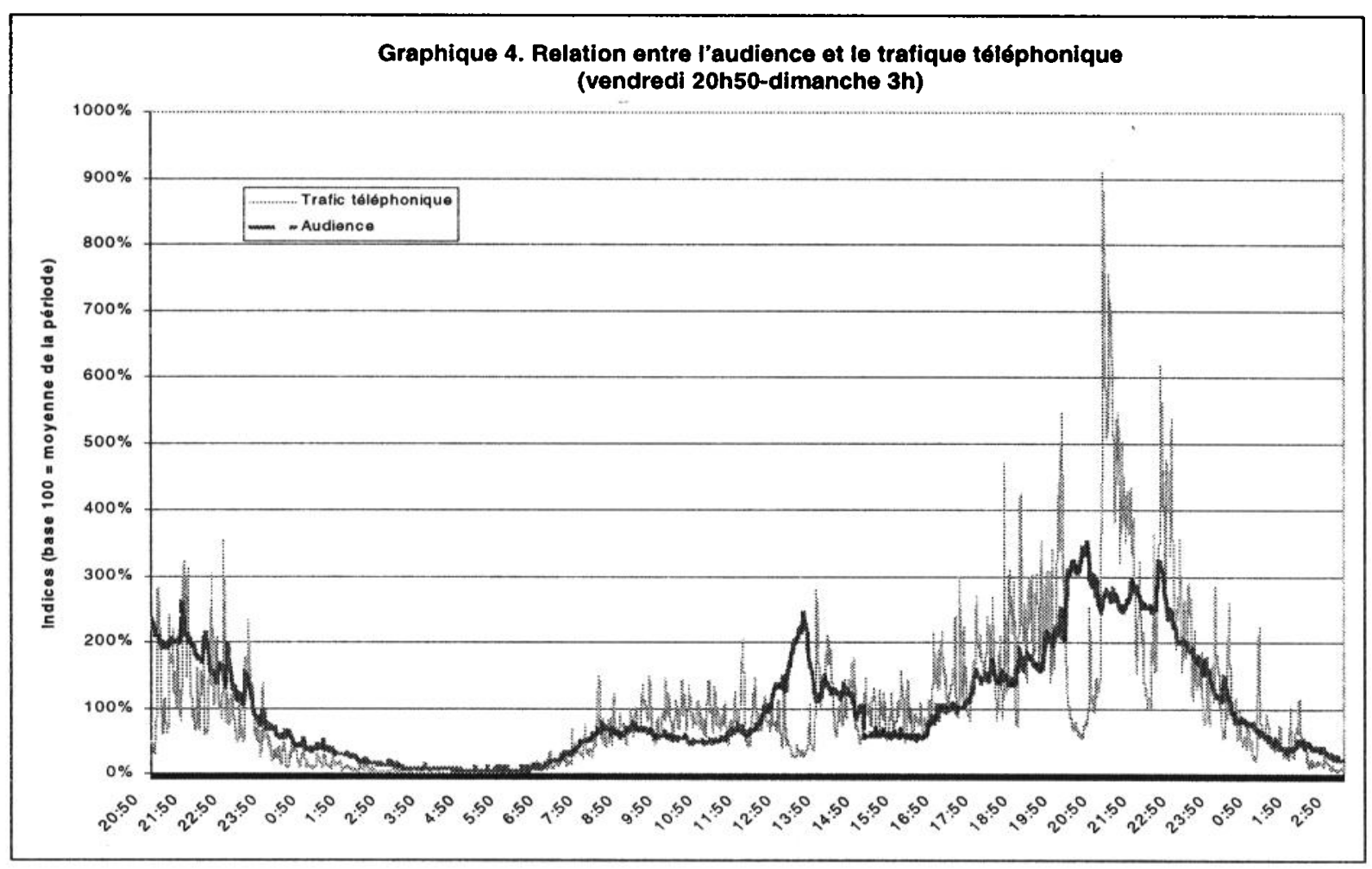

REMARQue.- Les périodes durant lesquelles l'audience est élevée et le trafic téléphonique faible (samedi vers $13 \mathrm{~h}$ et $20 \mathrm{~h}$ ) correspondent aux périodes de diffusion du journal télévisé (seules interruptions du Téléthon).

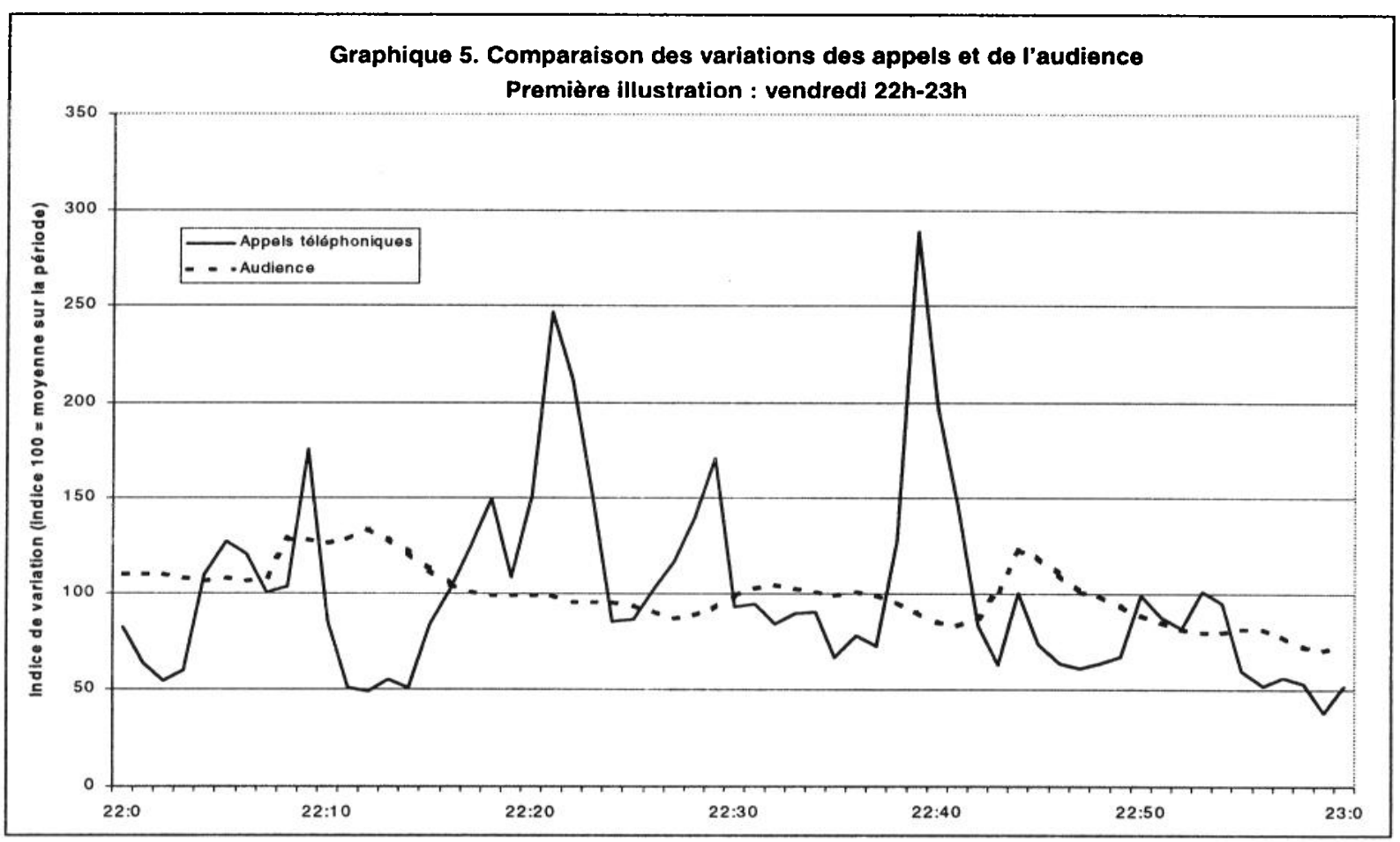


Si la liaison entre l'audience et la courbe de don est évidente à l'échelle «macro », elle disparaît en revanche à l'échelle de l'heure, de la demi-heure ou de quelques minutes. Comme le graphique 5 le montre, il est difficile de mettre les variations de trafic téléphonique sur le compte des variations d'audience. A l'échelle d'observation de ce graphique (une heure), les variations de trafic sont indépendantes des variations d'audience: le trafic connaît des mouvements rapides de grande amplitude, tandis que l'audience reste relativement stable.

Le calcul des coefficients de corrélation, à diverses échelles, entre le trafic téléphonique et l'audience confirme avec plus de certitude ce que le graphique précédent suggère (cf. tableau 2). Plus la période d'observation est longue, c'est-à-dire plus l'échelle d'observation est grande, plus la liaison entre le trafic téléphonique et l'audience est élevée. A l'échelle de quelques minutes, les coefficients de corrélation sont très faibles. A l'échelle de l'ensemble de l'émission, la corrélation est élevée ${ }^{13}$. Et entre ces deux situations (entre une et quatre heures notamment), les corrélations sont intermédiaires: elles rendent probablement compte du cycle de vie des téléspectateurs qui, arrivant sur le programme du Téléthon à des moments précis, ont des durées d'écoute assez proches les unes des autres ${ }^{14}$.

Tableau 2. Corrélation entre audience et trafic téléphonique

\begin{tabular}{|c|c|}
\hline $\begin{array}{c}\text { Echelle - période } \\
\text { (durée des périodes sur lesquelles sont calculées } \\
\text { les coefficients de corrélation) }\end{array}$ & $\begin{array}{c}\text { Valeur moyenne du coefficient de } \\
\text { corrélation }\end{array}$ \\
\hline 10 minutes & $-0,02$ \\
\hline 15 minutes & 0,02 \\
\hline 20 minutes & 0,05 \\
\hline 30 minutes & 0,09 \\
\hline 45 minutes & 0,13 \\
\hline 1 heure & 0,15 \\
\hline 2 heures & 0,26 \\
\hline 4 heures & 0,39 \\
\hline 6 heures & 0,45 \\
\hline Ensemble de l'émission & 0,68 \\
\hline
\end{tabular}

LECTURE.- Nous avons calculé le coefficient de corrélation pour chacune des séquences d'une durée fixée (par exemple 15 minutes) puis avons calculé la moyenne des coefficients ainsi obtenus (ici : 0,02).

13. Test de significativité bilatérale : $\mathrm{p}<10^{-22}$.

14. Cf. pour une analyse des effets de cycle de vie du téléspectateur dans les études d'audience, CHALVON-DEMERSAY, ROSENTAL, 1998. 
Ainsi, si l'audience est une mesure de la force d'une émission, elle témoigne de l'attractivité du programme pris dans son ensemble, ou au moins pris dans la durée : même s'il est facile de zapper d'une chaîne à l'autre, il existe une inertie et un besoin minimal de cohérence qui conduit le téléspectateur à ne pas pouvoir réagir immédiatement et systématiquement au programme en changeant de chaîne à tout moment. En somme, la mesure de l'audience est peut-être un bon outil pour apprécier le niveau d'attraction ou de répulsion d'un programme (il est en tout cas interprété ainsi par les chaînes et les agences publicitaires) mais c'est un outil fournissant une évaluation globale d'un programme ou d'une part significative d'un programme. En aucun cas l'audience n'est une mesure de la réactivité instantanée ou quasi instantanée des téléspectateurs au programme (tout au plus est-ce une mesure de la réactivité instantanée lors des changements d'émission, notamment lors des fins d'émission et des séquences publicitaires).

\section{Le programme comme variable explicative}

Puisque l'audience ne permet pas d'expliquer les variations importantes et brutales des flux téléphoniques, et qu'à audience identique les bouleversements de ces flux peuvent être très importants, l'explication de la courbe accidentée des appels téléphoniques au 3637 doit-elle alors être cherchée du côté du contenu de l'émission ? La nature des séquences télévisuelles, leur enchaînement, le contenu du programme diffusé peuventils permettre de rendre compte des trafics téléphoniques? Une première esquisse de réponse se trouve dans le graphique 6 , représentant simultanément la nature des séquences télévisuelles diffusées entre 20 h 53 (heure de reprise de l'émission après le journal télévisé) et $22 \mathrm{~h} 21$ et le volume des appels téléphoniques vers le 3637 durant cette même période.

Ce graphique fait d'emblée apparaître le caractère extrêmement accidenté de la courbe des dons; accidents qui, à la simple lecture, ne semblent ni contingents ni aléatoires. En effet, chaque début de séquence donne une inclinaison à la pente de la courbe des appels pour l'ensemble de la séquence. Ici, en début de soirée du vendredi, ce sont les plages musicales (en blanc sur le graphique) qui correspondent toutes à une chute considérable des appels. Pendant la chanson $(22 \mathrm{~h} 10-22 \mathrm{~h} \mathrm{14})$ interprétée par Marie-Jo, une malade lourdement handicapée, la courbe se stabilise même à un niveau extrêmement bas puis connaît une très forte augmentation, lorsque le programme bascule sur un nouveau duplex. 


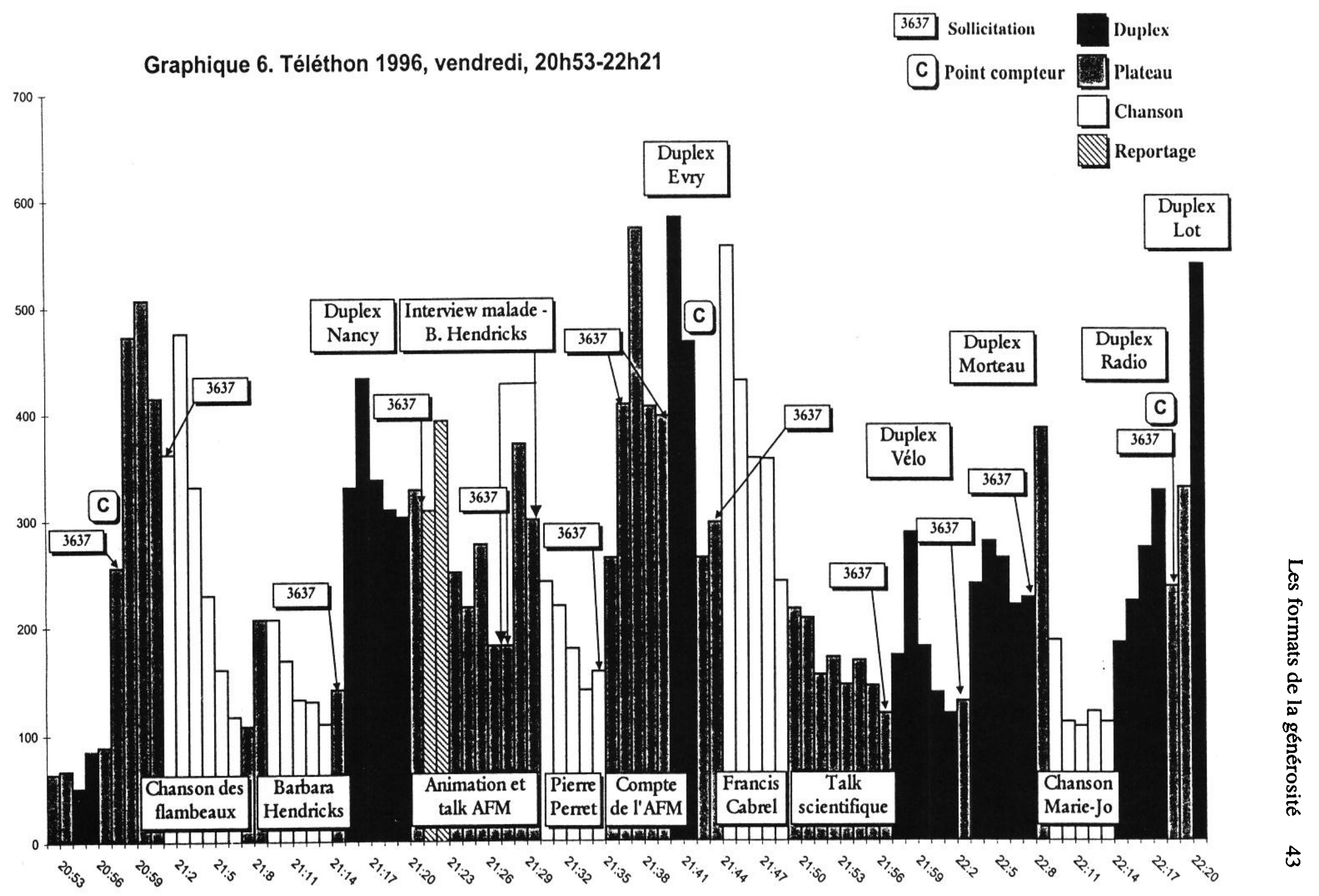


A l'inverse des chansons, toutes les séquences d'animation en duplex (à Nancy, à l'Agora d'Evry, avec les cyclistes, à la Maison de la radio) connaissent une forte augmentation du trafic. Enfin, les sollicitations et/ou les points compteur correspondent aussi à de très fortes pointes du trafic dans la minute qui suit. Il semble donc exister un lien entre la nature des séquences (ou certaines de leurs propriétés) et le niveau de trafic téléphonique $^{15}$. Afin de donner une consistance statistique à ces corrélations observées entre le programme et les donateurs, on utilisera le codage des différents types de séquences télévisuelles construit dans la partie précédente ${ }^{16}$.

\section{L'effet immédiat des sollicitations}

Parmi les événements télévisuels composant l'émission le vendredi et le samedi soir, 194 séquences, de formes et de longueurs très différentes (cf. supra), correspondant à des sollicitations à composer le 3637 , ont été identifiées. Prises dans leur ensemble, ces séquences ont indéniablement des effets sur le trafic téléphonique: si aucune augmentation du trafic n'est notable au moment où la sollicitation est produite, en revanche, l'augmentation est très nette durant les trois minutes qui suivent. Ainsi, durant la minute qui suit la sollicitation (quelle qu'elle soit), près de $22 \%$ d'appels supplémentaires sont enregistrés ${ }^{17}$; durant la deuxième minute, près de $30 \%$ d'appels supplémentaires sont enregistrés ; et enfin, durant la troisième minute, l'écart se situe aux alentours de $16 \%$. Ces variations globales, statistiquement significatives, établissent avec certitude la relation étroite et tendue qui se noue entre l'instruction donnée par les animateurs aux téléspectateurs et le comportement de certains d'entre eux.

15. Les niveaux sont des pourcentages exprimant l'écart entre le trafic téléphonique à un instant donné (une minute donnée) et la moyenne du trafic sur une période de trente minutes (15 minutes avant et 15 minutes après).

16. Le codage des séquences télévisées a été réalisé indépendamment des premières analyses des trafics téléphoniques par des personnes différentes. Il s'appuie donc uniquement sur les principes de découpage télévisuel du programme.

17. C'est-à-dire que le nombre total d'appels enregistrés est de $22 \%$ supérieur à la moyenne enregistrée sur la demi-heure environnante (15 minutes avant, 15 minutes après). 
Tableau 3. Effet des différentes sollicitations sur le trafic téléphonique

\begin{tabular}{|l|c|c|c|c|c|c|c|c|}
\hline \multicolumn{1}{|c|}{ SOLLICITATION } & $\begin{array}{c}\text { Nbre de } \\
\text { minutes }\end{array}$ & $\mathbf{T}_{\mathbf{0}}$ & $\mathbf{T}_{\mathbf{0}}+\mathbf{1}^{\prime}$ & $\mathbf{T}_{\mathbf{0}}+\mathbf{2}^{\prime}$ & $\mathbf{T}_{\mathbf{0}}+\mathbf{3}^{\prime}$ & $\mathbf{T}_{\mathbf{0}}+\mathbf{4}^{\prime}$ & $\mathbf{T}_{\mathbf{0}}+\mathbf{5}^{\prime}$ & $\mathbf{T}_{\mathbf{0}}+\mathbf{6}^{\prime}$ \\
\hline Petit point compteur & $\mathbf{3 8}$ & - & - & - & - & - & - & - \\
\hline Bref appel au don & $\mathbf{1 0 6}$ & - & $\begin{array}{c}* * * \\
+18 \%\end{array}$ & $\begin{array}{c}* * * \\
+23 \%\end{array}$ & $\begin{array}{c}* * * \\
+15 \%\end{array}$ & $\begin{array}{c}* \\
+3 \%\end{array}$ & $\begin{array}{c}* \\
-6 \%\end{array}$ & $\begin{array}{c}* * * \\
-16 \%\end{array}$ \\
\hline Point compteur & $\mathbf{1 0}$ & - & $\begin{array}{c}* \\
+30 \%\end{array}$ & $\begin{array}{c}* * \\
+40 \%\end{array}$ & $\begin{array}{c}* \\
+31 \%\end{array}$ & $\begin{array}{c}* \\
+29 \%\end{array}$ & - & - \\
\hline $\begin{array}{l}\text { Appel au don avec } \\
\text { justification }\end{array}$ & $\mathbf{1 7}$ & - & - & $\begin{array}{c}* * * \\
+47 \%\end{array}$ & $\begin{array}{c}* * \\
+30 \%\end{array}$ & - & - & - \\
\hline $\begin{array}{l}\text { Appel au don avec } \\
\text { justification et point } \\
\text { compteur }\end{array}$ & $\mathbf{2 3}$ & - & $\begin{array}{c}* * * \\
+59 \%\end{array}$ & $\begin{array}{c}* * * \\
+76 \%\end{array}$ & $\begin{array}{c}* * * \\
+32 \%\end{array}$ & $\begin{array}{c}* * \\
+25 \%\end{array}$ & - & - \\
\hline \multicolumn{1}{|c|}{ TOTAL } & $\mathbf{1 9 4}$, & - & $\begin{array}{c}* * * \\
+22 \%\end{array}$ & $\begin{array}{c}* * * \\
+30 \%\end{array}$ & $\begin{array}{c}* * * \\
+16 \%\end{array}$ & - & - & - \\
\hline
\end{tabular}

LECTURE.- Une minute après un bref appel au don, le trafic téléphonique augmente en moyenne de $18 \%$ et cette variation est significative (niveau de risque $<0.001$ ). Il y a 106 sollicitations de ce type.

REMARQUES.- Les éventuels effets des sollicitations sont observés au moment de la sollicitation (temps $\left.T_{0}\right)$ puis durant les sept minutes qui suivent $\left(T_{0}+1\right.$ minute à $T_{0}+6$ minutes). Les cases de ce tableau indiquent la variation moyenne enregistrée (en \%) et le niveau de significativité de cette variation. Les cases comportant le signe «-» renvoient à des situations où aucune variation significative n'a été enregistrée. Les étoiles indiquent le niveau de significativité (test de Fisher ANOVA) : * correspond à un niveau de risque (probabilité) compris entre 0.01 et $0.05 ;{ }^{* *}$ à une probabilité comprise entre 0.001 et $0.011^{* * *}$ à une probabilité inférieure à 0.001 . Dans tous les cas $(*$ à $* * *)$ le test permet de conclure à une significativité des variations.

Cette corrélation apparaît de façon encore plus manifeste si l'on distribue cet effet selon les différents types de sollicitation qui ont été identifiés précédemment (cf. supra). Plus le solliciteur incorpore dans son message des justifications, plus les variations de trafic sont fortes. Ainsi, la mise en scène complète de la sollicitation par l'animateur (rappel des précédents événements télévisuels, justification générale de la cause, mise en scène de l'urgence, invitation directe et explicite à téléphoner sans attendre, changement du chiffre du compteur, applaudissements) déclenche la plus forte augmentation des appels : environ $59 \%$ en plus durant la minute qui suit la sollicitation, $76 \%$ durant la deuxième minute et près d'un tiers d'appels en plus trois minutes après. Lorsque la sollicitation n'est pas accompagnée d'un point compteur, la variation à deux minutes se situe aux alentours de $47 \%$. L'effet de ces deux types de sollicitation semble par ailleurs renforcé par leur placement en fin de séquence plateau, et le plus souvent avant un duplex. Même lorsque la sollicitation est brève («Faites le 3637 ! ) et non accompagnée de justification, les variations du nombre 
d'appels sont certes moins importantes mais elles restent fortes et nettement significatives $:+40 \%$ deux minutes après la sollicitation. En revanche, les points compteurs qui ne sont pas accompagnés de sollicitation (cf. «Petit point compteur ») n'ont pas d'effets significatifs, tout comme le passage des défilants dont il est impossible d'évaluer l'effet ${ }^{18}$. Ces résultats signent de manière incontestable la performance des dispositifs de sollicitation. La «pression » exercée par la sollicitation exerce un impact immédiat sur le trafic téléphonique et plus cette «pression » est exercée avec force, plus le nombre d'appels augmente. La coordination des gestes des donateurs avec le programme apparaît encore mieux si l'on observe des périodes de 15 secondes.

\section{Graphique 7. La sollicitation de Barbara Hendricks}

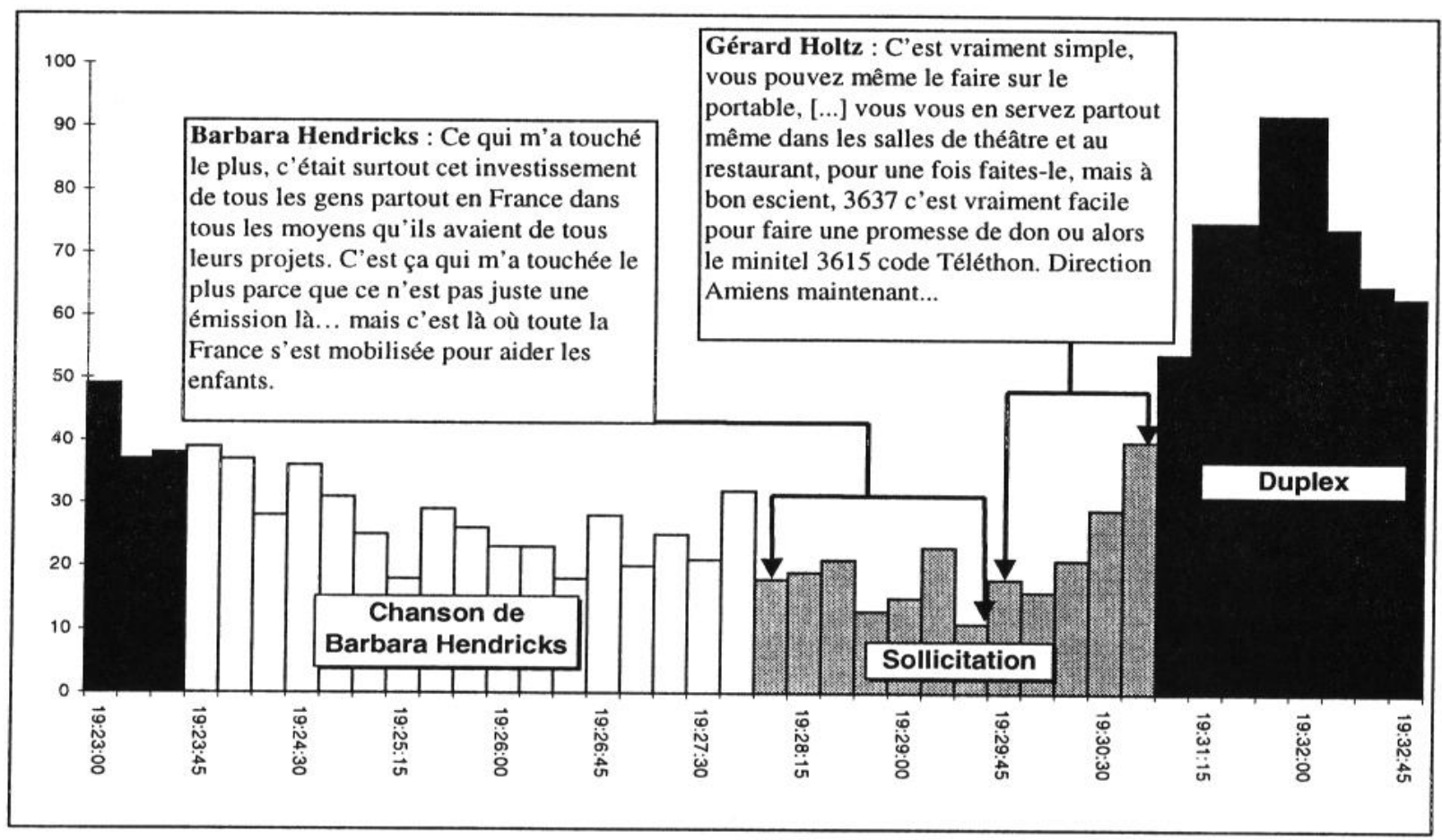

18. L'efficacité de la sollicitation dépend également du type de solliciteur. Un animateur «central », c'est-à-dire totalement inséré dans l'émission, disposant d'un temps réservé pour effectuer un appel au don plus long et doté d'un savoir-solliciter supérieur, a un impact beaucoup plus fort que les animateurs locaux, les scientifiques ou les partenaires qui interviennent ponctuellement pour réaliser, à l'improviste, un appel au don $(+46 \%$ contre $17 \%$ durant la deuxième minute). Entre ces deux situations, entre ces deux niveaux d'efficacité, se trouvent les vedettes qui exercent un effet moins fort que les animateurs centraux mais plus fort que les « petits animateurs » ( $+29 \%$ durant la deuxième minute). 
L'exemple précédent en témoigne (cf. graphique 7). Après la chanson de Barbara Hendricks, le flux des appels commence à grossir dès la fin de la sollicitation pour prendre ensuite son essor de façon extrêmement rapide en mordant sur la séquence de duplex suivante.

Tout se passe donc comme si les sollicitations venaient, avec régularité, « lever» des pics au sein de la courbe du trafic téléphonique, soutenant ainsi le volume des appels pendant la durée de l'émission. Mais sont-elles pour autant indispensables? Ces pics pourraient simplement constituer la signature autonome de la fin d'une séquence, que le téléspectateur identifierait comme un moment opportun pour effectuer un geste qu'il projetait de faire indépendamment des demandes réitérées par le programme.

L'examen d'une partie de la soirée du samedi (cf. graphique 8) tend à prouver le contraire - et à justifier, a contrario, la mécanique des sollicitations à répétition. Jusqu'à 21 h 18, l'enchaînement des séquences suit la logique habituelle de l'émission et la courbe téléphonique enchaîne pics et creux à un rythme à peu près régulier. Mais à partir de $21 \mathrm{~h} 30$ et d'une longue séquence musicale au château de Versailles, le programme s'accélère sans adresser de sollicitation aux téléspectateurs. A 21 h 40 , un chanteur, François Feldman, arrive sur scène. Il fait un triomphe et la salle lui demande une deuxième chanson. Les séquences se suivent ensuite à grand rythme. A $22 \mathrm{~h} 03$, le réalisateur est même obligé de couvrir simultanément deux fils rouges (l'arrivée simultanée du train et des cyclistes). Chose extrêmement rare dans le Téléthon, les duplex s'enchaînent les uns les autres sans repasser par le plateau central. Bref, le programme s'est emballé. Pendant ces trois quarts d'heure de programme, on ne compte que deux brèves sollicitations et quelques points compteurs. Parallèlement, la courbe des appels téléphoniques connaît une diminution extrêmement forte sur toute la période. Lorsque le programme s'apaise et que des sollicitations plus longues et plus rapprochées sont à nouveau produites, à partir de $22 \mathrm{~h} 15$, la courbe des appels connaît un accroissement sensible. Cet exemple montre comment l'ensemble de la collecte est couturé à point serré par les sollicitations réitérées tout au long du programme ; dès que les points de contact avec les téléspectateurs se distendent, la courbe des appels s'affaisse. 


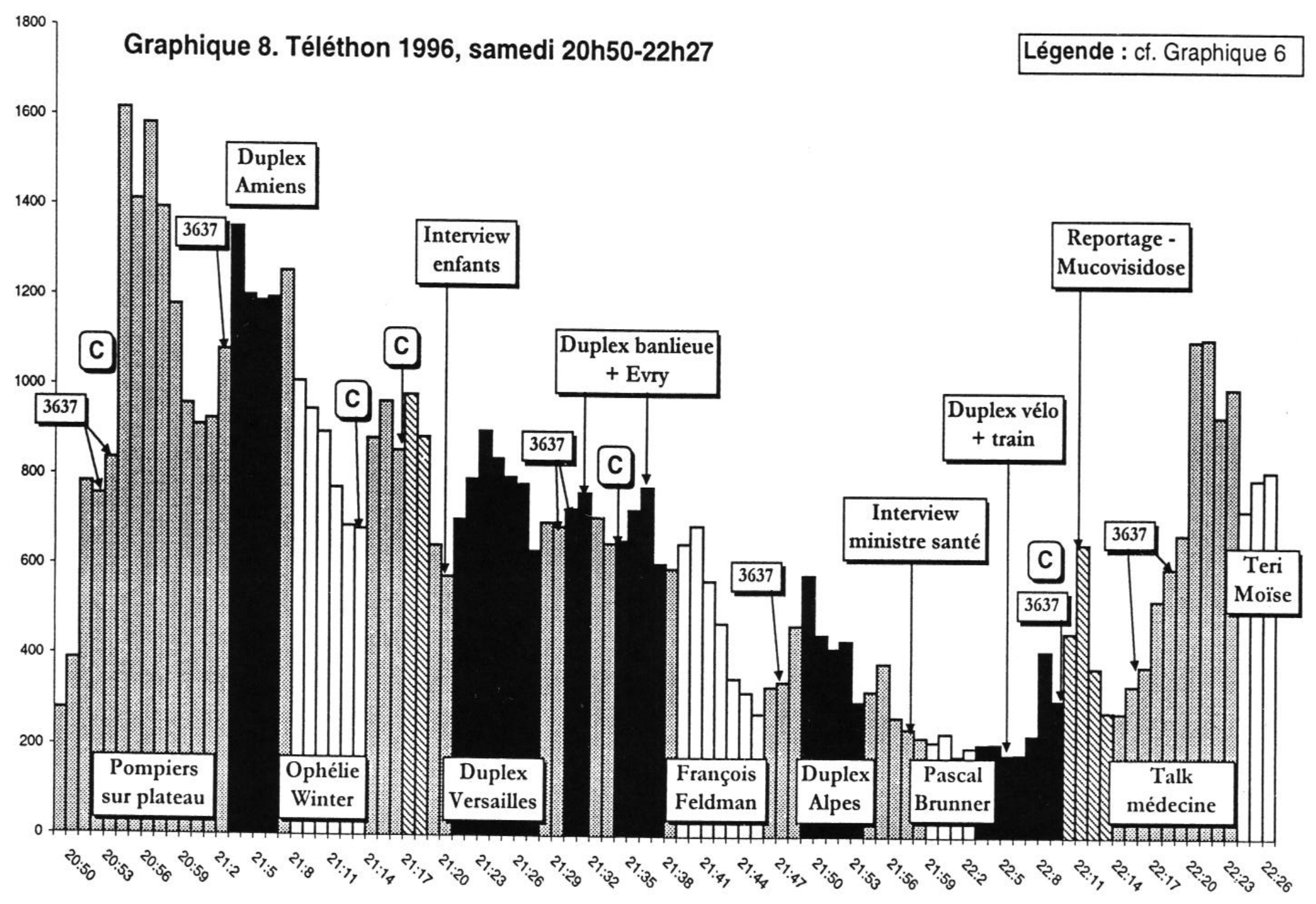




\section{L'attractivité des séquences}

La seule mise en correspondance graphique du trafic téléphonique et du découpage des séquences de l'émission (cf. graphiques 6 et 8) suggérait déjà l'existence d'un lien entre la nature de ces séquences et le niveau des flux téléphoniques. Ce lien et sa force peuvent maintenant être mis en évidence en examinant, sur les deux soirées du vendredi et du samedi, les relations statistiques qu'entretiennent le volume du trafic téléphonique instantané (minute par minute) et les caractéristiques des événements télévisuels qui leur correspondent. En reprenant le découpage minuté des séquences, réalisé à partir des catégories de la production télévisuelle (chanson, duplex, talk enfants, etc., cf. supra), il apparaît bien que le type de séquence télévisée a, en lui-même, une incidence sur les flux téléphoniques de la séquence. La lecture du tableau 4 permet de distinguer trois types de séquence selon leur effet sur la courbe des appels. Les duplex et les talk animateurs, d'abord, se caractérisent par une augmentation très significative du trafic téléphonique. $\mathrm{Si}$ pour les talks animateurs, ces pointes de trafic s'expliquent par la présence importante des sollicitations et des points compteur (79 minutes sur 118), l'effet des duplex semble bien associé à la nature même de la séquence considérée; l'augmentation du trafic est même significative jusqu'à la quatrième minute. A l'inverse, les fils rouges sur le plateau central, les talks enfants, et plus encore les chansons et les reportages engendrent une chute généralement très importante du trafic téléphonique. Enfin, pour les autres types de séquence, les talks sponsor, scientifique ou associatif, les variations statistiques enregistrées ne sont pas significatives et n'ont pas d'incidence sur la courbe des dons.

L'interprétation de ces effets oblige à faire une présupposition sur le comportement du téléspectateur-donateur. On considérera qu'il sera plus facilement enclin à se détourner du programme pour appeler le 3637 (se détourner du flux télévisuel, se lever, quitter la pièce, chercher le téléphone, etc.) que son attention au programme sera moins forte. Le trafic téléphonique de la séquence serait un rapport inverse de l'attraction du programme pour le téléspectateur; celui-ci profiterait des «fenêtres » qu'ouvre le programme pour interrompre son écoute dans les séquences moins attractives. Si cette hypothèse est juste - elle est en tout cas plausible au niveau d'agrégation où se situe l'analyse statistique -, les différentes séquences du programme peuvent être discriminées en fonction de leur plus ou moins grand pouvoir d'attraction sur les téléspectateurs. Les chansons diffusées depuis le plateau central, les reportages sur les malades (et les 
interviews plateau qui les accompagnent) constituent les deux types de séquence télévisuelle qui présentent le plus d'attractions. Les duplex présentent en revanche le moins d'attraction et sont donc les plus propices au don téléphonique. Ce différentiel d'attractivité du programme, tel que le mesure la courbe des appels téléphoniques, s'explique d'abord par la continuité de la trame narrative des reportages (présentant un début et une fin enserrant une intrigue) et des chansons (comportant aussi un début et une fin à laquelle succède une postface : le dialogue de l'artiste avec l'animateur et un malade ${ }^{19}$ ). A l'inverse, le caractère extrêmement saccadé des événements ayant lieu dans les duplex ne crée que des zones d'attraction courtes et ponctuelles.

Tableau. 4. Corrélation entre le flux téléphonique et les séquences télévisuelles

\begin{tabular}{|l|c|c|c|c|c|c|c|}
\hline \multicolumn{1}{|c|}{ Séquences } & $\begin{array}{c}\text { Nbre de } \\
\text { minutes }\end{array}$ & T0 & T0+1 & T0+2 & T0+3 & T0+4 & T0+5 \\
\hline Talk animateur & $118^{\prime}$ & - & $\begin{array}{c}* * * \\
+29,9 \%\end{array}$ & $\begin{array}{c}* * * \\
+37,3 \%\end{array}$ & $\begin{array}{c}* * * \\
+19,4 \%\end{array}$ & - & - \\
\hline $\begin{array}{l}\text { Chansons - } \\
\text { vedettes }\end{array}$ & $121^{\prime}$ & $\begin{array}{c}* * * \\
-14,5 \%\end{array}$ & $\begin{array}{c}* * * \\
-22,5 \%\end{array}$ & $\begin{array}{c}* * * \\
-22,8 \%\end{array}$ & $\begin{array}{c}* * * \\
-17,4 \%\end{array}$ & $\begin{array}{c}* * \\
10,2 \%\end{array}$ & - \\
\hline $\begin{array}{l}\text { Talk : science et } \\
\text { associations }\end{array}$ & $65^{\prime}$ & - & - & - & - & - & - \\
\hline Talk enfant & $48^{\prime}$ & $\begin{array}{c}* * * \\
-29,4 \%\end{array}$ & $\begin{array}{c}* * \\
-19,7 \%\end{array}$ & - & - & - & - \\
\hline $\begin{array}{l}\text { Fil rouge sur } \\
\text { plateau central }\end{array}$ & $41^{\prime}$ & - & $\begin{array}{c}* \\
-12,6 \%\end{array}$ & $\begin{array}{c}* * \\
-17,5 \%\end{array}$ & $\begin{array}{c}* * \\
-16,3 \%\end{array}$ & - & - \\
\hline $\begin{array}{l}\text { Intervention des } \\
\text { sponsors }\end{array}$ & 16 & - & - & - & - & - & - \\
\hline Duplex & 269 & $\begin{array}{c}* * * \\
+13,8 \%\end{array}$ & $\begin{array}{c}* * * \\
+9,2 \%\end{array}$ & $\begin{array}{c}* \\
+5,6 \%\end{array}$ & $\begin{array}{c}* * \\
+6,2 \%\end{array}$ & $\begin{array}{c}* \\
+5 \%\end{array}$ & - \\
\hline Reportage & $44^{\prime}$ & $\begin{array}{c}* * \\
-1,9 \%\end{array}$ & $\begin{array}{c}* * * \\
-31,8 \%\end{array}$ & $\begin{array}{c}* * * \\
-35,9 \%\end{array}$ & $\begin{array}{c}* * * \\
-26,2 \%\end{array}$ & - & - \\
\hline
\end{tabular}

LECTURE.- Cf. tableau 3.

19. Il apparaît ainsi que les téléspectateurs ont des attentes définies à l'endroit de la performance des vedettes et une connaissance tacite du format télévisuel de leur prestation. Par exemple, ils attendent leur départ du plateau pour faire un appel téléphonique car leur présence constitue une attraction qui les maintient devant le poste de télévision. 


\section{La programmation de l'attention et de l'engagement du téléspectateur}

L'étude de la courbe des dons éclaire sous un jour nouveau la construction composite et enchevêtrée des différents événements du Téléthon. Le programme ne cesse de se tendre et de se relâcher : tantôt il aménage des zones d'attractions fortes (les reportages et les performances des vedettes), qui contribuent à affaiblir considérablement le trafic du 3637, tantôt il aménage des zones d'attraction faible et autorise l'accroissement du nombre d'appels; entre ces deux dynamiques contradictoires, la sollicitation $s$ 'intercale pour donner une forte impulsion afin de maintenir le volume des appels téléphoniques ${ }^{20}$. La scénographie particulière de l'émission alternant à un rythme soutenu des séquences de nature très différentes trouve ainsi une nouvelle explication : elle programme des moments de captation et de dispersion de l'intérêt du téléspectateur. Le programme anticipe l'économie attentionnelle de son téléspectateur-donateur idéal. Tantôt il cherche à attirer l'attention afin de maximiser l'audience, tantôt il la relâche afin d'aménager des respirations propices à l'accomplissement du don.

Mais ce couple tension/diffraction peut aussi s'appliquer à la place qu'occupent au sein de l'émission les « raisons » que déploient les acteurs du Téléthon pour encourager le soutien du public. De très nombreux éléments du programme (la présence et le témoignage des malades et de leur famille, les prises de parole des responsables associatifs, les explications des chercheurs, etc.) réfèrent directement à la lutte contre les maladies neuromusculaires. Elles peuvent être appropriées par les téléspectateurs comme des raisons de s'engager. Si ces raisons sont fortement présentes dans certaines séquences, comme les reportages ou les débats scientifiques, elles sont en revanche très rares ou beaucoup plus allusives dans d'autres, comme les chansons, les divertissements dans les duplex ou certaines scènes de plateau réservées aux facéties des vedettes et des animateurs. Le lien entre ces séquences et les maladies neuromusculaires est extrêmement lâche, ou, tout moins, questionnable. La «cause» ne cesse ainsi d'aller et de venir dans le programme, d'en occuper le centre puis de s'effacer à l'arrière-plan. Ces variations sont constitutives de la "grande fête du Téléthon » qui mêle les images, saisissantes, de la vie des malades et les images, amusantes ou

20. Ce qui explique aussi que les sollicitations-compteur sont de préférence placées avant les duplex plutôt que devant les chansons ou, surtout, les reportages qui les rendent « improductives » en dirigeant l'attention du téléspectateur vers le poste de télévision plutôt que vers le téléphone. 
divertissantes, du spectacle. Ce choix de construction télévisuelle s'explique par la volonté des programmateurs de ne pas compromettre l'audience en maintenant trop longtemps un ton grave et sérieux. Il participe aussi à la définition du format de l'engagement dans le Téléthon. Mouvement de solidarité télévisuelle, le Téléthon propose aux personnes une offre d'engagement à « coût réduit »: de même qu'il suffit de passer à proximité d'une action locale de la Force $T$ pour y participer, l'accès du téléspectateur au cercle des donateurs est immédiat et aisé. C'est parce que le Téléthon fait preuve de «réalisme » dans l'appréhension des capacités des personnes à entrer dans des communautés mobilisées, qu'il ne leur demande pas de faire montre d'un intérêt préalable ou d'une connaissance approfondie de la cause, ni d'être le siège d'une profonde inclination altruiste.

Attractions/dispersion, raisons/distraction. Ces deux balancements ne se recoupent qu'imparfaitement selon les types de séquence proposés dans le Téléthon. Il est désormais nécessaire, à titre simplement analytique, de décomposer les différentes séquences de l'émission dans la grammaire télévisuelle des programmateurs ainsi que les effets qu'elles engendrent dans l'économie de la sollicitation. En dispensant ainsi avec des niveaux différents des attractions et des raisons, la construction télévisuelle du Téléthon propose un équilibre entre audience et engagement ${ }^{21}$.

Tableau 5. Répartition des différentes séquences du Téléthon selon leur « teneur » en attractions et en raisons

\begin{tabular}{|c|c|c|}
\hline Séquences & Raisons fortes & Raisons faibles \\
\hline Attractions fortes & $\begin{array}{c}\text { Reportage } \\
\text { Effet faible pendant puis } \\
\text { fort après }\end{array}$ & $\begin{array}{c}\text { Chanson } \\
\text { Effet faible pendant puis } \\
\text { fort après }\end{array}$ \\
\hline Attractions faibles & $\begin{array}{c}\text { Talk science } \\
\text { Effet indécidable }\end{array}$ & $\begin{array}{c}\text { Duplex } \\
\text { Effet fort pendant }\end{array}$ \\
\hline
\end{tabular}

\section{Si le dispositif n'avait pas de force...}

La force du dispositif ne peut plus désormais être mise en doute, ni le savoir-faire-donner des professionnels du marketing humanitaire. Le

21. Cette description des stratégies de construction des séquences accentue fortement le caractère rationalisé des pratiques des programmateurs. Dans la réalité, ceux-ci agissent de manière plus incertaine; ils ne disposent pas, en effet, d'instrument d'objectivation aussi précis du trafic téléphonique. 
comportement des donateurs semble avoir été capturé par le programme qui parvient, de façon remarquable, à synchroniser les gestes téléphoniques. Les donateurs refusent pourtant de reconnaître qu'une force ait pu s'exercer sur leur conduite. Ils proposent une interprétation de leur geste qui n'a absolument rien à voir avec celle que donne à lire l'exploitation des données du trafic téléphonique. Lorsqu'on leur demande à quelle heure ils ont téléphoné au 3637, si la télé était allumée à ce moment-là, si quelque chose dans le programme les a décidés à appeler, ils répondent d'une même voix $^{22}$ : «Ah non, non, pas du tout... En fait, c'est pas vraiment l'émission qui m'intéresse, c'est beaucoup plus la cause qu'elle défend " $(\mathrm{H}$, informaticien, 33 ans, 1995) : «Absolument pas, absolument pas, absolument pas. Non c'est pas lié à une heure spéciale... c'est pas lié à un truc que j'ai vu! Q. Au chiffre ? Absolument pas. Non, absolument pas, ma décision est prise dès l'instant où je sais que l'émission va passer » (F, 56 ans, gardienne, mariée).

Les donateurs expliquent d'abord que la question de l'heure d'appel est, à leurs yeux, parfaitement contingente. La décision de donner procèderait d'une délibération antérieure au programme. Ils savent que l'émission va avoir lieu. Ils en ont discuté en famille. Il vont donner. Peu importe le moment. Il suffit de choisir une période calme, le samedi matin ou en début d'après-midi, afin d'éviter l'affluence au 3637. Certains, fidèles de la première heure, ne regardent même plus le Téléthon et se contentent de téléphoner: "J'ai un autre support qui est La Vie qui m'apporte l'information, alors je préfère lire La Vie que de regarder la télévision, parce que souvent, il y a des choses qui sont assez pénibles. La télévision pour moi ça fait spectacle, alors des fois on est bien obligé d'en passer par là, mais si je peux éviter, je préfère » $(\mathrm{H}, 73$ ans, militaire à la retraite). Les autres, ceux qui regardent et appellent en début de soirée, aux heures d'affluence, considèrent tous que leur geste trouve sa justification dans le discours de l'AFM, dans l'événement pris dans son ensemble, dans le courage des malades, la ténacité des chercheurs ou la force de la mobilisation. Leur geste n'a pas de motifs localisables dans une séquence du programme, un reportage, un témoignage ou une sollicitation. L'appel téléphonique s'insère simplement dans les agencements pratiques de la vie quotidienne. Vous regardiez le programme? "Ah non, non, non, j'étais en

22. Pendant les Téléthon 1995 et 1996 , un dispositif d'enquête permettant de rappeler un certain nombre de donateurs a été mis en place. Des enquêteurs se sont rendus dans un centre de promesses téléphoniques afin de rappeler les personnes juste après qu'elles aient fait un don au 3637 pour réaliser une interview téléphonique. Ces données seront traitées ultérieurement. 
train de faire cuire une poule (rires), j'ai donné à cette heure-là » (F, 70 ans, employée retraitée de la Sécurité sociale) ${ }^{23}$. Si lors de cette interview téléphonique, les donateurs évoquent parfois une séquence ou une image qui les a marqués, ils n'y «logent » toutefois pas l'origine de leur geste. Le couplage «tendu » entre le geste du don et le programme s'est évanoui. Les donateurs n'en concluent pourtant pas à l'absence totale d' « effets forts » du programme. Mais ils estiment que ces effets ne s'exercent que sur les autres... «Q. Mais ce n'est pas lié à ce qui se passait dans le poste ? Ah! Pas du tout. Q. Finalement ce que vous dites, c'est que l'émission n'a aucun effet sur le don ? Ben c'est pour les nouveaux, si vous écoutez il y a des gens qui donnent depuis le début et ceux-là sont toujours les mêmes, c'est pour avoir les nouveaux et puis c'est tout » (F, 46 ans, travaille dans la publicité). Beaucoup soutiennent d'ailleurs, qu'à bien y regarder, "ce genre d'émission, [...] ne devrait même pas exister. C'est vrai! La générosité, elle est naturelle. C'est tous les jours. Moi je trouve dommage qu'on soit obligé de forcer les gens comme ça» (F, 42 ans, aide-soignante). Même si ces extraits n'ont pas la rigueur des corrélations statistiques, le contraste entre ces affirmations et les résultats issus du traitement des chiffres du trafic est si fort qu'il impose d'orienter l'enquête dans une autre direction...

\section{L'ENQUETE RECEPTION}

Le contraste entre le trafic téléphonique et les raisons des donateurs sépare sur deux plans indépendants la force du dispositif et les motivations généreuses $^{24}$. Comme nous le montrerons à la fin de ce texte, cet effort incessant pour affranchir le don des instruments qui l'ont suscité constitue

23. "Alors là vous me posez une colle, je sais pas parce que l'on a dû finir de déjeuner à cette heure-là, on regardait pas trop à cette heure-là " (F, 29 ans, employée de bureau, mariée); "Non, j'ai eu un petit creux dans la matinée, j'étais un peu pressée parce que j'avais des invités à déjeuner; alors j'ai profité d'un petit creux» (F, retraitée, 75 ans); etc.

24. Les manuels de marketing de collecte de fond, indispensables instruments de construction du «marché de la générosité », assument parfaitement ce découplage entre les dimensions techniques et morales de la sensibilisation humanitaire. Dans d'étranges préfaces, leurs auteurs, en bons «professionnels », revendiquent le «sale boulot ». Ils vont bien détailler sans fard les stratégies rhétoriques les plus performantes pour établir des messages de sensibilisation, des mailing de fidélisation, des méthodes de scoring permettant de segmenter les profils de donateurs, etc. Mais, auparavant, il se sentent tenus d'évoquer, à grand renfort de citations d'auteurs de philosophie morale, la nature fondamentalement altruiste de l'être humain, de louer les vertus du don désintéressé. de la gratuité et de la liberté du donateur. VACCARO, 1987 ; GENDRE, 1996. 
un trait dominant de notre culture de la générosité que renforce la diffusion dans l'espace public d'une critique des méthodes de sensibilisation de l'humanitaire. La revendication du don personnel, intime et spontané apparaît dès qu'un décalage temporel sépare le temps de la sensibilisation et celui de la justification du donateur. C'est pourquoi il nous a paru nécessaire d'entreprendre une enquête de réception afin de saisir sur le vif la manière dont les téléspectateurs construisent les articulations entre le dispositif et les raisons de donner, ce que l'analyse de la courbe téléphonique ne permet pas de faire apparaître. Des étudiants ont été invités à réaliser un travail monographique sur la réception du Téléthon par un groupe de téléspectateurs de leur choix. Cette enquête a permis de récolter des données issues de l'observation de 61 groupes dont les conversations devant la télévision ont été intégralement enregistrées (cf. encadré «Portrait des enquêtés »). Au contact du programme, le comportement des téléspectateurs ne ressemble guère à ce qui était présupposé par l'analyse des relations «tendues » entre le programme et la courbe des dons. Les téléspectateurs balancent entre prises et déprises, approbations et critiques; ils négocient leur engagement, décryptent les procédés des programmateurs tout en se laissant emporter, par intermittence, dans le mouvement que parvient à constituer le programme.

Dans toute l'analyse de la réception, deux outils de description de l'activité des téléspectateurs seront utilisés pour décrire ces articulations «souples » entre eux et le programme : la distanciation et l'association. Ils constituent deux «plans» différents sur lesquels les téléspectateurs déploient leurs rapports au programme. Sur le plan de la distanciation, les téléspectateurs se rapprochent ou s'éloignent du programme, soit pour être en prise avec lui (se réjouir, s'émouvoir, montrer de l'intérêt, etc.), soit pour exercer leur capacité d'analyse et de critique. En procédant à des distanciations, ils ouvrent un espace argumentatif qui permet de confronter des jugements et des opinions sur l'émission. Ce faisant, ils séparent la cause et son instrument, et reconnaissent l'émission comme un dispositif instrumental. Sur le plan de l'association, les téléspectateurs expérimentent ou n'expérimentent pas le sentiment d'être solidaires des engagements que propose le Téléthon. En procédant à des associations, ils manifestent, propagent et généralisent le lien qui unit les uns et les autres, téléspectateurs, chercheurs, et malades. Ce faisant, ils ne distinguent pas la cause et son instrument, mais reconnaissent l'émission comme un dispositif moral. 


\section{Portrait des enquêtés}

Le guide d'enquête proposé aux étudiants se décomposait en cinq étapes guidant (1) le choix et la constitution du groupe d'enquête, (2) la réalisation du portrait des enquêtés et la description de l'environnement de réception, (3) l'observation ethnographique de la réception, (4) l'organisation d'un débat collectif après l'émission comprenant une phase de discussion libre puis la passation d'un questionnaire et, enfin, (5) la rédaction d'une synthèse monographique du cas étudié. Au total, 61 groupes de réception (de une à huit personnes) ont été constitués. Ils ont regardé la télévision pendant la soirée du vendredi (25 groupes, soit 90 personnes) ou la journée du samedi (36 groupes, soit 96 personnes). La constitution de ces groupes dépendait en grande partie des ressources relationnelles dont disposaient les étudiants-enquêteurs pour réunir des personnes avec lesquelles ils entretenaient des rapports suffisamment familiers pour qu'elles acceptent de se soumettre à un dispositif d'enquête assez intrusif. Afin d'éviter un effet d'étrangeté difficile à gérer par des enquêteurs novices, nous leur avons demandé de retenir des personnes appartenant à un même réseau de sociabilité, ayant des pratiques d'échanges, de fréquentation et d'invitation mutuelles. Les groupes ont ainsi été constitués soit sur la base de liens familiaux ( $38 \%$ des enquêtés se trouvent dans un groupe constitué par leur famille nucléaire ; $37 \%$ dans un groupe familial élargi aux collatéraux), soit sur la base de liens amicaux $(25 \%)$. Les conditions de constitution des groupes de réception ne permettaient donc pas d'obtenir un échantillon représentatif de la population française, de l'audience du Téléthon ou du groupe des donateurs. Le corpus comprend 6,5\% d'adolescents en âge scolaire, $20,4 \%$ d'étudiants, $6,5 \%$ de femmes au foyer, $2,7 \%$ de chômeurs et $4,3 \%$ de retraités ; les actifs se décomposent ensuite en artisans et commerçants (5\%), ouvriers $(8 \%)$, employés $(20 \%)$, profession intermédiaire $(14 \%)$ et cadres $(12,9 \%)$. La forte surreprésentation de la population étudiante joue sur la structure d'âge de l'échantillon. Si $31 \%$ des enquêtés ont moins de 25 ans, $27 \%$ seulement ont plus de 50 ans ; $42 \%$ ont entre 25 et 50 ans. En conséquence, les fidèles spectateurs ou donateurs du Téléthon (54\% de femmes) sont sous-représentés dans la population formée par les groupes d'enquête. Par ailleurs, $36 \%$ des enquêtés déclarent qu'ils n'auraient pas regardé le Téléthon s'ils n'avaient pas été sollicités pour l'enquête, $29 \%$ ne l'auraient regardé que de temps à autre: $35 \%$, en revanche, affirment qu'ils l'auraient regardé, même en l'absence d'enquête. Influencés ou non par leur participation à l'enquête, $38 \%$ de nos enquêtés appartiennent à un groupe qui a effectué un don lors du Téléthon.

\section{Monter le son devant la TV}

Les enquêteurs avaient pour consigne de placer un magnétophone entre le poste de télévision et les téléspectateurs afin d'enregistrer simultanément le son du programme et celui des discussions du groupe réuni pour l'occasion ${ }^{25}$. Les groupes étaient invités à regarder le programme dans la soirée - moment où la télévision fait le plus l'objet d'une attention soutenue et collective ${ }^{26}$.

25. Pour 14 groupes de réception l'enregistrement s'est fait en vidéo.

26. Les enquêtes récentes sur l'usage de la télévision insistent sur la permanence du caractère collectif et partagé de l'écoute de la télévision dans la pièce centrale du lieu d'habitation, 
Comme le rappelle Stuart Hall, «le fait de regarder la télévision est presque toujours accompagné d'arguments, de commentaires, de débats et de discussion $»^{27}$. Les «conversations télé » ont ainsi pu être retranscrites dans leur totalité et synchronisées avec les séquences du programme. Il a ainsi été possible de tirer profit d'une ressource de la situation télévisuelle rarement exploitée par les travaux de sociologie des médias.

Les enquêteurs devaient maintenir autant que possible le cadre naturel d'une conversation ordinaire devant le poste de télévision. Ils étaient toutefois invités à entretenir la dynamique de la conversation (d'en "monter le son ", comme nous le leur avions expliqué métaphoriquement), en procédant de temps à autre à des relances (préfacées par un «pourquoi ? »), pour inviter les téléspectateurs à clarifier leur attitude, à préciser le sens de leurs propos et à argumenter leurs prises de position ("Pourquoi tu n'aimes pas cette séquence ? », « Pourquoi tu as été ému par Marie-Jo? »). Dans la pratique, ces relances n'ont pas toujours été nécessaires. La conversation des groupes s'est animée d'elle-même sans que l'enquêteur n'ait à intervenir. Les étudiants sont parvenus à établir un climat favorable à l'entretien d'une conversation suffisamment soutenue et à la mise en place de conduites routinières devant la télévision (grignotage, prise de repas, assoupissement, tricotage, pause toilettes, sortie du chien, etc.), et ce, bien que le dispositif d'enquête fût toujours visible aux participants - ne serait-ce que par la prise de notes ostensible de l'enquêteur ou la présence du magnétophone ${ }^{28}$.

Dans quelques rares cas, le dispositif d'enquête a conduit à certaines formes d'autocontrôle au sein des groupes. Des téléspectateurs ont ainsi tempéré le caractère familier de leur propos, se sont refusés à faire de l'humour noir jugé déplacé - ou à s'amuser ostensiblement du contenu de certaines séquences ( Tu enlèveras ça de la bande. On va passer pour des monstres au cour froid! "; "Cela va être affreux tes commentaires, il faut que je me

même si une importante dynamique d'individualisation des pratiques se développe dans les pièces fonctionnelles et périphériques ; JOUËT, PASQUIER, 1999.

27. Préface à l'ouvrage de D. MORLEY, 1986, p. 9. Dans la sociologie de la réception, la «conversation télé » a surtout été abordée comme un moyen d'introduire des sujets télévisuels dans les échanges interpersonnels ; LULL, 1990.

28. Sur les 25 groupes du vendredi soir qui ont fait l'objet d'un découpage thématique spécifique (cf. infra) le dispositif d'enquête intervient dans la conversation à 80 occurrences (sur 3715 thèmes) : 39 fois comme simple mention et 31 fois comme un thème de discussion plus long obligeant l'enquêteur à s'expliquer. Dans la majorité des cas, les personnes évoquent surtout l'enquête pour savoir quand ils pourront arrêter de regarder l'émission. Pour 6 des 25 groupes, le dispositif n'apparaît jamais dans la conversation. 
calme»). Le membre d'un groupe de réception, impatient de pouvoir sortir en boîte de nuit et qui manifestait ouvertement son hostilité à la poursuite de l'enquête, jugée trop longue à son goût, a ainsi pris le parti de saper le travail de l'enquêteur, en perturbant l'attention des autres personnes présentes par des remarques incessantes. Les relations entre la famille d'une enquêtrice et ses voisins de palier, qui étaient jusque là très courtoises, se sont envenimées au cours de leur commune observation du Téléthon, l'un des voisins n'ayant pas hésité à afficher ouvertement des convictions eugénistes. Une autre étudiante a assisté, impuissante, à une scène de jalousie entre son amie et son compagnon qui revenait de vacances en Italie et a vainement tenté, tout au long de l'observation, de rappeler aux participants leurs "obligations» de téléspectateurs. Une enquêtée, qui s'était présentée à l'enquêtrice comme une donatrice fidèle, dut reconnaître, très gênée, devant son mari et ses enfants, qu'il n'en était finalement rien. Ce sont donc moins les effets exercés par la mise en place du dispositif d'enquête (prise de notes, enregistrement) qui ont le plus embarrassé les étudiants que le «parasitage» de la situation d'observation par des événements étrangers au Téléthon. L'importance prise par ces événements inopinés fait ainsi apparaître l'entrecroisement incessant des relations interpersonnelles et de l'attention portée au programme télévisé.

Ce protocole d'observation ne vise en aucun cas à reconstituer une situation naturelle. Il ne s'agit pas ici de contester l'effet propre des contraintes exercées par le dispositif d'enquête sur les productions énonciatives, mais, au contraire, d'en tirer profit pour l'étude de la réception. Le fait que les téléspectateurs sachent que leurs propos, énoncés ici et maintenant, sont susceptibles d'être transportés ailleurs, d'être entendus par d'autres ( ton prof', il va se marrer en écoutant les bandes ») et qu'ils serviront à une étude sur le Téléthon ("il faut pas dire d'âneries pour les chercheurs du $C N E T »)$, contribue à rehausser, partiellement et de façon intermittente, les contraintes de publicité pesant sur la réception télévisuelle. Les participants sont alors conduits à adopter un comportement ou à produire des jugements recevables publiquement - c'est-à-dire honorant des conditions de normalité et d'intelligibilité propres à un espace public. La présence du dispositif d'enquête dans la situation de réception a donc contribué à donner une amplitude plus grande au spectre des conversations possibles devant la télévision en favorisant l'alternance de moments de familiarité, d'ironie, d'emprise émotionnelle, de critique ou de controverse. 


\section{La place du contexte}

L'écoute des bandes sonores des groupes de réception frappe par les très grandes variations qui affectent l'atmosphère des groupes d'enquêtés, leurs comportements et leurs propos tout au long de la durée d'observation. Ils étaient sérieux, les voilà qui s'amusent. Ils se passionnaient pour le programme, ils discutent maintenant d'un événement personnel sans se préoccuper de la télévision. Ils avaient entrepris un débat argumenté sur la place de la maladie dans la société et voilà qu'ils sifflotent une chanson, s'occupent de sortir le chien ou se moquent d'un malade qu'ils viennent de voir à l'écran. Ils ont été émus par le regard d'un malade, ils dénoncent à présent les propos que l'animateur lui fait tenir. L'analyse des conversations tenues par les téléspectateurs conduit l'enquêteur à se perdre dans un dédale de propos hétéroclites, charriant, sans ordre apparent, des éléments issus tantôt du programme, tantôt de la vie personnelle des téléspectateurs, tantôt du contexte immédiat de la réception. C'est le cas, par exemple, de la discussion de ces étudiants, qui rebondissent sans cesse d'un élément de leur environnement immédiat (le visage de l'un d'entre eux, la plaque de chocolat...) à un élément extrait du programme (le visage d'une animatrice, les images d'un challenge...), pour soudain s'abstraire du contexte de la réception et se focaliser sur un aspect particulier de la séquence en cours (la présence de malades à l'écran), sans toutefois se départir du ton ironique qui est le leur depuis le début.

G. Holtz est à l'écran.

Corinne : Mais, enlève ta salade! [elle croit avoir aperçu un bout de salade coincé dans les dents de Gérard Holtz]

Karine : Et ta perruque!

Laure : L'autre fois, on m'a dit que je lui ressemblais.

Corinne : A Gérard Holtz?

Laure : Ouais. C'est un mec qui m'a dit ça. S'il essayait de me draguer, c'était raté!

Corinne : Et ben ça.

Karine : On t'as déjà dit que tu ressemblais à Maureen Door?

Corinne: A toutes les sauces, on lui a dit.

Laure: Quand je travaillais en colonie l'année dernière.

Début de la séquence football au Téléthon.

Mylène : Qu'est-ce que ça vient faire le foot là-dedans?

Karine et Corinne: Parce qu'il y a un challenge.

Laure : Je peux prendre un bout de chocolat?

Corinne : Je savais qu'on le finirait dans la soirée (rire de Laure) 
Karine : Spécial Téléthon!

Corinne : Le chocolat spécial Téléthon! Nous aussi, on fait un challenge.

Bouffer une plaquette de chocolat à deux ! [...]

Laure : C'est du tout et du n'importe quoi, cette émission.

Corinne : On prend un grand sac et on mélange.

22 h 57 Parc des Princes

Laure : Il y a toujours des myopathes au premier plan.

Karine : Eh bien oui, tu ne vas pas les foutre derrière! (rires)

Laure : Ils en ont rien à foutre, là.

Karine : Attends, c'est quand même pour eux que l'on fait ça!

Laure : Mais ce n'est pas eux qui courent!

Karine: Ils sont venus assister. Tu imagines, si chaque myopathe rentrait chez lui et dormait... alors que tout le monde se mobilise pour eux!

Laure : Non, mais là, ça fait vraiment deux potiches devant.

Corinne : C'est la nana à poils qui vend sa voiture. (Karine baille).

Karine : C'est souvent parce qu'ils ont des myopathes dans leur commune, leur ville...

Laure : Ça y est, Pivot s'est fait opérer de la cataracte!

Corinne : Ah ! C'est Pivot (sifflement de Corinne). Je ne l'avais pas reconnu. Ah, ils vont faire du foot fauteuil, quand même.

La lecture des comptes rendus des enquêteurs révèle l'irruption continuelle d'événements sans lien avec le programme télévisé dans le cours de la réception. Loin d'être contingents ou réductibles à des «bruits » parasites, ces événements révèlent au contraire que l'attention au programme ne peut être autonomisée de la trame ordinaire des activités domestiques. Elle en est l'une des modalités et se détache, avec plus ou moins d'intensité, de son fond contextuel. Un codage précis des thématiques conversationnelles et des activités de 25 des groupes du vendredi soir a été entrepris (cf. encadré « Le codage des conversations de la réception »). $5 \%$ du corpus conversationnel est consacré à des activités «contextuelles », n'ayant pas de lien direct avec le programme ${ }^{29} ; 4 \%$ des thèmes de conversations n'ont pas de relation directe avec le Téléthon - même si par des détournements allusifs ou métaphoriques, les téléspectateurs peuvent créer un lien avec le programme.

29. La liste de ces différentes activités fait apparaître la place centrale de la nourriture (manger, boire, servir, se passer des aliments, aller chercher les plats, commenter le repas, remercier ; $25 \%$ ), des animaux domestiques (les sortir, les caresser, jouer avec eux, leur parler, leur expliquer le Téléthon, raconter leurs derniers exploits ; $12 \%$ ), des déplacements hors de la pièce (téléphoner, aller travailler, aller aux toilettes, sortir en boîte, aller fumer dans une autre pièce ; $25 \%$ ) ; et des activités qui autorisent une attention oblique au programme (feuilleter une revue, réparer l'appareil auditif, tricoter, changer de place, s'assoupir, etc. ; $38 \%)$. 
On évoque le travail, les amis, la ceinture que l'on vient d'acheter, le nouveau logiciel utilisé au bureau, l'entraînement de danse, les vacances en Sicile et toutes autres sortes de sujets. Si l'on ajoute encore les mentions relatives à la fatigue et au sommeil, qui interviennent fréquemment dans les groupes qui ont veillé plus qu'à l'accoutumée pour participer à l'enquête, près de $10 \%$ des thèmes conversationnels échappent plus au moins au Téléthon. Bien que de statuts différents, ces multiples éléments constituent autant d'occasions de distribuer l'attention vers d'autres foyers de pertinence. Le poste de télévision n'est alors présent qu'en pointillé dans la scène, les acteurs ne s'y réfèrent que de temps à autre, pour contrôler à distance ce qui s'y déroule et prélever à l'occasion un élément qui permettra de nourrir la conversation.

En dépit du caractère plastique et imprévisible des activités des téléspectateurs, peut-on proposer une grille de lecture des centaines de pages de transcriptions de conversations tenues devant la télévision? Ou faut-il se résoudre à ne voir dans ces bavardages qu'un brouhaha insaisissable ? On formera l'hypothèse que ces conversations possèdent des propriétés organisationnelles communes et qu'il est possible de mettre à jour certaines des spécificités de l'attention des téléspectateurs au programme.

\section{La synchronisation des prélèvements}

Pour parvenir à circonscrire la prolifération des conversations de réception, il est utile de revenir dans un premier temps au programme afin d'opérer des coupes temporelles à l'intérieur des conversations. Celui-ci constitue, en effet, un élément structurant de l'organisation des arènes de réception. Prenons un exemple simple, extrait de la réception de la chanson de Francis Cabrel à laquelle ont assisté 22 groupes le vendredi soir. Pendant la chanson, le réalisateur glisse un plan de quelques secondes sur le batteur du chanteur. Cette image suscite une interpellation immédiate et simultanée dans 8 des 22 groupes : "Il est jeune le batteur, ils auraient dî̀ mettre un myopathe à la batterie! » $\left(n^{\circ} 6\right)$; "Oh, il est jeune à la batterie, dis-moi » $\left(n^{\circ} 8\right)$; «II a l'air vachement jeune le batteur... peut-être aussi à cause de son look casquette» $\left(n^{\circ} 26\right) ;$ "Oh, il est jeune hein, le garçon à la batterie! » $\left(n^{\circ} 20\right)$. Comme l'atteste ce petit exemple, les conversations des différents groupes enquêtés se synchronisent fréquemment en opérant simultanément des prélèvements remarquablement précis et identifiables dans le programme. Ophélie Winter, une chanteuse, arrive sur le plateau : 
"Oh! Elle s'est coupé les cheveux! "; une animatrice d'émission de jeux présente la musique militaire dans les jardins du Château de Versailles: "Non, mais t'as vu sa casquette!"; un énorme aimant de plusieurs tonnes arrive à l'Institut de Myologie dans un reportage: "C'est incroyable ce truc! »; etc. La lecture en parallèle des transcriptions de conversation fait invariablement apparaître des motifs identiques, des images communes, des points d'appui qui viennent se placer, avec une synchronie quasi parfaite au même moment du programme.

Parmi le flux d'images, de paroles, de gestes et de situations présenté pendant le Téléthon, certains événements imposent des cours d'action spécifiques aux groupes de réception. Ceux-ci se caractérisent d'abord par des ruptures dans l'organisation corporelle de la situation : les personnes se redressent; les activités connexes sont provisoirement suspendues; les regards se fixent simultanément sur l'écran ${ }^{30}$. Ces moments se caractérisent aussi fréquemment par une thématisation du prélèvement qui vient d'être opéré. Une simple remarque ou une longue conversation prend alors forme à partir d'un mot, d'un geste ou d'une attitude du programme ${ }^{31}$. L'organisation du programme produit des discontinuités dans le flux télévisuel (des ruptures, des surprises, des tensions) : le Téléthon, en sautant régulièrement d'une province de sens à l'autre, des duplex aux malades, des chanteurs aux chercheurs, des animateurs à la Force $T$, interrompt, à intervalles rapprochés, le régime ordinaire de typification propre à chaque genre de séquence, et contribue ainsi à reformater les horizons d'attente des téléspectateurs, à les «reprogrammer ». Ainsi, en dépit de l'extrême diversité des contextes, l'organisation de la situation de réception ne cesse d'être configurée par les différentes ressources que le programme, avec des gradations d'intensité différentes, offre aux téléspectateurs.

30. Cf. CALBO, 1998.

31. De façon assez inattendue, il nous est rapidement apparu qu'il était assez aisé de découper les conversations en unités thématiques - cf. le codage des conversations, infra - en prenant comme ouverture le moment d'identification par les téléspectateurs d'un événement télévisuel et comme clôture soit l'épuisement du thème conduisant le groupe au silence, soit la mise en évidence d'un nouvel événement qui vient interrompre ou clore le développement thématique organisé à partir du prélèvement précédent. 


\section{LA DISTANCE AU DISPOSITIF}

Cependant le prélèvement opéré par le téléspectateur sur le programme peut être utilisé très différemment dans la situation. La manière dont il est prélevé, découpé parmi les autres éléments du programme (un vêtement sur un corps, la danse des animateurs, un extrait de discours, le sourire d'un malade ou la manière de le cadrer, etc.), transporté dans la conversation, exploité de façon coopérative par les participants, etc., caractérise la constitution pratique de la situation de réception en arène, dotée d'une forme particulière et de traits typiques. Si le programme impose à l'ensemble des téléspectateurs une structure de pertinence particulière, qui cadre avec plus ou moins de force les possibilités de saisies, il ne dispose guère de moyens de contrôler la diversité des configurations des arènes de réception. Celles-ci, comme l'ont montré de très nombreux travaux d'ethnographie de la réception, se caractérisent notamment par des variations de la distance au programme. Les téléspectateurs ont en effet développé des compétences leur permettant de remonter de l'instruction télévisuelle vers l'intention qui la guide en transportant les messages télévisuels dans un espace d'analyse permettant le décodage, la déconstruction ou le repérage des effets du message sur les «autres» téléspectateurs ${ }^{32}$.

Un exemple tiré d'une séquence permet d'illustrer le mouvement par lequel les téléspectateurs en viennent à se distancier du programme, en prélevant en son sein un élément qu'ils jugent particulièrement critiquable. Il est 23 h 04, vendredi. Le «train de l'espoir » entre en gare de Carcassonne. L'animatrice tente vainement de faire dire à l'enfant atteint de myopathie qui l'accompagne (cf. photo $\mathrm{n}^{\circ} 6$ ) à quoi sert le Téléthon puis, à force de pressions, parvient à obtenir de lui l'aveu d'un secret espoir : qu'il puisse un jour... courir : "Donc vous savez ce qu'il vous reste à faire si vous voulez aider Alexandre à courir et à grimper bientôt dans les arbres... » conclutelle. Sur les 10 groupes qui ont assisté à cette séquence, trois ne relèvent pas

32. Ces opérations cognitives ont donné jour à de multiples oppositions conceptuelles dans les travaux de sociologie des médias : entre lecteur «naïf » et « malin » (ECO, 1985), lecture « référentielle » et «critique » (LIEBES, KATZ, 1990), " hégémonique », " négociée » ou « oppositionnelle » (HALL, 1994). T. LIEBES (1994) invite à distinguer deux axes différents des travaux sur les capacités de décodage des téléspectateurs. Le premier est esthétique : s'opposent référentialité et déconstruction, sémantique naïve et syntactiques évoluées. Le second est politique et correspond à l'acceptation ou au rejet des valeurs imprimées dans l'instruction télévisuelle. 
de fautes de l'animatrice. L'un remarque qu'il n'est pas bon de faire veiller trop tard les enfants, un autre regrette que l'animatrice n'ait pas précisé l'âge du petit Alexandre et le troisième, qui débattait de la construction de l'Institut de Myologie, se saisit des propos de l'animatrice et de la présence courageuse d'Alexandre comme d'un argument pour encourager l'œuvre entreprise. En revanche, les sept autres groupes se fixent, violemment, sur la technique d'interrogation de l'animatrice. Au même moment, comme si toutes ces exclamations synchrones pouvaient lui parvenir aux oreilles, les interviewés accusent : "Oh! C'est pathétique ça. C'est horrible comme question!"; "Ça c'est nul, je trouve ça nul!»; "C'est odieux, tu hallucines »; "T'as vu comment elle le traite? [...] Qu'est-ce que tu veux qu'il réponde? [...] Elle lui parle comme à un débile! ». Dans cinq de ces groupes, ce moment de saisie du programme va ouvrir au sein de l'arène de réception un espace conversationnel permettant aux participants de discuter du Téléthon, de l'instrumentation des malades par le programme et du rôle des animateurs de télévision. Dans deux cas, la conversation va se déployer en mobilisant de nombreux répertoires argumentatifs extérieurs au programme afin de mettre en question la manière dont la télévision choisit telle ou telle maladie pour en faire un programme de solidarité et interroger le rôle de l'Etat dans le financement de la recherche médicale.

\section{Le codage des conversations de la réception}

Un codage systématique des conversations devant le Téléthon a été mené à bien en procédant au dénombrement et à la catégorisation de certains types de situation et d'énoncé. Une telle entreprise comporte de nombreux risques. Les catégories du codage sont discutables et sa mise en œuvre pratique ne peut se défendre contre l'accusation d'arbitraire qu'en revendiquant la cohérence interne de ces procédures. Deux types de catégories (le découpage des thèmes conversationnels et les niveaux de distanciation) ainsi que les tableaux de résultats qui sont à l'origine de la typologie des formes conversationnelles sont ici présentés.

\section{Le découpage des thèmes conversationnels}

L'ensemble des séquences conversationnelles a été découpé et catégorisé en fonction du thème conversationnel initié. Certaines unités correspondent à une simple exclamation ("Oh! Barbara Hendricks! "); d'autres à des séquences de quelques minutes lorsque les personnes entreprennent de discuter de la sincérité des participants au Téléthon à la suite d'une simple remarque faite devant l'écran par un participant : "Le comble, f̧a serait d'apprendre que Thierry Lhermitte est payé pour faire ça!". Les thèmes conversationnels ont ainsi été distingués selon qu'ils étaient initiés par un événement du programme (les prélèvements) ou par un événement propre au monde du locuteur (les appuis). Cette dernière catégorie réunit : 
- les appuis contextuels qui ont pour thème le seul contexte de sociabilité de la réception (discussion sur la nourriture, la position des personnes devant la télévision, les animaux domestiques, etc.) ;

- les appuis hors Téléthon qui ont pour thème un événement sans rapport avec le Téléthon (amis, famille, travail, etc.);

- les appuis argumentatifs qui ont pour thème le Téléthon, mais sans être initiés ou faire directement référence à ce qui se passe sur l'écran. Il s'agit, le plus souvent de discussions générales, à forte teneur argumentative, sur la myopathie, le scandale de l'ARC, le sidaction et le Téléthon, le rôle de l'Etat dans le financement de la recherche, etc.

Deux types particuliers de thèmes conversationnels issus de prélèvements télévisuels ont été isolés :

- les raccords rassemblent les thèmes conversationnels qui mettent en équivalence un moment, une personne ou une action du Téléthon avec un autre moment, personne ou action du monde télévisuel en général ou du Téléthon en particulier ;

- les rapprochements réunissent toutes les séquences conversationnelles pendant les lesquelles le locuteur produit une association explicite entre ce qui est vu à la télévision et son monde à portée de main (il peut par exemple faire le rapprochement entre une image d'animation Force $\mathrm{T}$ et ce qui se déroule dans sa commune ou bien entre un malade vu à la télévision et une personne souffrante qu'il connaît ou qui lui est proche).

Les autres thèmes conversationnels extraits du flux télévisuel sont simplement appelés des prélèvements et font l'objet d'un second codage.

\section{Les niveaux de distanciation}

A l'instar du codage entrepris par T. Liebes et E. Katz, nous avons procédé à un classement des formes énonciatives échelonnées en cinq niveaux de distanciation distincts, chacun - sauf le premier - étant lui-même partagé entre des évaluations positives ou négatives. Ces niveaux de distanciation marquent à la fois des positionnements sensiblement différents du ou des locuteurs à l'égard du programme et la mobilisation de ressources argumentatives plus ou moins denses dans la séquence conversationnelle considérée.

Le premier niveau - perceptif - rassemble toutes les formes énonciatives qui extraient du programme un élément pour en faire une courte mention: il s'agit principalement d'exclamations ("Oh, mais c'est Francis Cabrel!"), de questions ("Il était à combien le compteur là ?») ou de courtes remarques ( $A h$, c'est Morteau, j'y suis passé l'année dernière ») n'appelant pas le développement du thème conversationnel.

Le deuxième niveau - appréciatif court - rassemble des énoncés brefs, immédiats, non justifiés, qui marquent l'approbation (approbation) ou la désapprobation (sarcasme) devant l'élément du programme prélevé. Ont été retenues, d'une part, toutes les formes brèves ("j'aime bien... ", «il me fait rire... », "c'est quand même incroyable ces trucs $q u$ 'ils font... ", etc.), et, d'autre part, tous les petits commentaires ironiques ou les marques de satisfaction.

Le troisième niveau - appréciatif long - rassemble des séquences conversationnelles portant une évaluation positive (soutien) ou négative (critique) de l'élément prélevé sur le programme en arrêtant le jugement sur une qualification ou une catégorie stable qui pourrait aisément être transportée dans un débat plus public (ce qui n'est pas forcément le cas des approbations et des sarcasmes).

Le quatrième niveau - justificatif - prolonge le niveau précédent mais s'en distingue par la taille, l'importance et la densité des justifications apportées pour soutenir une argumentation 
favorable (justification) ou défavorable (dénonciation) à la thèse soutenue depuis le prélèvement. Certains thèmes conversationnels prennent alors parfois la forme d'une polémique entre plusieurs locuteurs développant des argumentations opposées (dans ce cas nous avons effectué le codage sur la position du locuteur qui a initié la conversation).

Enfin, le cinquième niveau - réflexif -, répertorie les jugements en forme de troisième personne. Le (ou les) locuteur(s) incorpore(nt) dans leur jugement l'effet du Téléthon sur les autres. Ces jugements se présentent moins comme des appréciations personnelles que comme des avis sur l'effet que le Téléthon exerce sur les autres ( $3^{e}$ personne en "eux») ou sur eux-mêmes, compris dans un «nous " collectif ( $3^{e}$ personne en "nous ») comme, par exemple, lorsqu'il est dit : "ils font ça pour nous faire donner... ».

\section{Quatre types de conversation : engagée, pragmatique, critique, ironique}

Dans cette perspective, un codage des conversations des groupes du vendredi soir a été entrepris (cf. encadré « Le codage des conversations de la réception »). Une analyse de classification hiérarchique effectuée à partir de ces variables permet de distinguer quatre groupes de conversation ${ }^{33}$. Ils présentent des différences sensibles dans la composition des thèmes conversationnels (appui contextuel, prélèvement, rapprochement, etc.) et dans la distribution des énoncés de distanciation. Ainsi, la classification fait d'abord apparaître deux ensembles opposés de quatre groupes d'enquête, les engagés et les pragmatiques, qui constituent les figures polaires de la conversation devant le Téléthon. Entre ces deux pôles se situent les deux classes de conversations les plus importantes : les pragmatiques (8 groupes) et les ironiques (10 groupes). Comme l'indique le tableau 6 , les conversations ironiques se caractérisent par l'importance des prélèvements effectués et la part non négligeable de raccords, rapportant dans la situation de réception d'autres éléments du monde télévisuel; les critiques par le nombre plus important d'appuis argumentatifs; les engagés par la part importante des rapprochements ; enfin, les pragmatiques par la double mise en avant de rattachements et d'appuis argumentatifs. Ces polarités entre les différents groupes de conversations apparaissent encore mieux quand on examine le degré de distanciation des thèmes conversationnels.

33. Ces différents thèmes conversationnels présentent des longueurs très différentes. Par exemple, les séquences conversationnelles dénonciation ou justification sont beaucoup plus longues (certaines font plus d'une page) que les mentions qui sont de brèves exclamations ou des remarques. Aussi avons-nous pondéré les séquences en affectant chaque niveau d'un coefficient 1 (mention), 2 (approbation, sarcasme), 4 (soutien, critique), 6 (justification, dénonciation) et 8 ( $3^{\mathrm{e}}$ personne en «nous » et en « eux ») afin de mieux faire apparaître les différences au sein de la distribution des catégories. 
Tableau 6. Les quatre formes de conversation devant le Téléthon

\begin{tabular}{|l|c|c|c|c|c|}
\hline $\begin{array}{l}\text { Forme des } \\
\text { conversations (\%) }\end{array}$ & Engagé & Pragmatique & Ironique & Critique & Total \\
\hline Prélèvement & 74 & 71 & 80 & 76 & $\mathbf{7 2}$ \\
\hline Rapprochement & 18 & 13 & 9 & 4 & $\mathbf{1 3}$ \\
\hline Appuis argumentatifs & 8 & 16 & 11 & 20 & $\mathbf{1 5}$ \\
\hline Total & $\mathbf{1 0 0}$ & $\mathbf{1 0 0}$ & $\mathbf{1 0 0}$ & $\mathbf{1 0 0}$ & $\mathbf{1 0 0}$ \\
\hline
\end{tabular}

\begin{tabular}{|l|c|c|c|c|c|}
\hline $\begin{array}{l}\text { Niveau de } \\
\text { distanciation (\%) }\end{array}$ & Engagé & Pragmatique & Ironique & Critique & Total \\
\hline Mention & 21 & 11 & 8 & 3 & $\mathbf{1 0}$ \\
\hline Approbation & 38 & 23 & 19 & 13 & $\mathbf{2 2}$ \\
\hline Sarcasme & 8 & 14 & 30 & 15 & $\mathbf{2 0}$ \\
\hline Soutien & 14 & 16 & 8 & 5 & $\mathbf{1 1}$ \\
\hline Critique & 9 & 14 & 18 & 22 & $\mathbf{1 6}$ \\
\hline Justification & 10 & 9 & 4 & 6 & $\mathbf{7}$ \\
\hline Dénonciation & 0 & 4 & 4 & 16 & $\mathbf{5}$ \\
\hline $3^{\text {e }}$ pers. en nous & 0 & 5 & 2 & 2 & $\mathbf{3}$ \\
\hline $3^{\text {e pers. en } \text { eux }}$ & 0 & 4 & 7 & 18 & $\mathbf{6}$ \\
\hline Total & $\mathbf{1 0 0 ( 6 6 2 )}$ & $\mathbf{1 0 0 ( 1 3 9 1 )}$ & $\mathbf{1 0 0}(\mathbf{2 0 4 8})$ & $\mathbf{1 0 0}$ & $\mathbf{1 0 0}$ \\
& & & & $(\mathbf{5 7 7})$ & $\mathbf{( 4 6 7 8 )}$ \\
\hline
\end{tabular}

Les conversations engagées présentent la particularité d'associer une forte capacité de rapprochement à une très faible distanciation. Elles ne dénoncent ni ne justifient et si certains éléments du programme retiennent la critique, c'est principalement à travers l'expression de soutiens que les participants affirment leur position vis-à-vis du programme. Par ailleurs, ces conversations sont celles dans lesquelles la place des éléments contextuels et de discussions hors thèmes est la plus importante ( $16 \%$ contre $6 \%$ pour tous les autres groupes). Les conversations pragmatiques, à l'inverse, pratiquent à la fois le rapprochement et la distanciation. Non seulement, ils partagent à part égale soutiens et critiques, ont recours aux sarcasmes mais ces groupes sont le théâtre de controverses à forte densité argumentative confrontant des dénonciations et des justifications du Téléthon. Les conversations ironiques ne montrent pas une aussi grande distanciation argumentative. Certes, elles opèrent un nombre non négligeable de rapprochements et d'appuis argumentatifs, qui les rendent comparables aux conversations pragmatiques. En revanche, elles montrent un niveau de distanciation moindre lorsque l'on considère ensemble les jugements favorables et défavorables au Téléthon. De fait, leur trait dominant est le sarcasme et l'approbation. Les conversations critiques, à l'inverse, distancient clairement en optant nettement pour la critique et la dénonciation au détriment des sarcasmes. Ces conversations ne procédant pas à des rapprochements, la place laissée au déploiement d'appuis argumentatifs est la plus importante. Elles se caractérisent enfin par la place essentielle jouée par les jugements en troisième personne. 


\section{Du groupe aux individus}

Comment les conversations de réception se connectent-elles aux propriétés individuelles des téléspectateurs? A la fin de la discussion collective qui faisait suite à la réception de l'émission, l'enquêteur posait des questions ouvertes à chaque enquêté. Leurs réponses permettent de distinguer de façon synthétique quatre postures à l'égard de l'émission pour 186 enquêtés : les fidèles (28\%), les favorables $(38,2 \%)$, les hostiles $(17,2 \%)$ et les indifférents $(16,7 \%)^{34}$. En construisant ces catégories, nous nous sommes efforcés d'établir des similitudes avec les qualifications des conversations (engagée, pragmatique, critique, ironique). Cependant, le lien entre ces deux systèmes de qualification n'a rien d'automatique ni d'homogène. Recueillir des opinions individuelles permet de s'affranchir de la logique de groupe (certaines opinions peuvent avoir été «écrasées» pendant la conversation) et de différencier deux moments différents, celui de la conversation devant le programme et celui de l'interview collective, qui réclame une réflexivité plus forte et appelle un jugement arrêté. Aussi est-il utile de confronter ces deux manières de coder la réception du Téléthon afin de délimiter la pertinence d'une description de la réception axée sur la seule capacité de distanciation des téléspectateurs.

Ces quatre postures à l'égard du Téléthon clivent des univers sociaux cohérents qui reproduisent les résultats traditionnels des enquêtes sur la générosité et le don ${ }^{35}$. Le groupe des fidèles se caractérise par la place importante des femmes (67\%), l'âge élevé ( $27 \%$ ont en 35 et 49 ans; $50 \%$ ont plus de 50 ans), l'importance des classes populaires (48\%) et des fractions basses de la classe moyenne (33\%). C'est aussi le groupe qui a la consommation la plus forte de la télévision, les enfants les plus âgés et qui est concerné à titre personnel $(22 \%)$ ou par proximité $(24 \%)$ par les questions de

34. Les enquêteurs demandaient aux groupes de réception d'apprécier le Téléthon dans son ensemble («Est-ce que vous êtes favorable à ce type d'émission? ») et de porter un jugement sur ses différents aspects (la place des malades, le rôle des variétés, les techniques de sollicitation, etc.). Les fidèles sont ceux qui notent favorablement le Téléthon dans toutes ces dimensions. Les favorables sont les individus qui évaluent positivement le Téléthon mais qui, en revanche, affectent de notes négatives certaines de ses composantes (trop de vedettes, pas assez de reportages, trop de sollicitations, etc.). Les hostiles sont ceux qui évaluent négativement le Téléthon dans son principe même (ils peuvent, par ailleurs, évaluer positivement certains aspects de l'émission). En revanche, les indifférents n'apprécient pas le Téléthon mais sans invoquer directement les principes de l'émission : ils ne se sentent pas concernés et avouent leur peu d'intérêt pour ce genre de programme.

35. ARCHAMBAULT, BOUMENDIL, 1997 ; PROUTEAU, 1998. 
santé. Enfin, en terme d'attitudes, les fidèles du Téléthon se positionnent à droite $(61 \%)$ et sont croyants pratiquants $(47 \%)$ - ces derniers résultats doivent cependant être tempérés par le taux important de non-réponse qui contribue à accentuer l'opposition entre donateurs croyants de droite et réfractaires athées de gauche. Le groupe des indifférents possède des caractéristiques exactement inverses, si ce n'est qu'il est lui aussi fortement populaire et que sa consommation télévisuelle est aussi importante. Il est très majoritairement composé de jeunes ( $51 \%$ ont de 18 à 24 ans) qui se déclarent non croyants $(43 \%)$ ou non pratiquants $(21 \%)$ et se positionnent très fortement à gauche $(73 \%)$. Ce groupe ne donne jamais au Téléthon, ni à d'autres causes. Il n'est pas concerné, de près ou de loin, par la maladie. Cependant, ce contraste fort entre deux groupes types ne se retrouve pas avec la même clarté dans l'opposition des favorables et des hostiles. Certes, ces derniers sont plus nombreux dans la classe des $18-24$ ans (40\% contre $23 \%$ ) et les favorables dans celle des 25-34 ans (27\% contre $17 \%$ ). Les favorables qui défendent le Téléthon, tout en critiquant certains aspects du programme, appartiennent plutôt aux fractions de la classe moyenne les plus proches du monde économique (cadres supérieurs du secteur privé, commerçants), les seconds plutôt aux fractions proches des activités publiques et des professions intermédiaires (enseignants, cadres moyens du secteur public). Enfin, les hostiles sont plus fréquemment masculins $(56 \%)$ que les favorables $(51 \%)$. Mais, comme en témoigne le niveau de diplôme à peu près similaire entre les deux classes, ou leur consommation moyenne de la télévision, ces deux groupes sont assez proches l'un de l'autre. Ils s'opposent en revanche sur les variables politiques et religieuses. Les hostiles se positionnent plus nettement à gauche et les favorables à droite, les hostiles sont majoritairement athées $(58 \%)$ et les favorables croyants $(75 \%)$.

Faut-il alors conclure que les variations conversationnelles observées lors de la réception ne font que traduire des oppositions qui pouvaient être lues plus aisément à travers les coordonnées sociales des personnes? Répondre à cette question demande d'abord d'établir un lien entre les conversations (engagées, pragmatiques, critiques, ironiques) et les positions individuelles (fidèles, favorables, hostiles, indifférents).

L'analyse détaillée menée sur la soirée du vendredi soir montre que cette relation n'est pas entièrement automatique et immédiate. Un écart significatif apparaît entre la manière dont les personnes regardent le Téléthon et la manière dont elles prennent position à son sujet. Ainsi, celles qui se sont révélées engagées dans l'écoute du programme vont se montrer 
beaucoup plus distanciées (parfois critiques) lors de l'interview; elles nuancent leur attachement au Téléthon par des réserves sur le dispositif (60\% sont favorables, $40 \%$ fidèles). Les individus des conversations ironiques se repositionnent complètement lors de l'interview; leurs opinions se distribuent sur l'ensemble du spectre de postures possibles à l'égard de l'émission (4\% sont fidèles, $42 \%$ favorables, $27 \%$ hostiles et $27 \%$ indifférents). En revanche, pour les groupes pragmatiques et critiques qui avaient déjà instauré un espace argumentatif pour effectuer une analyse distanciée de l'émission pendant l'écoute du programme, la correspondance entre la qualification du groupe et le positionnement des personnes est plus forte. Les individus des conversations pragmatiques se déclarent effectivement favorables à l'émission lors de l'interview (75\% sont favorables, $20 \%$ fidèles et $5 \%$ indifférents) et ceux des conversations critiques sont hostiles ( $75 \%$ ) ou favorables ( $25 \%)$.

L'identité sociale des individus apparaît donc comme une variable fortement prédictive de la capacité de distanciation des personnes. Un diplôme et un statut professionnel élevé favorisent l'expression d'une distance argumentée à l'égard du programme. Ces capacités réflexives apparaissent aussi plus fortes pour les hommes (sauf chez les jeunes où la différence sexuelle n'intervient pas), les étudiants et ceux qui regardent peu la télévision. A l'inverse les femmes âgées, peu diplômées et d'origine populaire constituent le seul public de notre enquête qui ne formule jamais de remarques critiques sur le Téléthon. Cette distribution sociale ne parvient cependant pas vraiment à expliquer (dans les limites des coordonnées sociographiques que nous avons pu recueillir) comment les groupes critiques et pragmatiques se différencient, puisque tous les deux font montre d'un fort taux de distanciation sans partager la même opinion sur le Téléthon.

\section{SEQUENCES TELEVISUELLES ET REGIMES D'ENGAGEMENT DANS LE TELETHON}

Si la totalisation sociographique individuelle échoue, en un sens, à proposer le principe de l'adhésion au Téléthon, si elle ne permet pas d'éclairer de façon plus précise l'ambivalence des conversations pragmatiques, sans doute faut-il lui substituer une approche plus combinatoire $^{36}$ des engagements dans l'émission, qui, en conservant la référence aux groupes

36. BASZANGER, DODIER, 1997. 
engagés, critiques, pragmatiques et ironiques, cherchera à restituer à leur expérience télévisuelle la dynamique séquentielle de leurs engagements dans le Téléthon. En effet, les arènes de réception dans lesquelles le programme est discuté et soumis à l'analyse sont d'une constitution instable et plastique. Les participants peuvent soudain faire émerger des principes intangibles, des indignations profondes et des arguments éprouvés, puis se replier dans le sarcasme et la plaisanterie avant de se laisser capturer par une image, un geste ou un mot. Cette expérience plurielle du programme s'organise certes autour de dispositions modales qui définissent et structurent un rapport socialement construit au programme. Cependant ce mode de représentation écrase sur un seul plan, celui des dispositions préalables et acquises, la diversité interne des expériences du programme qui s'est exprimée dans l'ensemble des groupes. Aussi étudiera-t-on ici non pas l'appréciation globale que les participants ont exprimé sur le Téléthon, mais le trajet de leur réception. On cherchera à faire surgir les figures d'articulation nouvelles de leur attention au programme, de leur situation de réception et du sens qu'ils prêtent au spectacle dans leurs conversations et dans leurs jugements. C'est donc à une combinatoire des situations de réception que seront consacrés les développements qui suivent, au regard des séquences jugées les plus emblématiques de l'émission: celles qui mettent en scène des malades, les duplex, les séquences de variétés et les séquences consacrées à la recherche génétique (cf. tableau 5, supra). Cette approche combinatoire des situations de réception permettra ensuite de proposer une typification des groupes en termes de cheminement à l'intérieur du programme.

\section{Reconnaître ou se soustraire : les séquences malades}

Vendredi 22 h 10. Marie-Jo, 32 ans, souffre d'une amyotrophie spinale. Elle arrive dans son fauteuil sur la scène centrale du plateau d'Evry, pour interpréter une chanson. A $22 \mathrm{~h} 14$, Claude Sérillon ponctue la séquence : «Marie-Jo Allegrini ! Tu nous a donné une des plus belles leçons de vie effectivement et de courage ! Merci Marie-Jo ! (cf. photo 7).

Samedi, 22 h 11. Diffusion d'un reportage consacré à la vie d'Agnès Lebars, atteinte de mucoviscidose (et présidente de l'AFLM, l'Association Française de Lutte contre la Mucovicidose) qui a subi une transplantation cœur-poumon à l'âge de 26 ans et repris depuis une activité à temps complet dans une entreprise.

Si l'on s'attache aux contextes de réception de ces deux séquences présentant des malades, on remarque immédiatement leur singularité : au début de la séquence "Marie-Jo », par exemple, onze groupes sur quinze 
marquent leur surprise, interrompent, ne serait-ce qu'un instant, leur conversation ou leur activité annexe. Autant d'éléments qui dénotent une focalisation de l'attention vers le programme télévisuel. Cette attention se marque d'abord par les silences et des interruptions de conversation, parfois ponctuées d'interjections émotives (du type "Putain, là... », "Hou, la, la... », "La vache... »). L'attention se marque, ensuite, par une immobilité des corps tournés vers l'écran de télévision, vers laquelle on se rapproche ou que l'on désigne parfois du doigt. Ces moments, qui résistent largement à l'opération descriptive, dénotent une « absorption » du téléspectateur dans le spectacle. L'ensemble des groupes ne s'est cependant pas maintenu, pendant l'ensemble des séquences-malades, dans cette proximité spatiale et ce mode attentionnel rapproché. Seuls les groupes initialement les plus distants, et notamment les groupes critiques, sont globalement restés dans l'emprise, tant la force de l'image des malades s'impose à eux sous le mode du drame et de la tragédie. Les groupes ironiques se caractérisent, quant à eux, après le moment de stupeur, par un recul corporel (détente corporelle immédiate, mise à distance de l'écran et du spectacle). La forme extrême de cette indisponibilité peut consister en une "fuite " devant ce qui est ressenti comme obscénité (le téléspectateur sort de la pièce ou zappe).

Parce que les moments d'emprise se caractérisent par « l'absence de rupture entre les êtres ${ }^{37}$, ils peuvent, dans un moment ultérieur de compréhension, déboucher sur une communication des expériences des spectateurs et des malades - c'est surtout le cas des groupes engagés (et dans une moindre mesure celui des pragmatiques). Si les regards continuent de fixer l'écran, gardant en quelque sorte en prise le spectacle des malades, ces groupes peuvent rompre le silence et déployer des conversations dont le trait distinctif est d'opérer des rapprochements et des associations imaginatives entre les existences (" c'est comme... ", " ça me rappelle... ", " on se rend compte qu'on dit qu'on a des problèmes, mais en fait, on n'a pas de problèmes »).

Irène : La fille de monsieur Lourmain était bien comme ça.

Lucienne: Oui, je m'en rappelle elle était comme celle que l'on a vue ce matin. Je ne sais pas si elle n'est pas morte.

Irène: Elle a eu deux enfants, elle était mariée avec quelqu'un comme elle. Elle était moins handicapée que lui. Ils habitaient à Montpellier, ils se débrouillaient mais ils avaient quand même quelqu'un.

37. BESSY, CHATEAURAYNAUD, 1995, p. 263. 
Lucienne : Et cette femme qui passe ici, c'en est une de myopathe, avec sa petite fille. C'est bien ces petits fauteuils à moteur.

Au total, l'espace de réception des séquences «malades » propres aux téléspectateurs engagés autorise, via les corps, une communication du monde des malades atteints de myopathie et du monde des téléspectateurs témoignant de leurs expériences personnelles. La façon dont, pour les groupes engagés, le spectacle de ces souffrances éloignées trouve, comme le dit Ricœur, « une ambiance et une audience », la façon dont il réfère alors véritablement 《 vers un monde et vers des sujets ${ }^{38}$ ne peut être comprise en dehors des possibilités sémantiques qu'offre le spectacle des malades. Ceuxci apparaissent d'abord dans une catégorie différente de celles utilisées ordinairement pour désigner des êtres «normaux », en bonne santé. Ils sont différents, mutilés, handicapés, meurtris, autres. Et cette différence, qui suscite un premier mouvement de stupeur, fait apparaître un écart générique, irréductible, entre la situation du téléspectateur et la leur. Le surgissement de l'émotion de sympathie, les rapprochements et la sollicitude sont intimement associés au constat que cette différence catégorielle n'est pourtant pas insurmontable, qu'elle peut être recouverte par une autre catégorie à laquelle les téléspectateurs appartiennent tous. Il est alors possible de desserrer l'étau de la première qualification, de restaurer l'humanité des personnes contre l'irréversibilité du handicap: le corps de Marie-Jo est irrémédiablement mutilé, mais elle chante ; Agnès Lebars a subi une transplantation cœur-poumon, mais elle est une salariée comme les autres.

Toute personne est en mesure de reconnaître qu'elle a une propension à la sollicitude. Cependant, cette reconnaissance peut connaître deux orientations différentes selon que la personne se rend disponible à l'envahissement émotionnel, ou bien qu'elle s'en détourne pour mettre en exergue l'intention d'émouvoir qui anime les producteurs du Téléthon. La séquence de Marie-Jo oppose donc moins ceux qui sont émus et ceux qui restent indifférents, mais partage, à partir d'un ressort commun ${ }^{39}$, ceux qui se rendent disponibles à l'émotion et ceux qui, reconnaissant l'intention d'émouvoir, se soustraient à son envahissement. Les comptes rendus de réception illustrent parfaitement ce partage entre sollicitude émue et soustraction à l'émotion. Certains groupes

38. RICCEUR, 1986.

39. Reconnaître l'intention d'émouvoir, c'est nécessairement avoir lu en soi la possibilité d'une émotion, un ébranlement commencé ou virtuel, qui a été refusé ou retourné. 
font presque disparaître les caractéristiques physiques de ces jeunes femmes (l'absence de jambes, la maigreur, les corps déformés, les fauteuils roulants, etc.) pour mettre en exergue de manière admirative des qualités morales, des traits de comportement ou des pensées (le courage, l'envie de vivre, l'espoir) qui les rattachent à l'ordre de la vie. On saisit bien, dans cette perspective, combien les séquences «malades » constituent pour ces groupes des raisons sensibles à leur engagement. A l'inverse, d'autres groupes ne font guère apparaître ces qualités qui relient les deux malades aux téléspectateurs, mais insistent presque uniquement sur l'altérité des malades, leur faiblesse, leur malheur, ce qui marque l'impossibilité de reconnaître une communauté d'expérience (et souvent cette impossibilité est motivée par le rappel de la spécificité de leur maladie, la myopathie). Cette altérité est alors reconnue comme insurmontable, et fige les téléspectateurs dans « l'horreur». Le retrait de l'émotion, effectivement vécue, se lit dans l'humour noir, mais également dans le soupçon jeté sur la mise en scène télévisuelle et la dénonciation de son intention manipulatrice ( Tu as remarqué : ils te montrent la tête mais pas le corps »; "Oui, ils te poussent à avoir de la pitié »; "C'est un moyen d'attendrir les gens. [...] Le cameraman qui vient dessus c'est pas innocent»).

\section{Voir la mobilisation ou rire d'Intervilles : les séquence duplex}

Le recul peut cependant ne pas être aussi radical. Il existe, en effet, des gradients dans le détachement à l'égard du spectacle télévisuel. Les groupes les plus détachés du Téléthon vont se positionner en lisière du spectacle télévisuel, dispersant leur attention entre l'image et les joutes oratoires de la conversation ironique. Les groupes critiques vont eux adopter une position de retrait comparable à celle d'un tiers, conférant ainsi à l'espace des conversations une dimension de publicité, et le transformer en un forum sérieux et raisonné. On ne saisit jamais mieux ces différentes formes de recul que dans les séances de duplex.

Vendredi 21 h 16. Duplex en direct de Nancy. Sur la place Stanislas, les journalistes présentent des fils rouges, une série de défis à réaliser durant les 30 heures du Téléthon. Diverses actions défilent à l'écran, auxquelles succède un point-compteur local, en compagnie d'un chanteur (cf. photo 3).

Vendredi $22 \mathrm{~h}$ 04. Duplex en direct de Morteau. Après un point-compteur local, sont présentées différentes attractions : vaches montbéliardes dont on peut boire le lait, fromages régionaux que l'on peut acheter, etc. L'animateur insiste alors sur le « monde fou » présent à Morteau. 
Vendredi 22 h 24. Duplex en direct de Villeneuve-sur-Lot. Une animatrice présente un spectacle de maréchaux-ferrants, dans une ambiance de fête médiévale. «Il y a vraiment une énorme mobilisation », ajoute-t-elle avant de passer la parole à un autre animateur présentant l'exploit réalisé par une équipe de rugbymen consistant à tirer un autobus à la force du poignet. L'animatrice reprend la parole pour lancer un sujet sur un jeune Agenais de 24 ans, handicapé depuis sa naissance, mais nageur de compétition.

Ce qui caractérise la réception des groupes engagés et ironiques, nonobstant la différence de sens qu'ils confèrent au spectacle, c'est l'espèce de midistance qu'ils entretiennent aux spectacles des duplex : il s'agit d'un regard qui autorise une attention à éclipse, dispersée. Les individus prélèvent des éléments du spectacle (les cheveux bleus d'un étudiant des Beaux-Arts, les maréchaux-ferrants sur une place de village, les sommes récoltées localement, les défis bizarres ou exceptionnels, etc.), accompagnant de leurs rires l'agitation bon enfant des mobilisations ou le désordre de la représentation télévisuelle. A l'opposé, critiques et pragmatiques adoptent une position éloignée, que soulignent le recul des corps et leur détournement de l'écran : ils ne prélèvent que rarement des éléments du spectacle, se ferment en quelque sorte à l'image, et dérivent les conversations vers des thèmes extérieurs à la représentation.

La caractéristique sémantique des conversations ironiques, critiques et pragmatiques apparaît d'emblée: à l'inverse des groupes engagés, les participants voient le dispositif télévisuel, remarquent immédiatement la forme dramaturgique de ces séquences en la détachant de leur intention. Il perçoivent le cadrage des séquences, et effectuent des «raccords » leur permettant de reconnaître, dans la présentatrice du duplex de Villeneuve-sur-Lot la « Miss Météo» de France 2; ils évaluent le «casting». du Téléthon, repèrent les moments de mise en scène ( $J e$ suis sûre qu'ils font semblant de téléphoner. La blonde devant, elle raccroche, elle note rien. Elle regarde comme ça puis après elle regarde son téléphone et après elle le décroche. C'est hyper bizarre. Tu vois elle a toujours rien noté, regarde!»), ils jugent le conducteur de l'émission ("Moi je trouve qu'il y a quand même des ratés dans cette émission, bon d'accord, c'est du direct... mais ça fait 10 ans qu'ils sont au point, quand même! [...] Par exemple il y avait un reportage de jeunes, il sera jamais vu... les jeunes ont fait ça pour rien! »). Les groupes les plus critiques en viennent à ne pas voir le spectacle en lui-même, l'ambiance festive et enjouée des duplex. Leurs conversations reviennent souvent, en ces instants, sur les fins de l'émission, la collecte d'argent, le soin aux malades, les progrès de la recherche. La critique de ces séquences procède du repérage d'une déconnexion entre la forme de l'émission et ses objectifs («Faut 
relativiser, les gens qui participent de la sorte sont de bonne foi, ils ont envie d'aider mais ils passent pour des andouilles, enfin ça c'est mon point de vue. [...] Bon, tu peux faire abstraction en te disant que tu donnes pour les malades, mais ce qui est chiant c'est l'émission en elle-même. Le but du Téléthon c'est de recueillir de l'argent pour la recherche sur les maladies génétiques, en cela elle remplit parfaitement sa mission mais c'est sur la forme que ça cloche! »). C'est également durant ces séquences - comme, on le verra, lors des moments de variétés - que ces groupes réclament plus de reportages, de véritables «topos » sur les avancées scientifiques, ou l'usage qui est fait de l'argent des dons : "Je commence un peu à m'emmerder... Moi, ce que j'attends c'est... Je m'en fous de ça! Je voudrais des reportages sur les maladies. Quelles sont-elles? Quels sont les progrès en matière de guérison? Ils ont parlé de la carte du génome humain, mais bon, ça c'est pas une guérison, ça sert juste à dépister... Je serais plus intéressée par des résultats concrets ». Pour autant, la distance prise par rapport au spectacle télévisuel ne débouche pas sur les mêmes espaces conversationnels. Ainsi les ironiques restent-ils dans une position déjà expérimentée : celle de la réception d'une émission comme Intervilles. Détendus, ils rient volontiers du spectacle, se moquant des présentateurs, les imitant dans leurs tics, leur accent. La distance qu'ils éprouvent à l'endroit des duplex n'est pas celle, sérieuse, des critiques, mais ils puisent dans leur culture télévisuelle, dans la connaissance qu'ils ont des animateurs ou des jeux qui mettent en scène les régions de France, les ressources mêmes de leur distance et d'une moquerie de surface de l'image. Ils restent ainsi dans le spectacle ou du moins, à l'aide de raccords, dans l'univers seulement télévisuel, en se refusant autant à ouvrir leur conversation, comme le font les critiques, à des arguments «en généralité » et extérieurs à l'univers de ce qu'ils voient, qu'à reconnaître le sens du spectacle. Les ironiques ferment ainsi la réception, suspendent toute interprétation, et se fixent sur la vérité objective de ce spectacle désordonné et un peu ridicule.

A l'inverse, les groupes engagés ou les pragmatiques engagent un rapport différent au spectacle des duplex. Sans rester éventuellement aveugles à la mise en scène télévisuelle, ils en décryptent immédiatement un sens non perçu par les autres groupes. C'est non le kitsch d'Intervilles mais la mobilisation qui est simplement vue, et dont ils retirent satisfaction et joie : "Je trouve plus émouvant de voir des gens ordinaires qui s'impliquent dans une action plutôt qu'une célébrité qui chante »; "Ce que je trouve de bien dans le Téléthon, c'est que ça permet aux gens de se réunir autour d'une cause. Cela permet de voir certaines manifestations, ça fait vivre aussi une commune. C'est un mouvement national quel que soit l'endroit où tu te 
trouves en France à cette date, ben tu sais qu'il va y avoir un marathon pour le Téléthon, enfin... qu'il y a une manifestation pour le Téléthon». C'est encore la forme de cette mobilisation, le déploiement d'énergie, les efforts consentis par des gens ordinaires et anonymes qu'ils perçoivent, et dont ils pèsent la leçon ( C'est vraiment donner de l'énergie à ceux qui $n$ 'en ont pas »). C'est enfin la dimension contagieuse de cette mobilisation qu'ils notent, entretenue par l'alternance à intervalles réguliers de ces duplex aux quatre coins de la France. L'émulation des régions et des villes par les défis et les exploits, la propagation de proche en proche de la mobilisation en viennent à la constituer en une véritable fête nationale, un «quatorze juillet en hiver », comme le répètent les animateurs du plateau central ("Chaque ville met en valeur sa spécialité, en fait, ça génère une sorte de solidarité entre les villes »; "Le coup des challenges, c'est quand même un bon truc développé par le Téléthon. Cela permet aux petites communautés de se mobiliser. Après, ils doivent faire une fête ensemble »).

\section{Plaisir ou incompréhension : les séquences « variétés »}

La tension observée, à propos des duplex, entre les fins publiques du Téléthon et la forme de certaines de ses séquences se trouve radicalisée avec les séquences « variétés » qui ponctuent de manière régulière le programme. $\mathrm{Si}$ les groupes ironiques et engagés vont s'ouvrir ou se fermer à ces séquences suivant la distribution de leur goût en matière de chansons, les groupes les plus critiques vont y trouver une forme de justification de leur position détachée.

Vendredi 21 h 45 . Introduit par un animateur du plateau central, un chanteur, Francis Cabrel, vient interpréter le titre-phare de son dernier album. Il est accompagné par un harmoniciste. Les seuls mots du chanteur sont pour commenter le plaisir qu'il a eu à faire son album et de « faire une télé » en compagnie de l'harmoniciste (cf. photo ${ }^{\circ} 10$ ).

Samedi 21 h 08. Après un duplex avec Amiens, un animateur du plateau central, Michel Drucker, annonce l'arrivée sur la plateau d'une chanteuse, Ophélie Winter : "Évidemment, je sais pourquoi tu es là : tu as dit à un de mes amis, il y a pas longtemps, 'trois minutes, c'est rien pour nous, mais c'est tellement pour les enfants' ». Le parrain de l'émission la compare à une fée avant qu'elle ne quitte le plateau.

Le fait d'apprécier le chanteur ou la vedette de variété commande, à lui seul, une distance corporelle plus ou moins affirmée au programme, et, partant, une attention plus ou moins éveillée. Pour les plus ironiques des téléspectateurs, c'est au fond la seule variable intéressante, celle qui 
imposera le silence pendant la durée de la chanson - éventuellement, on accompagnera, en chantonnant ou en tapant du pied le chanteur -, ou, à l'inverse, l'envahissement de la réception par le contexte hors-thème. Pour les groupes engagés, cette variable d'appréciation joue un rôle moindre dans la mesure où l'horizon de réception n'est pas ordonné par l'attente de chansons, qui, de fait, les déçoivent souvent. L'attitude de ces groupes est dès lors caractérisée par une attention dispersée et le déploiement de discussions hors-thèmes.

L'apparition récurrente de vedettes de la chanson au cours de l'émission pose en revanche problème à ceux, pragmatiques et critiques, qui prennent au sérieux le Téléthon. Ces séquences appellent un moment de distance critique, que marque, en général, une posture de recul physique vis-à-vis de l'écran. Le caractère incongru de ces chanteurs est ainsi souvent souligné : "Non, moi, je trouverais, moi, je trouve que les vedettes n'ont rien ... enfin rien, rien à faire, pas une question de cela. Mais, chanter, et tout ça, ils feraient mieux de venir et hein, et puis dire... Oh, je ne sais pas. Je ne ferais pas comme ça. [...] Pour moi, eh bien, les vedettes, ils viennent, ils assistent, ils leur causent. Ils parlent aux enfants, et puis un don ». Ce hiatus est alors souvent retraduit dans les termes d'un agir intéressé de la part des chanteurs. On les soupçonne ainsi de venir sur les plateaux du Téléthon dans le but de «se faire un peu de publicité ", de gagner une audience : "Tous ces gens qui viennent, c'est bien qu'ils viennent faire le Téléthon. Mais je ne vais pas changer dans ce que je disais; tous ces gens qui viennent, en contrepartie, ça leur fait quand même de la pub! C'est pas innocent. C'est bien de se déplacer et de ne pas être payé mais en contrepartie ça leur fait de la pub! ».

Moi, ce que je n'aime pas, c'est que c'est du spectacle et justement ce que je réprouve moi c'est le spectacle associé à des choses aussi terribles quoi. Bon du spectacle on a, toutes les semaines on fait, on regarde des émissions comme ça de spectacle hein! Pour notre plaisir, et là, si tu veux, c'est un peu le même spectacle mais pour donner de l'argent si tu veux à des gens qui sont myopathes ou des trucs comme ça, je ne sais pas pourquoi cela me gêne moi, tout ce monde du spectacle associé à ce truc désespéré quoi. C'est ça qui me gêne, parce que le monde du spectacle en lui même est un monde pas franc, pas... et ce que je réprouve moi, et justement, ce que je disais tout à l'heure, est-ce que ces gens du spectacle ne profitent pas de ce monde là, du truc du Téléthon, pour se remettre en place, pour se remettre un peu au premier plan, tu vois ce que je veux dire? Il y a par exemple des acteurs ou des chanteurs qu'on n'a pas vus depuis quelques mois ou même depuis des années qui vont réapparaître à ce moment-là. 
Le problème est en général résolu en scindant le jugement porté sur l'émission. Ainsi, les groupes pragmatiques continuent-ils d'affirmer le caractère inutile, incongru, des chansons - mais il en va de même pour tout ce qui peut être rangé dans la catégorie des « attractions sans raison »-, en revanche, ils jugent que, pour ceux qu'ils convoquent sous l'espèce des « gens », des « Français moyens » ou de la «population », ces variétés sont susceptibles de jouer un rôle attracteur et mobilisateur pour le Téléthon, et qu'à ce titre elles restent utiles et bénéfiques. Cette «perception de troisième personne » peut être lue à de nombreuses reprises dans les comptes rendus de réception : "Il faut que ça touche un public assez large, les jeunes aussi, quelques jeunes regardent. Mais je pense qu'ils auraient pu mettre des chanteurs de leur génération. Des chansons françaises très bien, mais aussi anglaises, parce qu'on touche plus de monde " "Cabrel est peut être aussi..., mais, je pense que quand même mais il faut pas voir comme ça parce que... ils vendent comment dire euh la télé, l'émission aux téléspectateurs, et pour tenir les gens en haleine devant la télévision, ils sont obligés de, euh, d'inviter des gens euh avec une notoriété parce que s'ils mettaient toujours les mêmes pfff...! »; Yvette : "C'était l'erreur du Sidaction, faut faire attention aux gens qui sont ciblés aussi. C'est pas les plus jeunes qui donnent... - Mais ça aussi on essaie dans le casting, de caresser dans le sens du poil. Y a un panel de téléspectateurs. - Ce serait vraiment bête de faire tout l'inverse! »

\section{Attention sérieuse ou ennui : les séquences « recherche »}

Les séquences «recherche » apparaissent comme les symétriques des séquences «variétés » et des séquences «duplex », tant dans les postures attentionnelles des différents groupes que dans le jugement qu'ils déploient à leur égard. Le contenu de ces séquences est, en effet, caractéristique de ce que l'on appelle des « raisons »: elles expliquent comment les dons ont été utilisés dans les domaines de la thérapie génique, elles expliquent les avancées scientifiques, les résultats obtenus, les projets et les objectifs à atteindre. Il s'agit aussi souvent de séquences sans attractions : talk-show sérieux, austères même, et relativement techniques, ou petits reportages, tel celui du vendredi 21 h 50, consacré au Généthon.

Vendredi 21 h 50. Reportage sur le Généthon, laboratoire financé par les dons du Téléthon. Les images montrent les robots et les paillasses, pendant qu'en voix off un chercheur insiste sur l'importance de l'informatique et de la robotique pour la recherche génétique. Après le reportage, c'est le chef de l'équipe de génétique moléculaire humaine à l'INSERM, et un 
spécialiste en génétique et en thérapie génique, qui dressent le bilan scientifique du travail du Généthon (cf. photo 11).

Vendredi 22 h 39 . Un chercheur est interviewé par un animateur du plateau central. Il parle de cette nouvelle discipline qu'est la myologie, et du nouvel institut qui est dédié à cette discipline : "Je crois que c'est la première fois qu'un institut dans le monde est créé avec la participation de ceux qui vont y travailler et de ceux qui vont s'y faire soigner et que tout a été fait en harmonie les uns avec les autres. Je ne connais pas d'autre exemple dans le monde ». Un chanteur, présent sur le plateau, insiste sur l'enthousiasme des chercheurs qu'il a rencontrés (cf. photo $n^{\circ} 12$ ).

Ces séquences « recherche » séparent très nettement les groupes critiques et ironiques, d'une part; les groupes engagés et pragmatiques, d'autre part. Cette séparation se lit tout d'abord dans l'attention portée aux séquences : autant les premiers focalisent leur attention sur le programme, dans une posture corporelle avancée et concentrée, prélevant de nombreux éléments des séquences, notamment le nom ou le titre des chercheurs, autant les seconds se détendent, laissent leur attention se disperser, et leur conversation dériver vers des thèmes hors contexte ou vers des rapprochements avec leur environnement immédiat. Ceux-là s'intéressent davantage aux instruments scientifiques ou aux bâtiments neufs abritant les laboratoires qu'aux chercheurs. Leur attention, cependant, reste d'une intensité plus faible que les groupes critiques, et souvent il « décrochent ».

Pour autant, les conversations déployées depuis ces pôles attentionnels apparaissent bien différentes. Ainsi, les groupes ironiques, sans doute parce qu'ils sont les plus jeunes, ne parlent guère durant ces séquences, écoutant simplement les explications, effectuant des raccords avec d'autres émissions scientifiques (notamment l'émission « Envoyé Spécial », qui, la veille, avait diffusé un reportage consacré à l'histoire de la cartographie du génome). Les critiques s'intéressent de manière plus prononcée à la recherche, aux acquis ou aux interrogations scientifiques et en discutent techniquement (avec une précision sémantique beaucoup plus grande en matière génétique). Leur distanciation critique s'effectue au regard de ce qu'ils jugent comme des imprécisions, une absence de pédagogie dans les explications ("Ce qu'il y a de plus honteux, c'est vraiment ces parties là. Tu as compris quelque chose? Ils nous montrent des chercheurs, mais il n'y a pas un discours scientifique abordable. Ça veut dire quoi ? On comprend rien! "; "C'est hallucinant, ils te montrent plein de trucs, mais ils t'expliquent rien »). C'est surtout le «mélange des genres » qu'ils déplorent, notamment quand sont associés sur un plateau ou dans un reportage scientifiques et malades. 
L'irruption du corps des malades est alors ressentie comme une incongruité. Leur critique vise ainsi à purifier les séquences « recherche » de tout aspect sensible pour leur réserver le ton calme et sérieux de la raison scientifique : "C'est un peu facile, on essaie de toucher les sentiments, ça fait pas appel du tout à la raison et aux gens qui réfléchissent! C'est le côté émotif, sensibilité, on va montrer des gens... Si on va te montrer un gosse qui est sur son fauteuil, évidemment c'est un moyen de toucher le public. Dans le type de société dans laquelle on vit, on est obligé de faire appel à des opérations médiatiques de ce genre là pour financer la recherche, [c'est une] société qui est pas adulte en tout cas!»

A l'inverse, dans les conversations des groupes engagés et pragmatiques, l'attention, plus dispersée, est immédiatement connectée à ces malades vus à la télévision. L'adhésion aux séquences « recherche » procède ainsi moins de la satisfaction intellectuelle «d'apprendre quelque chose » que de l'usage de la recherche pour le soin aux malades. C'est donc moins de génétique que l'on discute que de médecine. Le souci des malades, dont le rappel des souffrances accompagne toujours leurs propos, est ainsi beaucoup plus présent pour les groupes engagés, qui inscrivent la recherche dans une dimension temporelle, entre un avant (avant le Téléthon, avant les découvertes scientifiques que les dons des années précédentes ont permis de faire), et un après, ce futur qui verra la guérison des myopathies. Cette attention au soin, détachée de sa dimension génétique, ouvre aussi les conversations à la comparaison avec d'autres maladies, et à la discussion du choix de consacrer l'ensemble des dons à la myopathie. C'est ainsi le privilège accordé à un seul type de maladie qui est contesté, et le rappel des autres pathologies orphelines délaissées : "Ouais, mais moi je ne suis pas tellement contente, parce que je me rends compte qu'il y a une sacrée partie du fric que je pourrais donner qui ne va que dans un seul domaine, la myologie. Or les maladies génétiques, il n'y en a pas qu'une, il y en a plusieurs. C'est l'autisme, aussi, faut le savoir quand même... Je veux bien donner pour la recherche génétique tant que toutes les maladies ont une importance égale. Pourquoi il n'y en a pas pour la maladie de Hunter? ". L'élargissement à d'autres maladies fait alors souvent déboucher les conversations, à partir des images de laboratoire ou des résultats annoncés, sur l'usage de l'argent collecté dans les précédents Téléthon ("On voit à quoi sert l'argent! »), et sur l'arbitrage en terme de politique publique entre les différentes formes de financement de la recherche. 


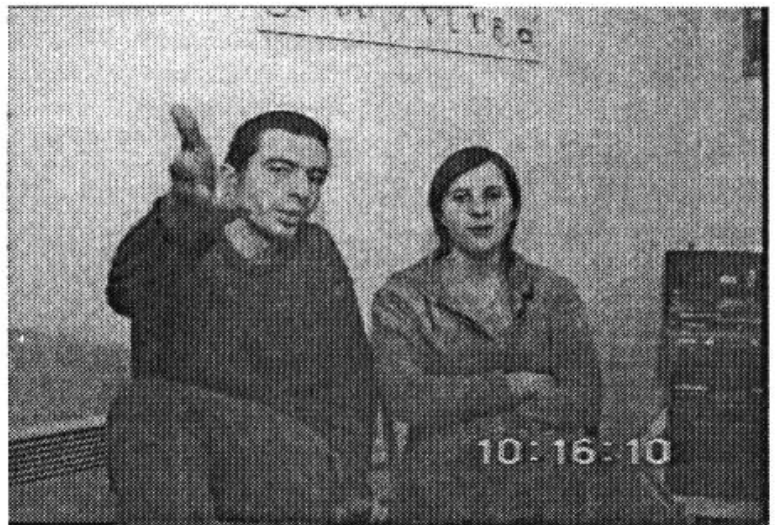

Photo 13. Recul critique : « Hallucinant! Ils expliquent rien!»

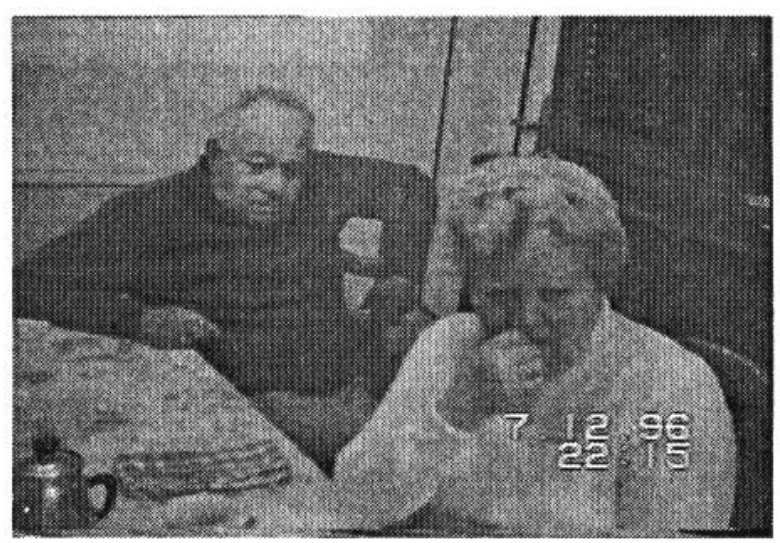

Photo 15. Attention émue devant Marie-Jo

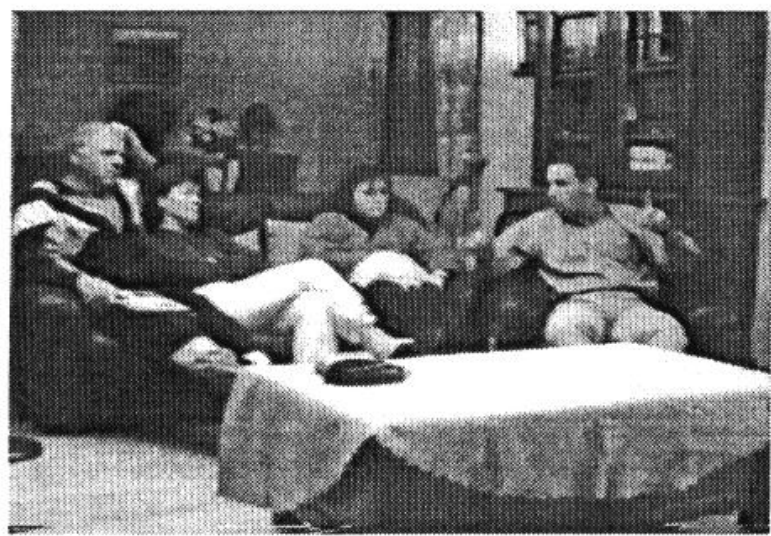

Photo 17. Discussion sur les buts du Téléthon pendant un duplex.

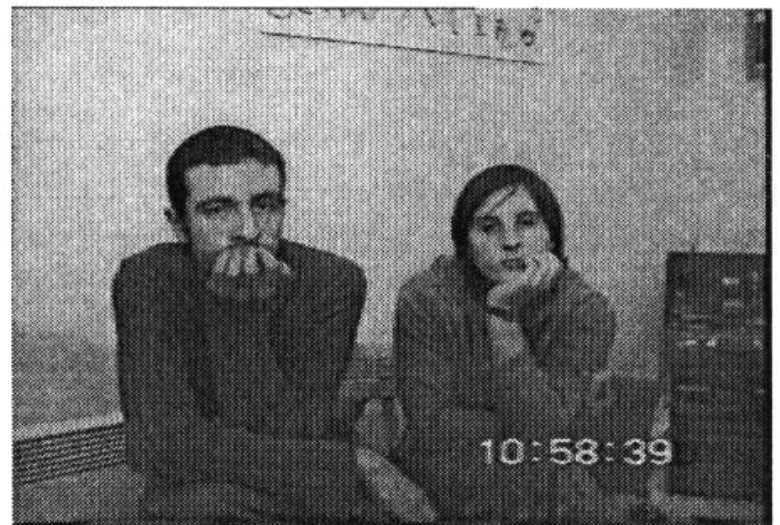

Photo 14. Moment de focalisation devant un reportage malade

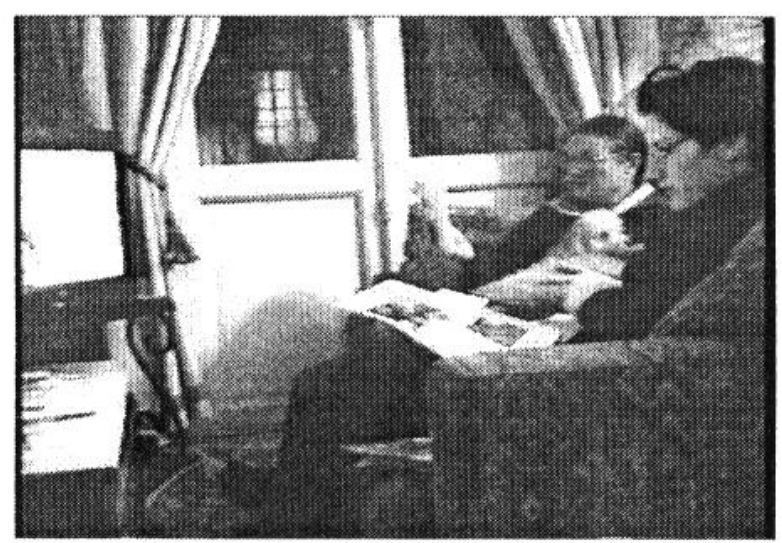

Photo 16. Attention oblique à la chanson de Francis Cabrel

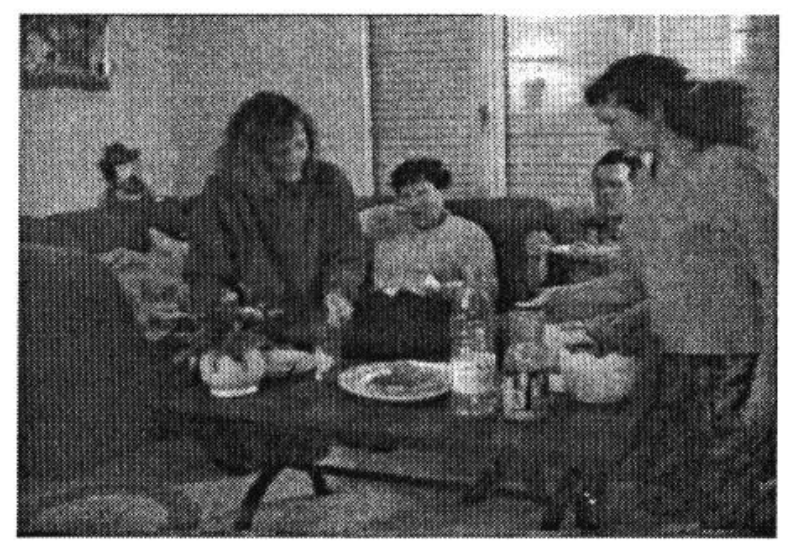

Photo 18. Dispersion 


\section{Configuration des arènes et carrière de téléspectateur}

$\mathrm{Au}$ terme de cette analyse combinatoire des cadres de pertinence ouverts par chaque séquence du Téléthon, il est possible de revenir sur les différentes formes de coordination opérées entre les téléspectateurs et le programme. Celles-ci sont le produit d'opérations intéressant les différentes postures attentionnelles possibles, et configurant de manière à chaque fois caractéristique l'arène de réception du Téléthon (cf. les illustrations de ces opérations sur les photos 13 à 18). La première opération peut être définie comme une focalisation, définissant une forme tendue de coordination entre le programme télévisé et ses récepteurs; coordination tendue que dénote l'attention concentrée, le suspens des corps, le silence ponctué de forts taux de prélèvements. Caractéristique des séquences « malades » pour l'ensemble des groupes ou des séquences « recherche » pour les groupes critiques, cette opération dispose l'arène pour les phénomènes d'absorption et d'emprise télévisuelle. Cette première opération trouve son pendant dans un autre type d'opération, identifiable sous le terme d'inversion. Typiques des séquences «malades» des groupes ironiques, ces inversions procèdent également d'une même attention «tendue » au programme et s'emploient à retourner contre l'émission, de manière quasi carnavalesque, les effets qu'elle exerce sur les téléspectateurs en en faisant un objet de moquerie, d'ironie et de dérision. Les contraintes de justification se trouvent ici comme suspendues. Un troisième type d'opération peut être spécifié par le recul. Il est principalement le fait des groupes pragmatiques et critiques lors des séquences de variétés. Ce recul, que manifestent les postures corporelles détachées, et le fort taux d'appuis argumentatifs, configure un mode analytique de coordination programme/spectateur, et confère aux arènes de réception un gradient supérieur de publicité. Les coordinations détachées entre Téléthon et récepteurs ne sont toutefois pas l'apanage de ce type d'opération, puisque les opérations de dispersion appellent également ce type de coordination. Ces opérations, typiques des séquences duplex pour les ironiques ou des séquences variétés pour les engagés, sont signalées par un mode attentionnel relâché, par de faibles taux de prélèvements et par la fréquence élevée des conversations hors thème. Enfin, un dernier type d'opérations, l'association, peut être isolé, spécifique des séquences duplex et «malades » pour les groupes engagés : en se plaçant dans une posture attentionnelle ouverte à l'intention du programme, les spectateurs dilatent l'arène de réception et la disposent à l'accueil des témoignages, aux rapprochements et à la connexion de leurs expériences personnelles ou locales à la représentation télévisuelle. 
A partir de la distribution hétérogène de ces opérations selon les groupes, il devient possible de dessiner les trajectoires de leur réception des différentes séquences de l'émission. Une analyse factorielle de l'ensemble des conversations selon les groupes et les séquences (cf. graphique 12), a été entreprise à cette fin. Le premier axe de l'analyse sépare distinctement le soutien et la critique du Téléthon; le second est constitué de l'opposition des conversations sarcastiques enfermées dans l'univers télévisuel à celles, émues, ouvrant leur espace aux rapprochements des expériences entre malades et spectateurs. Au vu de ce graphe factoriel, on constate tout d'abord que chacune des séquences rapportée aux groupes critiques, engagés et ironiques s'inscrivent bien dans des zones de proximité : les critiques à gauche du graphe, les engagés à droite, les ironiques dans le quadrant supérieur gauche. A l'exception des pragmatiques, chaque groupe privilégie ainsi un type d'opération pour se coordonner au programme et configurer leur situation de réception - autant dire, pour installer un «climat» ou une «ambiance» de réception. Ainsi les groupes critiques privilégient-ils les opérations de recul : en se détachant corporellement de la représentation télévisuelle, ils tendent à se retrancher du public, et à s'instituer en tiers vis-à-vis de l'événement télévisuel. Ce faisant, ils contribuent à reconfigurer l'espace de leur réception en espace public ${ }^{40}$. Surtout, cette position d'extériorité au spectacle, comme à l'ensemble réel et imaginé du public télévisuel, les institue en position d'arbitre ou de tribunal adéquate à la forme critique de leur engagement. La position des groupes engagés se caractérise, à l'inverse, par une plus grande prégnance des opérations d'association ${ }^{41}$. Leur espace de réception manifeste ainsi une moindre sensibilité aux sautes du programme. Les engagés maintiennent un rapport voisin à ces deux séquences antithétiques que sont les séquences « recherche » et les duplex, en les inscrivant dans un même horizon, celui de la fête destinée au soin des malades; ils gardent en prise le programme, mais l'ouvrent sur un espace de témoignages personnels ou locaux, qui permettent de relier leur expérience au but et au contenu du programme. Les groupes ironiques, quant à eux, ont recours de manière dominante à des opérations d'inversion ${ }^{42}$ : ils vont entretenir pendant la quasi-totalité de leur réception une volubilité moqueuse, faite de réparties vives, d'incessants

40. CARDON, HEURTIN, LEMIEUX, 1995.

41. La position excentrée au regard du premier axe de la séquence « recherche » conserve cependant la trace de leur dispersion durant ces séquences.

42. Si l'on excepte les séquences chanson, dont on a vu qu'ils les appréciaient, et qui correspondent à une focalisation plus grande sur le spectacle télévisuel. 
prélèvements. En se maintenant en lisière du spectacle, comme en surface du programme, ils se tiennent dans une posture intermédiaire entre le rapprochement des groupes engagés et le recul de la critique argumentée. Leur réception du Téléthon, s'interdisant toute position de surplomb, dessine un régime impersonnel $d^{\prime}$ 'engagement ${ }^{43}$, essentiellement voué au divertissement et au persiflage télévisuel.

C'est cependant pour les groupes pragmatiques que l'on constate la plus grande dispersion des séquences. S'ils se trouvent bien dans une position intermédiaire entre engagés et critiques, proches des critiques durant les séquences de chansons et proches des engagés pendant les séquences «duplex » ou «recherche », cette dispersion indique le recours à des opérations de coordination différentes au programme : ils se reculent durant les chansons, associent pendant les séquences « malades », dispersent durant les séquences « recherche». Leurs arènes de réception du Téléthon sont ainsi soumises à des transformations fréquentes, à des reconfigurations périodiques selon les types de séquence.

La plasticité extrême de ces trajectoires fournit une indication sur le caractère ambivalent de la position des conversations pragmatiques, oscillant de séquence en séquence, entre approbation et critique, entre recul et engagement, entre l'intérieur et l'extérieur du Téléthon, jusqu'à parfois faire coexister en eux-mêmes leurs critiques et la reconnaissance du caractère utile et bénéfique du Téléthon. A plus d'un titre, il ne s'agit pas là d'une posture marginale, ou simplement intermédiaire, mais sans doute la figure la mieux partagée dans nos sociétés du rapport aux dispositifs médiatiques de sollicitation humanitaire.

43. On pourrait ainsi parler de libertinage télévisuel, en ce que le libertinage est caractérisé par un retrait du moi. Celui-ci se retire au profit du «plaisir social dont il faut gratifier l'interlocuteur, et s'affirme comme indépendance, droit à la superficialité et au primesaut, désir du divertissement » (REICHLER, 1987). 


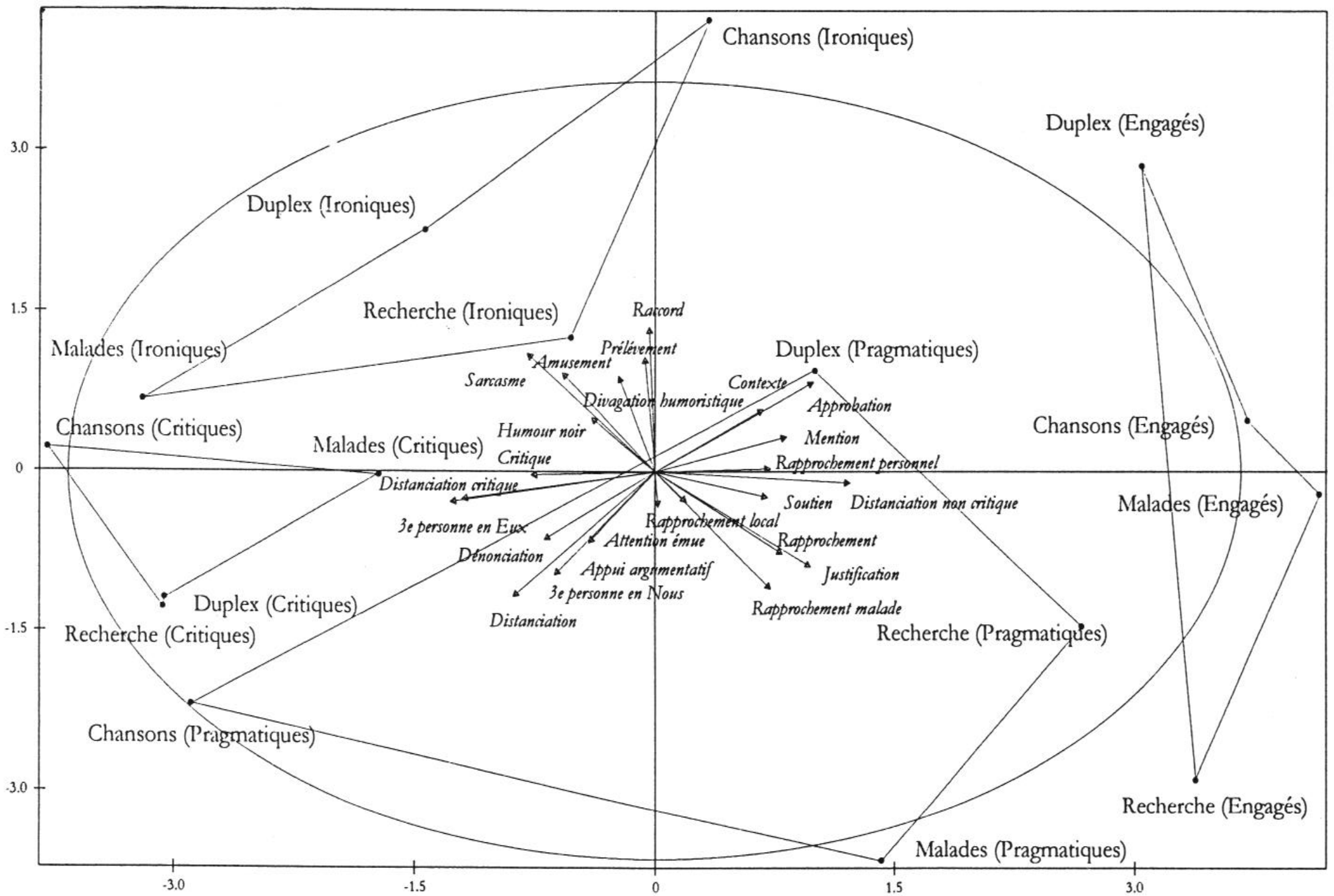




\section{S'ATTACHER AU DISPOSITIF}

Emprunté à l'outillage conceptuel de la sociologie des médias, le plan de la distanciation repose sur un ensemble de distinctions fermes et claires. Il partage ceux qui sont pour et ceux qui sont contre, ceux qui sont à l'intérieur et ceux qui sont à l'extérieur, ceux qui ont un rapport référentiel et ceux qui ont un rapport réflexif au programme, ceux qui analysent et argumentent et ceux qui, absorbés par l'émotion, sont saisis par la pitié. En outre, il parvient à distribuer (sexuellement, socialement ou culturellement) cette compétence entre les personnes. Cependant, comme nous venons de le montrer, la faculté de distancier joue un rôle paradoxal dans la réception de l'émission. Dès que les personnes sont en situation de juger et d'évaluer le programme, elle procèdent presque toutes - bien qu'à des degrés moindres et sur des aspects différents du programme - à une critique du dispositif. La distanciation ne parvient donc pas à faire solidement tenir la ligne de démarcation entre le dedans et le dehors de la mobilisation ; celle-ci apparaît beaucoup plus poreuse et incertaine. Certains qu'on n'attendait pas là se sentent concernés ; d'autres qu'on y voyait déjà n'y sont pas. Si les rapports au Téléthon sont bien polarisés par l'opposition tranchée des groupes engagés et critiques, la trajectoire imprévisible des groupes pragmatiques au sein des différentes séquences, le retournement de certains groupes ironiques, parfois prêts à participer au Téléthon sans cesser d'en rire, fait apparaitre une zone d'incertitude dans laquelle engagements et adhésions ne sont pas nécessairement en phase.

Un autre ensemble de variables parvient en revanche à cliver de manière plus pertinente les conditions dans lesquelles les téléspectateurs s'attachent, et sont attachés, au dispositif de sollicitation. Sous la catégorie de rapprochement, nous avons identifié dans le corpus des conversations toutes les séquences dans lesquelles les locuteurs procédaient à des connexions entre l'univers télévisuel et leur propre monde (cf. tableau 6). Ce sont tous les moments où les personnes rapprochent la situation de malades qu'ils connaissent des malades vus à l'écran, évoquent les manifestations de la Force $\mathrm{T}$ et leurs propres actions. Ils ouvrent l'arène de réception vers des êtres et des agissements qui, de près ou de loin, les lient à la mobilisation. Si l'on croise les quatre groupes sur deux plans, celui de la distanciation (qui oppose les conversations ironiques et engagées, d'une part, et critiques et pragmatiques, d'autre part) et celui de l'association (qui oppose conversations ironiques et critiques d'une part, engagées et pragmatiques, d'autre part), on constate alors que ce dernier plan est un meilleur outil de 
description et d'interprétation des différentes postures qu'adoptent les téléspectateurs envers la cause défendue par l'AFM (cf. tableau 7). Si le Téléthon ne parvient guère à convaincre, il arrive en revanche à faire agir beaucoup de ceux qu'il n'a pas convaincus.

Tableau 7. Positionnement des quatre groupes de conversations sur les plans de la distanciation et de l'association

\begin{tabular}{|l|c|c|c|}
\cline { 3 - 4 } \multicolumn{2}{c|}{} & \multicolumn{2}{c|}{ Distanciation } \\
\cline { 3 - 4 } \multicolumn{2}{c|}{} & Faible & Forte \\
\cline { 2 - 4 } & Faible & Ironique & Critique \\
\cline { 2 - 4 } & Forte & Engagé & Pragmatique \\
\hline
\end{tabular}

\section{Au contact des malades}

La très suggestive lecture comparée des anthropologies des morales occidentales et chinoises proposée par François Jullien ${ }^{44}$ peut nous aider à décrire les plans différents de la distanciation et de l'association comme s'appuyant sur deux anthropologies étrangères l'une à l'autre. Le mouvement de la pitié, tel qu'ont pu le clarifier Rousseau, et avant lui Smith et les moralistes français du XVII siècle, repose sur une différence fondamentale entre celui qui souffre et celui qui éprouve la pitié ; différence que seule la faculté d'imagination permet de combler. La philosophie occidentale suppose un sujet clivé et autonome qui, par le truchement de représentations, échange sa place avec celle du souffrant. Dans la réception du Téléthon, il n'est pas rare que de telles opérations imaginatives soient à l'œuvre. Pour autant, la forme de l'émotion de sollicitude que ressentent les spectateurs peut prendre un tour fort différent. Il apparaît ainsi que les groupes engagés et pragmatiques qui procèdent à des rapprochements développent une forme singulière de sympathie à l'égard des malades. La façon d'inviter dans les conversations télévisuelles leur propres malades, ceux qui leur sont proches (la tante atteinte de sclérose en plaques, le père qui souffre d'une rétinite pigmentaire, les filles qui ont une maladie de peau d'origine génétique), ceux qu'ils connaissent (une éducatrice qui a des enfants mongoliens, la fille d'une amie, myopathe, qui « est juste limite pour porter sa fourchette à sa bouche ») ou ceux qu'ils ne font que croiser (la gosse de la cité dont le père a un camion spécial, ou cet handicapé que l'on

44. JULLIEN, 1995. Cf. également dans ce numéro, l'article de M. Callon et V. Rabeharisoa. 
voit toujours passer avec «la même surprise, le même émoi »), etc., ne conduit pas le spectateur à se transporter par imagination dans la position de la victime, à « se mettre à la place de celui qui souffre » (tout en connaissant «la douceur », comme le dit Rousseau, de « ne pas souffrir comme lui $»^{45}$ ), mais à mettre au jour les liens, même ténus, qui le rattachent à des malades et à la maladie ( regarde Pascal... », « regarde la fille à la tante Lina »).

Ce faisant, les téléspectateurs s'inscrivent moins dans l'anthropologie occidentale de la pitié, mais peuvent être décrits dans le cadre d'une autre anthropologie qu'a valorisée la tradition chinoise développée par Mencius commenté par Jullien, où l'expression de la sollicitude repose précisément sur la découverte d'un partage des existences : cette existence menacée dans celui qui souffre est reconnue, par le biais des rapprochements, comme commune. Parce qu'elles sont innées et immanentes, les réactions morales n'ont pas besoin d'une architecture de mobiles intimes, d'intériorité psychologique ou de transports intersubjectifs. La réaction morale, explique Jullien, est comme l'ébranlement du «"bout" d'un fil qui, resté à l'intérieur, ne nous [apparaît] pas » mais unit l'ensemble des existences. Lorsque «menacée en lui, je réagis en moi », " nous communiquons, au fond de nous, par notre existence - [...] nous sommes tous les deux branchés sur elle ${ }^{46}$. Ainsi, la sollicitude ne naît pas en nous, mais «entre nous », dans un «procès d'interaction » ${ }^{47}$. Ces connexions apparaissent très clairement dans la confrontation des expériences rapprochées à laquelle procèdent les téléspectateurs lorsqu'ils débattent de l'origine génétique des différentes maladies, cherchent à couvrir le spectre des affections concernées, comparent le degré d'autonomie des malades de l'écran de ceux qu'ils connaissent, décrivent la situation des uns dans le vocabulaire des autres $^{48}$. Ils s'inquiètent aussi de la place qui est faite aux malades dans les lieux publics. Comment les personnes handicapées peuvent-elles parcourir les mêmes espaces qu'eux, mener une existence qui soit identique à la leur, connaître des expériences qui soient semblables aux leurs ? "Est-ce que vous avez vu une fois quelqu'un en fauteuil roulant faire ses courses au Géant? [...] Mais y a pire que ça, par exemple à l'université, normalement

45. ROUSSEAU, 1961 , p. 260.

46. JULLIEN, 1995, p. 41 et passim.

47. De là viennent les conceptions assurancielles, que nombre de donateurs ont développé pour justifier leur don : le « ça pourrait m'arriver », que l'on aurait tort de moquer, est bien la manifestation de ce partage d'existence, que notre sens de la pitié ne saurait comprendre.

48. Sur cette forme d'appropriation des témoignages dans le cas de l'émission de Menie Grégroire, cf. CARDON, 1995. 
c'est aménagé un peu. Y avait Jean-Mi qu'avait interviewé un handicapé, il était obligé de faire tout le tour... [...] Ouais... Même les trottoirs ils sont pas assez larges, mais c'est vrai que c'est plein de trucs, mais t'imagines quoi t'es handicapé, tu peux rien faire! ».Toutes ces opérations contribuent à dessiner une société qui construit autrement qu'elle ne le fait les relations des bien portants avec les malades.

Véronique : Dans cette société les malades sont dans des hôpitaux, les fous sont dans les asiles. Chacun a son trou quoi. Je veux dire que c'est bien quoi, les handicapés font partie de la société. Tu te rends compte, si demain je suis handicapée, alors je serai condamnée à rester dans mon trou. Personne ne viendra me voir. C'est bien parce que cela permet de voir que c'est des gens comme tout le monde. Enfin, il se trouve qu'ils ont un handicap quelque part; leur handicap est physique. Nous, on a des handicaps aussi : ils sont psychologiques, moraux. On a peut-être des handicaps sentimentaux, je ne sais pas moi, des handicaps qui ne se voient pas. Eux, leurs handicaps ils se voient, mais cela ne veut pas dire qu'ils ne savent pas rire... Ils ne sont pas moins que nous. Et c'est bien, ils ont trente heures pour qu'on puisse les voir. [...] Même nous, c'est-à-dire par notre regard, on provoque un certain apitoiement. Je pense qu'on devrait changer notre façon de voir parce que pour eux, s'ils viennent là, c'est pour nous montrer que c'est des gens comme tout le monde. On n'a pas à s'apitoyer il faudrait qu'on les voie comme nous quoi, tu vois. [...] C'est les étrangers en France, il faut les intégrer.

Mais la confrontation aux représentations télévisuelles des malades ne s'arrête pas là, et est souvent pour les groupes engagés et pragmatiques le siège d'une expérience émotionnelle qui tend à renverser la polarité du couple malheureux/bien portant. Si, en effet, entravés dans chaque geste, appareillés de lourds équipements, soumis au rude traitement des soins intensifs, les malades apparaissent d'abord plus dans leur faiblesse, leur souffrance et leur difficulté à vivre, les reportages les saisissent toujours, à la manière d'un conte moral, comme triomphant de leur handicap et s'inscrivant dans les forces de la vie. Ils chantent, jouent du saxophone, font face à l'adversité, conjurent la maladie, rient avec leurs amis, se passionnent pour l'informatique, se font gronder quand ils font des bêtises, affrontent la maladie avec lucidité, rassurent les parents inquiets, etc. Bref, par leur courage, ils font montre d'un surcroît de vie ; une vie qui, à cette lumière, semble manquer au téléspectateur ${ }^{49}$. A la différence des groupes critiques, souvent abattus et silencieux devant l'image des malades, d'autres groupes

49. CARDON et al., 1998. 
s'émerveillent et se réjouissent de voir la vie l'emporter : ils relèvent " la pêche des malades", leur "force de caractère", leur manière simple et déterminée de conjurer le sort. "C'est bien de voir ça. Ça montre pourquoi tout le monde fait tellement des épreuves physiques... C'est pas de la pitié, ça, c'est je sais pas comment dire... C'est de l'admiration, ouais, plus que de la pitié ». En transformant la pitié en admiration, les téléspectateurs donnent une forme toute différente au procès de sympathie avec les malades. L'imagination du téléspectateur ne se transporte plus dans la place des victimes (pour «souffrir en lui » dit encore Rousseau), mais se retourne vers lui pour explorer sa propre existence. Laure, bouleversée, dit : "Le fait de la regarder ça fait penser à soi-même! "; "Tu te dis que les petits problèmes qu'on $a$, à côté de ce qu'ils ont... "; "C'est ce qui t'encourage, ceux qui n'ont pas grand chose, à se dire bon, j'ai pas à me plaindre.[...] Oui, on court, on chante, on saute, on n'a pas de problèmes". Cette interrogation est alors pour le téléspectateur le motif qui dirige l'inspection de ses propres capacités. Eux sont malades, lui est bien portant. Eux débordent de vie, il en manque. "Si ça nous arrivait demain, si on avait un accident de voiture, et on se retrouve handicapé, est-ce qu'on pourrait faire aussi bien ? ; "Il faut voir avec quel courage ils acceptent. Quand on voit ces gens et que nous on se plaint pour des bricoles... ». En d'autres termes, le téléspectateur reconnaît qu'il dispose de forces, d'une santé qu'il n'emploie pas dans la même mesure que les malades : ces malades, loin de paraître affaiblis, deviennent des exemples qui appellent à être suivis. Le téléspectateur est, dans cette expérience, invité à reconnaître la leçon de vie que lui proposent les malades. La force des malades devient ainsi le vecteur de son engagement. Cette morale de l'engagement dessine en même temps sa forme : il s'agira, en suivant l'exemple des malades, de montrer de l'énergie, d'entrer dans l'action et de s'imposer des défis.

\section{Les intrications de la Force $\mathbf{T}$}

Intriqués dans le réseau de la maladie, les téléspectateurs qui opèrent des rapprochements se découvrent aussi des liens avec les acteurs de la Force $\mathrm{T}$ qu'ils voient à l'écran : soit parce qu'ils ont participé, dans les années précédentes, aux actions collectives organisées à l'occasion du Téléthon, soit qu'ils y participent eux-mêmes cette année ou qu'ils connaissent des gens qui prennent part à de telles actions. Ces rapprochements sont préférentiellement activés dans les conversations engagées et pragmatiques et le sont aussi, mais dans une moindre mesure, dans les conversations 
ironiques $^{50}$. En effet, qu'elles réclament un investissement minimum (prêter du matériel de sonorisation aux pompiers de la ville, acheter le parfum d'un sponsor du Téléthon ou des «sucettes du Téléthon») ou appellent un engagement plus important (faire du volley pour le Téléthon, se joindre à une randonnée SNCF, tricoter une immense écharpe, participer en rollers à un circuit en compagnie de personnes en fauteuil, etc.), les actions entreprises par ces téléspectateurs contribuent toutes à tisser des liens entre les personnes. Peu importe leur caractère incongru, bizarre ou fantasque. L'essentiel, en effet, est qu'elles encouragent les individus à «faire des choses ensemble » et qu'elles fassent courir entre eux des liens multiples, denses et diversifiés.

Ces actions enjoignent ceux qui y participent de se manifester mutuellement les liens de solidarité qui les obligent les uns à l'égard les autres ${ }^{51}$. Chaque action repose en effet sur une division extrêmement précise des tâches, qui sont assumées, à tour de rôle, par des personnes différentes, de sorte que chacun se trouve dans une situation de dépendance mutuelle à l'égard des autres membres du groupe. Cette interdépendance est manifeste dans les dispositifs exigeant la participation du public - comme ce curieux «magnéto-pédalotor», dont la musique ne peut être diffusée qu'à la condition que des volontaires alimentent de coups de pédale des bicyclettes reliées à une énorme dynamo transformant leur énergie en un courant électrique destiné au magnétocassettes. Mais elle est aussi présente dans les manifestations organisant un face-à-face entre des bénévoles accomplissant un défi et des spectateurs : les élèves perchistes d'un club sportif ne peuvent entreprendre de sauter des hauteurs cumulées équivalent à celle du Puy-deDôme qu'à la condition qu'un public nombreux vienne les encourager, que des volontaires mesurent les sauts, actualisent le registre des performances et rehaussent la marque portée sur la toise symbolisant la hauteur du Puy. En un sens, le Téléthon interdit aux personnes de n'investir que leur singularité. Le participant à une action de la Force $T$ est avant tout un être lié aux autres.

50. De façon significative, ce sont les individus qui sont membres des groupes engagés et pragmatiques qui montrent aussi la plus forte inscription dans la vie locale à travers l'appartenance associative (respectivement pour 42 et $34 \%$ d'entre eux, contre 32 et $7 \%$ pour les critiques et les ironiques).

51. Comme l'indiquent Michel CALLON et Bruno LATOUR (1997), autant que le calcul, le don se déploie dans des dispositifs qui contribuent à faire naître et à entretenir les attaches entre les personnes; les dispositifs « associationistes " ne tendent pas à clore les relations entre les personnes mais au contraire à les endetter mutuellement afin qu'elles ne soient jamais quittes. 
Les actions collectives du Téléthon sont là pour rendre visible, pour objectiver cette interdépendance. Elles prennent en effet appui sur des liens d'appartenance déjà existants (les « habitants de... », les « écoliers de... »), réactivent des liens de sociabilité noués au sein de groupements volontaires (en se glissant dans des collectifs sportifs, associatifs, etc.), viennent se greffer sur des pratiques festives traditionnelles (kermesses, fêtes de paroisse, joutes intervillages, etc.) et convertissent la force cohésive des groupes ainsi constitués en « une chaleur qui échauffe ou ranime les cœurs, qui les ouvre à la sympathie, qui fait fondre les égoïsmes $»^{52}$. Les individus atteints de maladie neuromusculaire sont systématiquement associés aux actions soit comme participants (en réalisant des créations infographiques sur ordinateur, en poussant de leur fauteuil le ballon au tout début d'un match de football) soit comme accompagnateurs ou spectateurs.

La solidarité entre les participants aux actions collectives de la Force $\mathrm{T}$ est renforcée par le recours à des technologies d'objectivation des liens qui les unissent : ils passent en effet leur temps à compter et à produire des chiffres. Cependant, il ne dénombrent pas des personnes - technique à laquelle recourent ordinairement les acteurs syndicaux, politiques ou associatifs pour montrer leur force ${ }^{53}$ - mais les multiples liens qu'ils ont générés. Mais comment compter des « liens »? Comment compter ce qui est invisible ? Tout simplement en ne regardant pas les participants aux actions de la Force $T$ comme des êtres réductibles à leur seule subjectivité, et les liens qui les unissent comme des liens intersubjectifs - donc inaccessibles à toute saisie -, mais en considérant au contraire que l'expression des solidarités est moins intérieure que déposée dans les gestes qu'ils accomplissent, dans les paroles qu'ils prononcent, dans les objets qu'ils manipulent. Ce ne sont pas les liens proprement dits qui sont mesurés, mais des mouvements, des choses, des objets qui font lien parce qu'ils circulent entre tous ceux qui prennent part aux actions de la Force $T$. Toutes les manifestations produisent ainsi du «chiffre » et de la valeur: chacune est assortie d'un instrument de mesure (l'œuf de l'omelette, la longueur de piscine, la ligne des mailles d'un tricot...), puis découpée en portions homogènes servant d'unité de compte, et enfin convertie en argent ( 5 œufs $=20$ francs) puisque le participant d'une action est censé «payer » pour y prendre part ou n'accepte de se mouvoir qu'à la condition qu'un spectateur « paye » pour lui.

52. DURKHEIM, 1978, p. XXX.

53. Voir par exemple OFFERLE, 1988. 
L'énergie dépensée dans ces dispositifs de solidarisation contribue ainsi à faire circuler entre les personnes les «positivités» que le courage des malades (aperçus à la télévision ou côtoyés dans les manifestations) a suscitées. Les conversations des téléspectateurs en témoignent. La plupart des engagés et des pragmatiques saluent la capacité du Téléthon à faire se mouvoir des « gens » qui n'ont pas pour habitude d'agir pour les autres, et à rassembler dans des actions communes des individus qui, sans la Force $\mathrm{T}$, ne se seraient peut-être jamais rencontrés : "A l'heure actuelle, les gens, ils bougent de moins en moins pour le voisin et là pour une même cause, beaucoup, pas tout le monde loin de là, mais beaucoup de gens bougent. Tu te balades dans le métro, tu te fais attaquer, personne ne bouge, et là, tout le monde bouge dans le même sens. Je trouve que c'est sympa comme truc. [...] C'est beau à voir; que l'on soit pour ou contre le Téléthon, loin de là ; mais que tout le monde bouge dans le même sens ». Les positivités émises par les malades laissent moins de traces dans les conversations qu'elles ne marquent l'ambiance du groupe. Elles teintent le climat d'une humeur qui n'est ni à la peine ni à l'affliction, mais plutôt faite de contentement et d'espérance. Ainsi, dans cette famille fidèle du Téléthon, dont tous les membres participent à des actions de la Force $\mathrm{T}$, la télé est allumée dès le samedi matin parce que "c'est vivant » et parce que le programme « répand sa bonne humeur dans la maison»: chacun commente les gestes ou les propos des animateurs, se moque de la prestation des chanteurs, raconte aux absents de la veille les anecdotes de la soirée d'hier et s'enthousiasme devant les défis parce que "la bonne humeur, ça fait bouger les gens ». Les malades? "Bah oui, des fois faut que ça soit triste pour qu'il y ait du fric... ", "mais moi je trouve pas ça tristounet", "Tout le monde se sent concerné par le Téléthon d'avoir réuni les gens entre eux. C'est une fête le Téléthon, c'est plus une maladie, c'est une fête ! ». Si, lors des séquences duplex, le Téléthon présente publiquement, à intervalles de plus en plus rapprochés jusqu'à la fin de l'émission, les mobilisations de la Force T, c'est bien pour actualiser chez les téléspectateurs une disposition à l'association. Les 30 heures de l'émission peuvent ainsi s'analyser comme la scénographie d'un rassemblement progressif, d'un élan contagieux, communicatif et sociable, dont la poussée bouleverse le script de l'émission ${ }^{54}$. Ainsi est-ce sans doute pour avoir le sentiment d'être de la fête

54. Ce mouvement fait fond ainsi sur ce que l'on peut nommer un enthousiasme, compris comme mouvement de la sociabilité, faculté d'association ou, pour reprendre les termes de Lord Shaftesbury, comme «affection sociale et communicative» (cité par JAFFRO, 1998, 
et d'agir de concert avec ceux qu'ils voient agir ensemble, d'un commun mouvement avec la Force $T$, que le téléspectateur répond aux sollicitations télévisuelles l'invitant à donner ${ }^{55}$.

\section{DONNER SANS ETRE FORMATE}

Il nous est désormais possible de revenir sur le décalage entre les raisons que les donateurs confèrent à leur geste et le guidage que le programme parvient à exercer sur leur conduite. Ce décalage - apparu comme une tension entre l'observation du trafic téléphonique et des conversations télévisées - peut trouver une explication dans une approche réflexive de la manière dont se constitue aujourd'hui le rapport ordinaire à la télévision et au don dans nos sociétés. En effet, pourquoi, lorsqu'elles argumentent, les personnes passent-elles sous silence les attaches qui les lient aux malades et aux mobilisations orchestrées par le Téléthon ? Pourquoi refusent-elles de reconnaître qu'elles se sont laissées guider par le programme, que la mobilisation a synchronisé leurs engagements, qu'elles ont donné à la faveur d'une sollicitation et se sont mues dans un cadre où les contraintes que chacun exerce sur chacun accumule une énergie que le Téléthon permet de mettre immédiatement en mouvement ? Parce qu'il est possible d'être pris dans les multiples dispositifs «associationnistes» du Téléthon sans nécessairement s'interroger ou éprouver le besoin de se prononcer sur le bien-fondé du dispositif. Les «plans » de l'association et de la distanciation ne sont ni opposés ni orthogonaux. Ils constituent simplement deux manifestations discontinues de nos capacités d'engagement et de jugement. On peut alors faire l'hypothèse que c'est pour cette raison que le geste téléphonique, inscrit dans le mouvement du programme et de ses sollicitations, ne laisse pas de «traces » dans les justifications que les donateurs apportent à leur geste. Il n'y a pas lieu de réclamer une cohérence entre le faire et le dire des acteurs, ni de mettre en procès ce décalage pour soupçonner leur duplicité ou leur hypocrisie. Les manières de faire lien avec les autres relèvent d'un mode de sensibilisation et d'une anthropologie qui ne sont pas les mêmes que ceux que nous utilisons aujourd'hui dans l'espace public pour critiquer les médias et définir la générosité. Le soupçon sur les

p. 61), par lequel les individus, dans le spectacle, vont réfléchir leurs propres attaches et leurs propres interdépendances.

55. En ce sens, avec le Téléthon, l'outil télévisuel parvient à réaliser concrètement la dynamique convergente des représentations qui a souvent été décrite sous le terme de « communauté imaginée ». Cf. DAYAN. 1998. 
intentions des solliciteurs, la réduction des gestes de don aux formes insidieuses de la contrainte ou aux ressorts dissimulés de l'intérêt, la méfiance à l'endroit des émotions, constituent des schèmes d'interrogation si partagés qu'ils polarisent les appréciations sur le Téléthon jusqu'à constituer l'horizon potentiel de toute discussion publique de l'émission, y compris parmi les téléspectateurs les plus favorables.

\section{Secret du don et critique publique}

Les interviews des donateurs montrent bien que, pour être reconnues comme telles, la générosité et la solidarité doivent exprimer un rapport personnalisé et intime à la société. Comme l'explique Pierre Bourdieu, «la difficulté particulière que nous avons à penser le don tient au fait que, à mesure que l'économie du don tend à n'être plus qu'un îlot dans l'océan de l'économie du donnant-donnant, sa signification s'en trouve changée ». Toujours soupçonnée de dissimuler une stratégie intéressée d'accumulation de capital symbolique, il est aujourd'hui compris comme «une sorte de prouesse éthique impossible parce que mesurée à l'idéal du don vrai, entendu comme acte parfaitement gratuit et gracieux, accordé sans obligation ni attente, sans raison ni fin, pour rien ${ }^{56}$. Les travaux sur le don dans les sociétés contemporaines enregistrent tous ce repli de la sphère du don dans le monde des relations privées, celui des «socialités primaires » qui se déploient à l'abri des dépendances fonctionnelles et des espaces marchands ${ }^{57}$, dans les échanges familiaux, les relations amicales et, éventuellement, la cession du sang ou des organes ${ }^{58}$. Beaucoup de travaux pour un «phénomène relativement insignifiant, étroitement limité aux relations intersubjectives de type privé, qui consolide l'amitié ou célèbre certains événements isolés ${ }^{59}$. Ce repli du don dans une opposition de plus en plus «imaginaire ${ }^{60}$ à la sphère du calcul a contribué à radicaliser les contraintes éthiques auxquelles le geste de donner doit se soumettre pour que nous le reconnaissions comme tel. Valeur refuge, il se métamorphose en "rêve inversé " ${ }^{61}$ de la force, du calcul, du profit et de la capitalisation. C'est bien cet horizon normatif du don qui s'est aujourd'hui imposé.

56. BOURDIEU, 1997, p. 234.

57. GODBOUT, CAILLE, 1992.

58. GODELIER, 1996, p. 291.

59. KARSENTI, 1994, p. 107.

60. GODELIER, 1996, p. 292.

61. PETITAT, 1995. 
Assez paradoxalement, lorsque l'on pense à l'ostentation du potlatch ou aux largesses princières ou royales dont l'analyse a nourri les premiers travaux sur l'anthropologie du don, le geste oblatif est regardé comme l'une des formes d'expression les plus intimes et les plus secrètes de la personne, un geste secret et fragile, qui montre une sensibilité extrême à la publicité. Car - ce point est souvent négligé dans le débat sur le don focalisé par la question de l'obligation, de l'intérêt et du retour -, le renversement le plus important que notre conception du don a subi tient au fait qu'il a été transporté de la sphère de visibilité publique vers celle des correspondances secrètes et tues entre les personnes. Avec l'accroissement des formes de domination symbolique, comme dirait Bourdieu, ce qui rend la générosité suspecte, c'est sa démonstration, la reconnaissance qu'elle cherche à obtenir des autres. Lorsqu'il se déclare, le don est aussitôt suspecté dans ses intentions (de retour, de renom, de prestige, de satisfaction narcissique, etc.). Comme l'écrit Jacques Derrida, «pour qu'il y ait don, il faut que le don n'apparaisse même pas, qu'il ne soit pas perçu comme don ${ }^{62}$. Dans sa critique du Téléthon, Pascal Bruckner s'émeut justement qu'«en s'adjoignant la publicité, la charité trahit son premier commandement : le tact et le secret ${ }^{63}$. Pour éviter que sa signification ne soit profanée, le don devrait ainsi rester invisible aux autres, voire, dans les interprétations les plus radicales, rester inaccessible à la conscience même du donateur. Bref, le don est devenu amour. Cette privatisation du don s'est accompagnée de la diffusion des instruments de déconstruction de l'intention de donner. La retraite du don dans la sphère du secret est le revers de la vigilance critique à l'égard du processus de rationalisation des échanges. Des deux côtés, c'est l'affirmation de l'autonomie du sujet qui s'exprime, dans le jugement distancié comme dans l'oblation secrète. En ce sens l'anthropologie sur laquelle s'appuie la critique enferme dans le même sujet, unitaire et autonome, sa disposition à la générosité. On comprend aisément que cette transformation de l'éthique du don s'accommode mal du Téléthon qui place dans l'espace public un instrument entièrement profilé pour produire et exhiber des gestes de générosité. Le don y est démonstratif quand il devrait être discret. Il est collectif quand il devrait être individuel. Il est programmé quand il devrait être spontané. Il est joyeux alors qu'il devrait être grave... Il existe un tel écart entre la conception du don qui constitue l'horizon d'attente des téléspectateurs et ce que réalise le Téléthon que rien ne semble permettre de les rapprocher sous un même dénominateur. Les donateurs sont

62. DERRIDA, 1991, p. 291.

63. BRUCKNER, 1995, p. 249. 
permettre de les rapprocher sous un même dénominateur. Les donateurs sont ainsi conduits à interpréter publiquement le sens de leur engagement dans un langage qui ne sait, ni ne peut reconnaître qu'ils ont été pris dans les rets du dispositif qui les a rassemblés.

\section{Les effets de troisième personne}

La culture critique des programmes télévisés exerce un autre «effet de théorie » sur les téléspectateurs. Elle invite les téléspectateurs à décrire leur expérience de la télévision avec recul et détachement, et à masquer les moments d'emprise et d'attachement. Ainsi, ayant à expliquer dans un contexte d'enquête, les manières dont ils regardent la télévision, les enquêtés ont fait preuve d'un très grand savoir faire dans la déconstruction des techniques utilisées par les programmateurs pour agir sur le public. En endossant cette posture, ils affirment aussi qu'ayant «vu le truc», ils échappent aux effets que la télévision pourrait exercer sur eux, tout en insistant sur la force que les procédés qu'ils ont décryptés, des "pièges » qu'ils ont éventés, exercent sur les autres. Ce type de postures a fait l'objet d'une attention particulière parmi les chercheurs anglo-saxons en sciences de la communication sous la rubrique d' "effet (ou de perception) de troisième personne ${ }^{64}$ : "Je me demande si le réaffichage des dons au fur et à mesure, ça a plus d'impact pour stimuler les gens à donner, pour atteindre, battre un record"; "J'ai l'impression que les enfants sont de bons vecteurs pour sensibiliser les gens à ce genre de truc»; "Je sais pas s'ils nous mettent pas les gamins là pour apitoyer les gens. Non mais ils doivent les chercher pour nous apitoyer. Ils prennent les gens pour des rigolos ». La généralisation de l'effet de troisième personne fixe ainsi le cadre légitime de toute discussion publique du Téléthon jusqu'au paradoxe. Une perception généralisée de troisième personne en viendrait, en effet, à ne renvoyer à chaque fois qu'à des "autres » toujours «ailleurs », jusqu'à éventuellement ne constituer qu'un ensemble vide -ce que dément l'ampleur de la mobilisation et la concrétisation par les donateurs de leur promesse. Là encore, l'obligation de montrer en public un rapport détaché et analytique à la télévision passe sous silence et écrase les expériences

64. C'est W. P. Davison qui le premier repéra ce phénomène, au terme duquel les individus exposés à une communication potentiellement persuasive prédiront que le message aura un effet bien plus grand sur les autres que sur eux-mêmes. Comme Davison l'a indiqué, «l'effet le plus marquant [du médium] ne sera pas sur « moi » ou sur «toi », mais sur « eux » - les troisièmes personnes ». DAVISON, 1983. 
beaucoup plus vives d'attachements au programme et les investissements émotionnels qui ont pu être observés, à travers la décomposition des séquences du Téléthon, dans presque tous les groupes.

\section{La fatigue de critiquer...}

Une trop grande distance à l'endroit du Téléthon peut justement être ressentie comme une faute morale par ceux qui maintiennent continûment une posture critique. Certains groupes ironiques et critiques ont ainsi été conduits à mener une sorte d'introspection collective interrogeant les raisons de leur manque de disponibilité pour le Téléthon. "Ils en ont peut-être marre qu'on dise que cette émission elle est glauque » reconnaît Céline en se demandant "pourquoi elle ne se sent pas concernée». Au sein de son groupe une longue discussion va se développer sur le thème de la relation entre critique et égoïsme. Même trouble dans ce groupe ironique qui avoue rapidement une certaine lassitude à "mitrailler tout ce qui passe ». Plus le travail de critique se poursuit, plus s'approfondit la distance qui les sépare du monde du Téléthon. Il suffit alors que cette exclusion leur apparaisse comme un manque, plutôt que comme une différence «élective », pour que s'installe une gêne: "j'ai l'impression qu'à la limite, s'ils essaient que ce soit gai, que ce soit la fête et tout, mais en fait je trouve que c'est vachement déprimant quoi ».

Ce dernier exemple est plus symptomatique encore. Le groupe qui regarde le Téléthon est distancié et critique, par profession. Il se compose de membres des professions artistiques (scénaristes, producteurs de télévision) et d'un chroniqueur de télévision dans un grand quotidien national, qui avouera au terme de cette expérience, "moi, tout cela me plonge dans un état de spleen, de spleen... très, très profond». C'est que, en recevant ses amis pour l'enquête, leur hôtesse leur a fait part d'une très surprenante nouvelle. Hier soir, elle était seule. Elle a regardé le Téléthon. "Bon, c'est vrai que c'est chiant. En plus, il y avait Sérillon qui discutait avec ceux qui faisaient du vélo, Antoine de Caunes, qui faisait le con, gentiment. [...] Et puis d'un seul coup, ils sont passés à autre chose et ils ont interviewé un type qui s'appelle Arnold Munich. J'ai retenu même son nom. Je me suis dit: "ce type est formidable!". Il y avait un reportage dans son service de généticien. [...] Il était avec une petite fille myopathe. En même temps, le lien avec la petite fille, il n'était pas du tout émotionnel. Il était bien, quoi. [...] Et ensuite, il était interviewé sur le plateau et je me suis dit : "Ce type est formidable!". 
Bon, et puis il n'était pas non plus - comment dire? - trop spectaculaire. Il $y$ avait un côté "authentique" [dit avec un accent, une grimace] qui faisait que je sais pas...". Comme une provocation adressée à ces amis, elle ajoute : "Là, je me suis dit: "Bon, je vais donner". [...] Tout à coup, je me suis dit je vais donner pour de vrai ». Ce moment de sensibilisation ponctuel n'a cependant pas résisté lors de la séance collective d'écoute du programme. Notre groupe regarde le Téléthon le samedi matin, à l'heure où sont mis en exergue les défis locaux de la Force T. Les remarques ironiques se multiplient devant les actions locales, l'échelle des pompiers, les cadres "lourdingues» du réalisateur sur les enfants, les groupes de musiciens folkloriques. Pourtant, en fin de séance, la discussion devient nettement plus introspective :

Françoise : Et le fait qu'il y ait dans la France entière des gens qui se mobilisent, ça vous fait quoi. Vous êtes pris dans un sentiment collectif?

Bénédicte : Ben ça nous montre surtout qu'on n'est pas comme eux... Moi, je me dis : «je ne suis pas comme eux ».

Guy : Moi, je suis toujours : partagé. J'ai ma raison qui me dit que c'est bien et puis j'ai... la déprime qui n'est pas bien loin. Une lassitude... une lassitude profonde...

Bénédicte: Parce que en même temps, c'est vachement bien, des gens comme ça qui se défoncent pour... Je ne vois pas très bien pourquoi moi je ne fais pas partie de ce truc. Mais en même temps, c'est clair, je ne fais pas partie de ce truc... Je ne suis pas comme eux!

Hélène : Je crois que c'était pas ça sa question... Ta question c'était : est-ce qu'on vibre avec eux... Moi, ça m'émeut. Moi, j'adore ça. Parce que tout à coup j'ai l'impression que les choses ont un sens. Qu'on est tous unis dans le même sens. J'adore ça. C'est pour ça que j'aime bien aussi l'arrivée du Tour de France. Les matchs de foot... et tout.. parce que d'un seul coup, je me dis "Mince, je ne suis pas toute seule».

Patrick: Oh la la la. Oh la la la... Qu'est-ce qu'elle nous fait là !

C'est alors la critique qui souffre de ne pas savoir faire lien. La télévision perd alors son statut d'instance susceptible de réunir autour du téléspectateur les autres téléspectateurs qui, avec lui, regardent le même programme. D'abord exclus en un tiers abstrait, le public mobilisé du Téléthon fait ici retour pour donner au téléspectateur détaché le sentiment qu'il s'est lui-même exclu du rassemblement enthousiaste qui s'opère autour des malades. 


\section{Le Téléthon entre association et distanciation}

Le dispositif d'engagement dans le Téléthon cadre les personnes dans un format qui n'est pas le même que celui dans lequel elles s'inscrivent pour exprimer leur liberté de donner ou pour critiquer la sensibilisation télévisuelle. Aussi, les engagements dans le Téléthon ne s'articulent-ils pas à l'espace de la discussion publique mais sont guidés vers des dispositifs qui créent, propagent et multiplient, par des actions communes et synchrones, les attaches entre les personnes. Se reconnaît ainsi une forme originale de construction des mobilisations qui diffère fortement du répertoire d'action collective construit par les mouvements politiques et syndicaux traditionnels qui ont toujours fait communiquer l'espace des sociabilités et l'espace public, la solidarité et la critique ${ }^{65}$. Pour autant, la critique ne disparaît jamais de la participation au Téléthon ; elle ne lui est pas extérieure mais s'exprime, sans grande conséquence, en son sein.

Il est alors paradoxal de constater - au terme d'une revue de presse des commentaires concernant l'émission sur plusieurs années - que le Téléthon ne semble plus aiguiser aujourd'hui la critique intellectuelle et télévisuelle avec la même force qu'à ses débuts. Même si certains de ses arguments restent pertinents, la critique ne constitue aujourd'hui qu'un «bruit de fond », certes tenace, qui accompagne la réception de l'émission. En connaissant un succès financier toujours plus important, en favorisant indéniablement les progrès de la recherche génétique française, en apportant aux malades des soins qui ont permis un allongement de leur espérance de vie, en montrant surtout la ferveur toujours renouvelée des engagements qui l'entourent, le Téléthon est parvenu à «fatiguer» ceux, intellectuels, essayistes, journalistes, qui avaient entrepris de le critiquer $^{66}$. L'affaissement de la critique de la sensibilisation télévisuelle tient incontestablement à la posture détachée et raisonnante de son discours à l'égard des solidarités à forte composante émotionnelle. La condamnation des émotions publiques se fait au motif que les personnes se montrent vulnérables au monde extérieur et ne font pas preuve de détachement et d'autonomie de jugement. Il faudrait

65. Comme l'a bien montré J. ION (1997), le croisement de ces espaces est central dans la construction de la figure du «militant». On saisit, dès lors, la façon dont cette désolidarisation signe bien une «nouvelle» forme d'engagement, que J. Ion nomme «implication distanciée », caractéristique des activités bénévoles et ponctuelles de la sensibilité humanitaire.

66. Les débats au sein des associations caritatives et du monde scientifique ne se sont en revanche pas éteints, même s'ils ont été transformés par le succès de l'AFM. 
pourtant proposer à la critique d'amender sa manière de déconsidérer les émotions publiques pour qu'elle parvienne à ouvrir une discussion plus active et plus dense du rôle et de la place acquise par le Téléthon dans la société française. Comme l'indique Martha Nussbaum, l'emprise que les émotions exercent sur nos existences tient au fait que «les gens placent à l'extérieur d'eux-mêmes beaucoup d'éléments de leur bien ", qu'ils se lient au destin des enfants, des parents, d'êtres chers, de concitoyens et que ces attaches contribuent à faire de la vie humaine « une affaire vulnérable, dans laquelle un contrôle rationnel total n'est ni possible ni même vraiment souhaitable $"{ }^{67}$. La réussite du Téléthon procède bien de l'activation de ces attaches, déposées dans les autres, que le dispositif parvient à réveiller et à faire vibrer pour encourager la mobilisation. En considérant les émotions comme l'expression de jugements de valeur qui sont attachées à certains types de solidarité entre les personnes, il est possible de débattre et d'arbitrer entre les différentes formes d'attachement que nous souhaitons voir s'afficher publiquement à travers le Téléthon et celles que nous préférons ne pas voir reconnaître. Si, comme l'indiquent Michel Callon et Vololona Rabeharisoa, le génome constitue l'opérateur principal du collectif constitué dans le travail de l'AFM pour connecter entre elles les différentes pathologies et procéder à une universalisation du « risque génétique » vers les bien portants ${ }^{68}$, on pourrait sans doute plaider pour une clarification au sein de l'émission des opérations par lesquelles se construit ce nouveau type de « lien social » et la manière dont se recomposent les solidarités entre les personnes. Notre enquête a d'une certaine manière montré que le Téléthon ne souffrait pas d'être discuté et critiqué ; la vigilance dont il est entouré constitue même un outil de contrôle réflexif essentiel au montage de l'opération. Cependant, les stratégies scientifiques de l'AFM et la délimitation des pathologies concernées, alors qu'elles sont fortement débattues dans les arènes médico-scientifiques plus restreintes, n'apparaissent pas dans l'émission, et n'étaient guère perçues par les téléspectateurs lors de l'enquête, en 1996. Le Téléthon ne propose pas de débattre des orientations scientifiques auxquelles il a contribué. On comprendrait aujourd'hui que, une fois retombée l'effervescence des 30 heures, une fois le compteur arrêté, une fois remisé l'attirail hétéroclite de la Force $T$, une fois les associations recouvertes par les engagements de la vie quotidienne, l'AFM et le Téléthon ouvrent publiquement la discussion sur leurs choix et la manière dont ils recomposent la société autour des malades.

67. NUSSBAUM, 1995, p. 27.

68. CALLON, RABEHARISOA, 1997. 
ALLARD Laurence (1994), "Dire la réception. Culture de masse, expérience esthétique et communication ", Réseaux, ${ }^{\circ}$ 68, novembre-décembre, p. 65-84.

ANDERSON Benedict (1996), L'imaginaire national. Réflexions sur l'origine et l'essor du nationalisme, Paris, La Découverte.

ANG Ien (1996), Living Room Wars. Rethinking Media Audiences for a Postmodern World, London, Routledge.

ARCHAMBAULT Edith, BOUMENDIL Judith (1997), Les dons et le bénévolat en France - 1997, Fondation de France.

BASZANGER Isabelle, DODIER Nicolas (1997), «Totalisation et altérité dans l'enquête ethnographique », Revue française de sociologie, XXXVIII-1, p. 37-66.

BESSY Christian, CHATEAURAYNAUD Francis (1995), Experts et faussaires. Pour une sociologie de la perception, Paris, Métailié.

BOLTANSKI Luc (1990), L'Amour et la justice comme compétences. Trois essais de sociologie de l'action, Paris, Métailié.

BOLTANSKI Luc (1993), La souffrance à distance. Morale humanitaire, médias et politique, Paris, Métailié.

BOURDIEU Pierre (1997), Méditations pascaliennes, Paris, Seuil.

BRUCKNER Pascal (1995), La tentation de l'innocence, Paris, Grasset.

CALBO Stéphane (1998), Réception télévisuelle et affectivité, Paris, L’Harmattan.

CALLON Michel, LATOUR Bruno (1997), «"Tu ne calculeras pas!" Ou comment symétriser le don et le capital », Revue du MAUSS, $\mathrm{n}^{\circ}$ 9, premier semestre, p. 45-70.

CALLON Michel, RABEHARISOA Vololona (1997), L'invention d'une nouvelle forme de mobilisation de la recherche. Le cas de l'Association française contre les myopathies, CSI-AFM, miméo, 200 p.

CARDON Dominique (1995), "Chère Menie..." Emotions et engagement de l'auditeur de Menie Grégroire », Réseaux, n 70, mars-avril, p.41-78.

CARDON Dominique, HEURTIN Jean-Philippe, LEMIEUX Cyril, «Parler en public », Politix. Travaux de science politique, $\mathrm{n}^{\circ} 31$, troisième trimestre 1995.

CARDON Dominique, HEURTIN Jean-Philippe, PHARABOD Anne-Sylvie, ROZIER Sabine (1998), "Mais qui fait bouger le compteur du Téléthon? Une construction télévisuelle de la solidarité », Sciences Sociales et Santé, vol. 16, n 3, septembre, p. 17-40. 
CEFAÏ Daniel (1998), Phénoménologie et sciences sociales. Alfred Schutz, naissance d'une anthropologie philosophique, Genève-Paris, Droz.

CHALVON-DEMERSAY Sabine (1994), Mille scénarios. Une enquête sur l'imagination en temps de crise, Paris, Métailié.

CHALVON-DEMERSAY Sabine, ROSENTAL Paul-André (1998), «Une démographie des comportements volatiles ? L'émergence de la micro-analyse dans la mesure de l'audience ", Quaderni, n 35, p. 129-147.

DAVISON William (1983), «The Third Person Effect in Communication », Public Opinion Quaterly, ${ }^{\circ} 22$, p. 91-106

DAYAN Daniel (1998), «Le double corps du spectateur », BOURDON Jérôme, JOST François, dir., Penser la télévision. Actes du colloque de Cerisy, Paris, Nathan/INA, p. 234-246.

DAYAN Daniel, KATZ Elihu (1996), La télévision cérémonielle. Anthropologie et histoire en direct, Paris, PUF ( $1^{\mathrm{e}}$ éd. américaine : 1992).

DERRIDA Jacques (1991), Donner le temps, I. La Fausse Monnaie, Paris, Galilée.

DUFOURCQ Nicolas, dir. (1996), L'argent du cour, Paris, Hermann.

DURKHEIM Emile (1978), De la division du travail social, Paris, PUF.

GENDRE Gérard (1996), Les stratégies de la générosité. Développement des ressources des associations : réflexions et méthodes, Paris, Economica.

GIDDENS Anthony (1994), Les conséquences de la modernité, Paris, L'Harmattan.

GODBOUT Jacques, CAILLE Alain (1993), L'esprit du don, Paris, La Découverte.

GODELIER Maurice (1996), L'énigme du don, Paris, Fayard.

HALL Stuart (1994), «Codage/décodage », Réseaux, n 68, novembre-décembre, p. 27-39.

ION Jacques (1997), La fin des militants?, Paris, Les Editions de l'Atelier.

JAFFRO Laurent (1998), Éthique de la communication et art d'écrire. Shaftesbury et les Lumières anglaises, Paris, PUF.

JAUSS Hans Robert (1973), Pour une esthétique de la réception, Paris, Gallimard.

JOUËT Josiane, PASQUIER Dominique (1999), «Les jeunes et la culture de l'écran. Enquête nationale auprès des 6-17 ans », Réseaux, n 92-93, p. 25-102.

JULLIEN François (1995), Fonder la morale. Dialogue de Mencius avec un philosophe des Lumières, Paris, Grasset.

KARSENTI Bruno (1994), Marcel Mauss. Le fait social total, Paris, PUF. 
LIEBES Tamar (1994), «A propos de la participation du téléspectateur », Réseaux, $\mathrm{n}^{\circ} 64$, p. 93-105.

LIEBES Tamar, KATZ Elihu (1990), The Export of Meaning. Cross-Cultural Readings of Dallas, New York, Oxford University Press.

LULL James (1990), Inside Family Viewing. Ethnographic Research on Television's Audiences, London, Routledge.

MORLEY David (1986), Family Television. Cultural Power and Domestic Leisure, London \& New York, Routledge.

NUSSBAUM Martha (1995), «Les émotions comme jugements de valeur », PAPERMAN Patricia, OGIEN Ruwen, dir., La couleur des pensées. Sentiments, émotions, intentions, Série «Raisons pratiques», Paris, Editions de l'Ecole des Hautes Etudes en Sciences Sociales, p. 20-32.

OFFERLE Michel (1988), «Le nombre des voix», Actes de la recherche en sciences sociales, $\mathrm{n}^{\circ}$ 71-72, p. 5-21.

PETITAT André (1995), «Le don: espace imaginaire, normatif et secret des acteurs », Anthropologie et Sociétés, vol. 19, n 1 et 2.

PROUTEAU Lionel (1998), «Les différentes façons d'être bénévole », Economie et statistique, $\mathrm{n}^{\circ} 311, \mathrm{p} .57-73$.

QUERE Louis (1996), «Faut-il abandonner l'étude de la réception ? », Réseaux, $\mathrm{n}^{\circ} 79$, septembre-octobre, pp. 31-37.

REICHLER Claude (1987), L'âge libertin, Paris, Minuit.

RICOEUR Paul (1986), Du texte à l'action. Essais d'herméneutique II, Paris, Seuil.

ROUSSEAU Jean-Jacques (1961), Emile ou de l'éducation, Paris, Garnier.

VACCARO Antoine (1987), Communication et collecte de fonds. Guide pratique à l'usage des associations et fondations, Paris, Chopin. 